\title{
Serving well by selling well : studies on customer service representatives' ambidexterity and its effectiveness
}

Citation for published version (APA):

Jasmand, C. (2011). Serving well by selling well : studies on customer service representatives' ambidexterity and its effectiveness. [Doctoral Thesis, Maastricht University]. Maastricht University. https://doi.org/10.26481/dis.20111209cj

Document status and date:

Published: 01/01/2011

DOI:

10.26481/dis.20111209cj

Document Version:

Publisher's PDF, also known as Version of record

\section{Please check the document version of this publication:}

- A submitted manuscript is the version of the article upon submission and before peer-review. There can be important differences between the submitted version and the official published version of record. People interested in the research are advised to contact the author for the final version of the publication, or visit the DOI to the publisher's website.

- The final author version and the galley proof are versions of the publication after peer review.

- The final published version features the final layout of the paper including the volume, issue and page numbers.

Link to publication

\footnotetext{
General rights rights.

- You may freely distribute the URL identifying the publication in the public portal. please follow below link for the End User Agreement:

www.umlib.nl/taverne-license

Take down policy

If you believe that this document breaches copyright please contact us at:

repository@maastrichtuniversity.nl

providing details and we will investigate your claim.
}

Copyright and moral rights for the publications made accessible in the public portal are retained by the authors and/or other copyright owners and it is a condition of accessing publications that users recognise and abide by the legal requirements associated with these

- Users may download and print one copy of any publication from the public portal for the purpose of private study or research.

- You may not further distribute the material or use it for any profit-making activity or commercial gain

If the publication is distributed under the terms of Article $25 \mathrm{fa}$ of the Dutch Copyright Act, indicated by the "Taverne" license above, 


\section{Serving Well by Selling Well \\ Studies on Customer Service Representatives' Ambidexterity and Its Effectiveness}

\section{Claudia Jasmand}

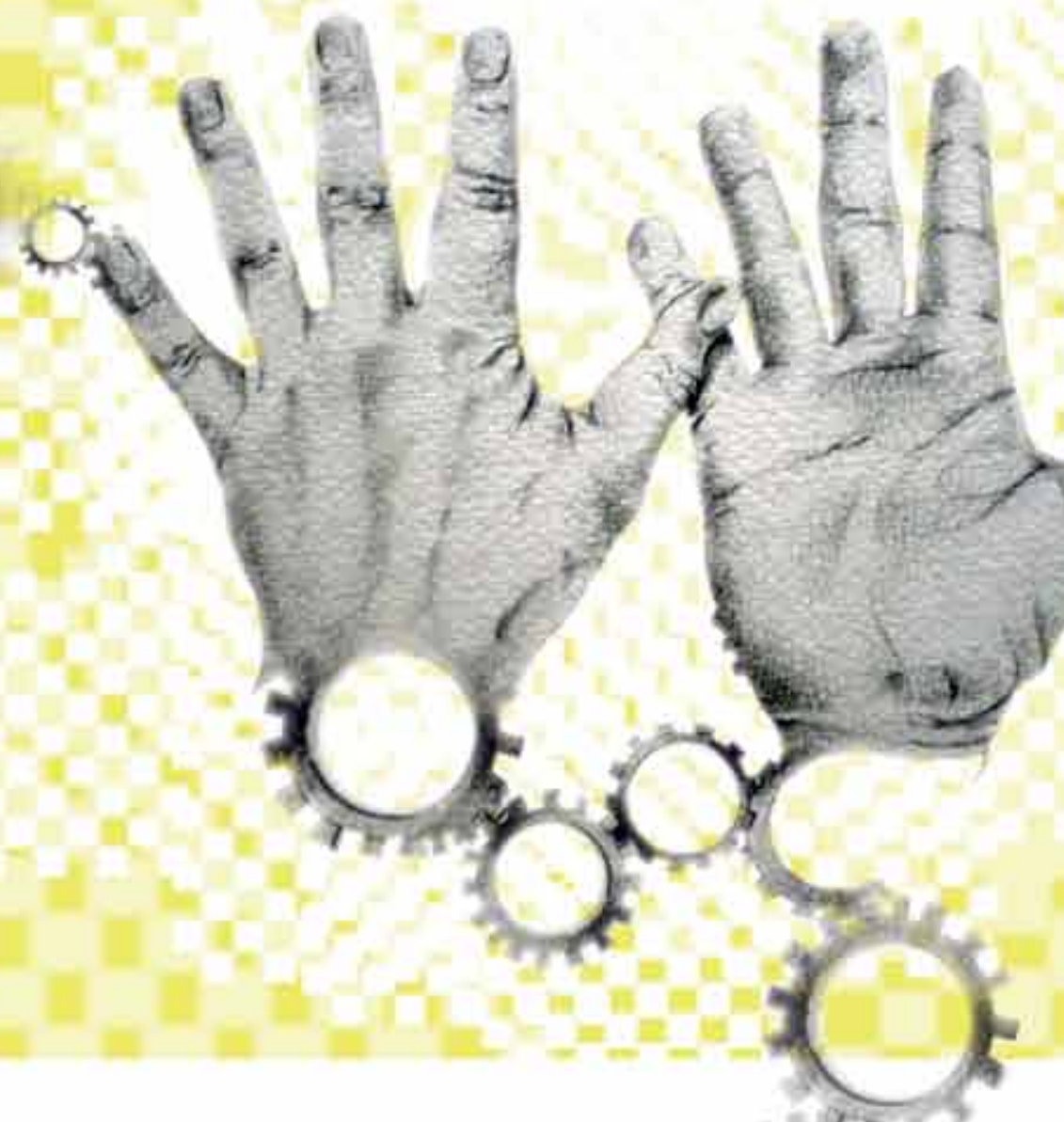




\section{Serving Well by Selling Well \\ Studies on Customer Service Representatives' Ambidexterity and Its Effectiveness}

Claudia Jasmand 
(C) 2011, Claudia Jasmand, Maastricht

All rights reserved. No part of this publication may be reprinted or utilized in any form or by any electronic, mechanical, or other means, now known or hereafter invented, including photocopying and recording or in any information storage retrieval system, without written permission of the copyright owner.

Chapter 2 is reprinted with permission from the American Marketing Association (Journal of Marketing, January 2012).

Cover Design: Christian Dresler

Printed by: CPI Wöhrmann Print Service, Zutphen, The Netherlands 


\title{
Serving Well by Selling Well \\ Studies on Customer Service Representatives' Ambidexterity and Its Effectiveness
}

\author{
Proefschrift \\ Ter verkrijging van de grad van doctor \\ aan de Universiteit Maastricht, \\ op gezag van de Rector Magnificus, Prof. Mr. G. P. M. F. Mols, \\ volgens het besluit van het College van Decanen, \\ in het openbaar te verdedigen \\ op vrijdag 9 december 2011 om 10.00 uur
}

door

Claudia Jasmand 


\section{Promotor}

Prof. Dr. J. C. de Ruyter

\section{Copromotor}

Dr. V. Blažević (Radboud University Nijmegen)

\section{Beoordelingscommissie}

Prof. Dr. M. G. M. Wetzels (Voorzitter)

Prof. Dr. A. de Grip

Prof. Dr. A. C. R. van Riel (Radboud University Nijmegen) 
"If we knew what it was we were doing, it would not be called research, would it?"

(Albert Einstein)

For Alex, my parents Doris and Georg, and my late grandpa Kurt 



\section{ACKNOWLEDGMents}

Oscar Wilde once said 'I am not young enough to know everything' which, I think, applies to me as well. Therefore, I would like to acknowledge and appreciate the help, support, and guidance I received, and say thank you to those who prepared, accompanied, and contributed to my $\mathrm{PhD}$ journey and this dissertation.

First of all, I would like to thank my supervisors Professor Ko de Ruyter and Dr. Vera Blazevic. Ko, you are an incredibly inspiring knowledge broker and idea generator. Your helicopter view, expertise, and enthusiasm for research are invaluable! As a supervisor and ko-author, you are always good for a surprise and you make things happen. I learned that particularly the latter is quite contagious and extremely helpful. Thank you! Vera, thank you very much for your enduring support, approachability, and responsiveness to my questions and concerns. You always spiced work up with social interaction, which resulted in many enjoyable and useful coffee breaks and lunches. Our discussions which preceded and followed the meetings with Ko and your free KoClaudia translation service were extremely helpful. Thank you for being such a valuable linking pin. Not to forget, it was you who helped me getting the $\mathrm{PhD}$ candidate position in Maastricht.

Very special thanks also go to Nina Belei (my paranymph). No way without you! We have gone on the $\mathrm{PhD}$ journey together, learned from each other, and had lots of fun, in particular during the numerous traffic jams on our way to work and during our endless brainstorming breaks. I will never forget our 12-hour-per-day service in the lab and the provision of exclusive one-person service to participants with Vla, chocolate, and Febreze. It is good that we never stopped laughing, especially when facing more difficult times. Together, we mastered the $\mathrm{PhD}$ courses - sometimes with very interesting team members -, explored Second Life, won the UM Education Prize, and discovered Chicago and the purple line. Thank you for having been such a wonderful friend and colleague and the awesome time we have had together. I hope there is more to come!

Moreover, I would like to thank my (former) colleagues at the Department of Marketing and SCM as well as the colleagues from the other departments and universities I got in touch with. In particular, I would like to thank my paranymph Jan Pelser and Linda Lichel for being such supportive colleagues and friends. Charlotte Rolef, thank you for the wonderful time in the Hotel Schmotel and in Brighton as well as the funny and relieving chats in between. Gwen, thank you for your helpfulness and for turning the Second Life project into an awesome experience. I would also like to thank all the people with whom I spent so many interesting and illuminating breaks, in particular, Simon Bartczek, Kris Chodakowski, Rudolph Baethge, Dr. Dani Osterrieder, Charlotte Büchner, Dr. Mirjam Schönert, Robert Merrin, Paulo Saraiva, Dr. Julius Andre, Dr. Clemens Köhler, Dr. Ingrid Beckers, Niek Hensen, and Dr. Nikos Kalogeras. In addition, I am indebted to Dr. Piet Pauwels. Thank you for your dedicated help and support, especially when we had to fight unwinnable battles against student complaints. I am also thankful to Professor Dawyne Gremler who encouraged me to pursue an academic career and infected me with his enthusiasm for services marketing. It was wonderful to see you again in Michigan. 
Special thanks go to Dr. Lisa Brüggen, Dr. Els Breugelmans, Dr. Bram Foubert, Dr. Kelly Geyskens, Dr. Lieven Quintens, Dr. Evelyne Vanpoucke, Dr. Kathleen Cleeren, and Dr. Caroline Goukens for sharing your expertise, giving me feedback, and helping me with participant acquisition for various surveys and experiments. Furthermore, I would like to thank the BEElab team and the students Marco Sposini, Basia Czarnocka, Rebecca Altmann, Michelle Weber, and Nicole Engelbert for facilitating the many experiments I conducted and helping me with data collection. I would also like to express my gratitude to the secretaries Nicole Hermans, Pascalle Prickaerts, and Eefje Nijst.

Moreover, I would like to express my gratitude to the call center outsourcing services provider for the opportunity to conduct the qualitative and quantitative studies at the call center sites (for chapter 2 of this dissertation) and, in particular, Dr. Tobias Grossecker for the tremendous support in collecting data and sharing his inspiring insights and experience.

Another thank you goes to Professor Rick Bagozzi for sponsoring my fruitful stay at the University of Michigan, Dr. Carolyn Yoon for the many insights into the world of consumer behavior, and Professor Fred Feinberg for sharing his knowledge about the academic job market. I also thank the Marketing and Management \& Organizations departments for the interesting and sometimes highly entertaining seminars.

I would also like to express my gratitude to the members of my dissertation committee, Professor Martin Wetzels, Professor Andries de Grip, and Professor Allard van Riel for the time and effort they spent on reading my dissertation.

Last but not least, I would like to thank my better half, Dr. Alex da Mota Pedrosa, my family, and friends. Alex, I am very grateful for your enduring support, inspiring and crazy ideas, commitment, energy, drive, and patience. You have helped me develop selfconfidence and keep my chin up. Thank you for the intensive brainstorming sessions, our discussions about research and the wider world, and your stamina when I talked your ear off. You are a wonderful person and I am so glad I have found you. Mutti und Papa, ganz lieben Dank an euch! Ihr habt mich immer unterstützt und gefördert, wo es nur ging. Ich möchte mich auch bedanken für eure endlose Geduld und euer Verständnis, wenn ich - wie so oft - zu beschäftigt für alle anderen Dinge im Leben war. Danke, dass ihr immer an mich geglaubt habt! I would like to thank my sister Tini and her better half, Birk Reifmann, who always made me aware of the fact that there is also a life beyond work, research, and academia. It feels good to know that I can always count on you! I want to thank my Opa (rest in peace) who always believed in me, but could only join me the first half of my $\mathrm{PhD}$ journey. Ich bin mir sicher, du wärst heute sehr stolz auf mich! Ganz lieben Dank auch an die Familie Wegner, insbesondere an dich, liebe Birgit. Ihr seid immer für meine Eltern dagewesen, während ich weit weg war. I would also like to thank my friends from Wismar, Paderborn, and Maastricht, who are now scattered throughout the world. Thank you for having been such great friends and having made my academic journey so enjoyable! Finally, I would like to thank my new colleagues at Imperial College who have welcomed me so warmly and sincerely. 


\section{Table of Contents}

\section{Chapter 1 Introduction}

1.1 Prelude

1.2 The Research Problem 3

1.2.1 The Managerial Dilemma 3

1.2.2 The Research Question 4

1.3 Theoretical Considerations 6

1.3.1 Customer Service and Cross-/Up-Selling for Relationships 6

1.3.2 The Pursuit of Seemingly Conflicting Goals 8

$\begin{array}{lr}\text { 1.3.3 Social Cognition in Service Encounters } & 10\end{array}$

$\begin{array}{lll}1.4 & \text { Theoretical Contributions } & 11\end{array}$

$\begin{array}{ll}\text { 1.4.1 Ambidexterity } & 12\end{array}$

1.4.2 Stereotyping of Ambidextrous CSRs 12

$\begin{array}{lll}1.5 & \text { Dissertation Outline } & 13\end{array}$

Chapter 2 Generating Sales While Providing Service: A Study of Customer Service Representatives' Ambidextrous Behavior 15

$\begin{array}{lll}2.1 \text { Introduction } & 16\end{array}$

$\begin{array}{ll}2.2 \text { Theoretical Background } & 17\end{array}$

2.3 Hypotheses Development 21

2.3.1 Effects of Locomotion and Assessment Orientations on Ambidextrous Behavior $\quad 21$

2.3.2 Moderating Effects of CSRs'Responses to Typical Call Center $\begin{array}{ll}\text { Characteristics } & 23\end{array}$

2.3.3 Performance Consequences of CSRs'Ambidextrous Behavior 25

2.4 Methodology 26

2.4.1 Research Setting and Data Collection 26

$\begin{array}{ll}2.4 .2 & \text { Measures } \\ 2.4 .3 & 27\end{array}$

2.4.3 Measurement Model and Analysis Approach 29

2.5 Results 31

2.6 Discussion and Implications $\quad 37$

$\begin{array}{ll}\text { 2.6.1 Theoretical Discussion } & 37\end{array}$

$\begin{array}{ll}\text { 2.6.2 Limitations } & 39\end{array}$

2.6.3 Managerial Implications $\quad 40$

Chapter 3 Cross-Selling in Service Recovery Encounters: Staying Under the Customer's Radar to Avoid Salesperson Stereotype ACtivation $\quad 43$

3.1 Introduction 44

3.2 Theoretical Background 46

3.2.1 Impression Formation and Stereotyping 46

3.2.2 Motivation and Cognitive Capacity 47

3.2.3 Stereotyping in Interactions $\quad 47$ 
3.3 Stereotyping in Recovery Encounters 48

3.4 Pre-Studies 51

3.5 Study 1

3.5.1 Method 52

3.5.2 Results $\quad 53$

3.5.3 Discussion $\quad 56$

3.6 Study 2

3.6.1 Method 57

3.6.2 Results $\quad 58$

3.6.3 Discussion 61

3.7 Study $3 \quad 62$

3.7.1 Method 63

$\begin{array}{lll}3.7 .2 & \text { Results } & 63\end{array}$

3.7.3 Discussion 64

3.8 Study $4 \quad 65$

3.8.1 Method 66

3.8.2 Results $\quad 66$

3.8.3 Discussion $\quad 68$

3.9 Study $5 \quad 68$

3.9.1 Method $\quad 68$

3.9.2 Results $\quad 69$

3.9.3 Discussion 70

3.10 General Discussion $\quad 70$

3.10.1 Theoretical Discussion $\quad 70$

$\begin{array}{ll}3.10 .2 & \text { Limitations } \\ 3.10 .3 & 73\end{array}$

$\begin{array}{ll}3.10 .3 & \text { Managerial Implications }\end{array}$

Chapter 4 Conclusion $\quad 77$

4.1 Introduction 78

$\begin{array}{ll}4.2 \text { Discussion } & 78\end{array}$

4.3 The Value of Serving Well by Selling Well 80

4.4 Directions for Future Research 82

$\begin{array}{lll}4.5 & \text { Final Thought } & 85\end{array}$

$\begin{array}{ll}\text { Appendix A } & 86\end{array}$

$\begin{array}{lr}\text { APPEndix B } & 88\end{array}$

$\begin{array}{lr}\text { Appendix C } & 89\end{array}$

$\begin{array}{ll}\text { REFERENCES } & 90\end{array}$

$\begin{array}{lr}\text { Curriculum Vitae } & 101\end{array}$ 
Chapter 1

INTRODUCTION 


\subsection{Prelude}

"It was the perfect storm. Leo was ready for it. He had a full fridge, a cozy fire, and a dozen videos. Then the electricity went out. When the power returned, he tried tuning into The Weather Channel to see when the rains would end. There was no picture. No sound. Nothing. So Leo called the 800 number on his instruction booklet. When he connected with CSR Laurie, he frantically asked about his warranty. Laurie quickly checked Leo's customer profile, explained the terms of his service protection plan, and set up a service call for the following morning. [...] Laurie had an idea:

Laurie: You might want to consider using a surge protector to prevent problems like this in the future. If you had plugged the television into a surge protector, the set wouldn't have been damaged.

Leo: $\quad$ I never thought of that. Where can I get one?

Laurie: As a matter of fact, I can place an order for one right now.

Leo: $\quad$ That would be great. I'll take it.

Laurie: Leo, your customer profile also notes that you purchased a PC late last year. Surge protectors also keep computers from crashing when there's an electrical storm.

Leo: $\quad$ That's all I need?! Maybe you better send me two surge protectors. How quickly can I get them?

Laurie: We can have them to you within 48 hours. And looking at my screen, I see that there's another big storm heading your way in 72 hours, so that's not a moment too soon."

(Spherion 2002)

As this prime example illustrates, cross-selling products or services during inbound customer service calls can help to solve customers' problems they call about better. The desired results: Enhanced customer satisfaction, additional revenues, and stronger customer-company relationships. Therefore, companies are increasingly attempting to align sales with service in their inbound customer service call centers and asking their customer service representatives (CSRs) to excel in serving well by selling well. 


\subsection{The Research Problem}

\subsubsection{The Managerial Dilemma}

Highly penetrated markets, intensified competition, and accelerated customer defection rates have induced companies to shift their main focus from customer acquisition to customer retention (Anderson and Ragsdale 2004). Yet, at the same time, customers are increasingly difficult to reach through conventional marketing channels. While traditional outbound marketing such as (e-)mail becomes more and more inefficient, restrictive telemarketing legislation (e.g., "do not call" list) heavily restrains companies' outbound calling for relationship enhancing activities (Anderson and Ragsdale 2004; Frankland 2008). In light of these challenges, companies are turning to their inbound customer service call centers to build profitable customer relationships. Customers' growing demand for convenience and technological advances allowing for high-volume, low-cost service delivery have turned call centers into the primary channel for personal interaction with customers for many companies (Aksin, Armony, and Mehrotra 2007). On average, call centers are contacted by nearly $70 \%$ of companies' existing customers (Bodine 2011). Cross-/up-selling products and services in inbound service calls is therefore seen as a promising way to build revenue and enhance customer relationships (ICMI 2007). CSRs are suggested to be in an excellent position to truly satisfy customers by taking care of their service requests and proposing a cross-/up-sell as a proactive service (Anderson and Ragsdale 2004; Beaujean, Davidson, and Madge 2006). A McKinsey \& Co. report points out that such cross-sell efforts can generate at least $10 \%$ of a firm's total revenues from sales of new products and services (Eichfeld, Morse, and Scott 2006). Unsurprisingly, about $60 \%$ of inbound call centers expect CSRs to serve well by selling well (CSO Insights 2007). However, many inbound call centers fail to successfully manage the transition to service-and-sales, facing returns that are far below expectations (Hash 2010; CSO Insights 2007). "Eager to experience the potential benefits of a cross-selling strategy, many service and tech support centers leap without looking. [...] The common result: lost customers, agents and revenues" (ICMI 2007).

The managerial literature illustrates the challenges and the comprehensive change management exercise call centers face (e.g., customerthink.com; Hash 2010). Inbound customer service call centers are built from day one to react to customer inquiries and requests (Minnucci 2009). Customer service operations and processes are traditionally standardized to ensure reliable and efficient service, asking CSRs to handle large call volumes in a quick and routine manner with limited discretion (Aksin et al. 2007). But cross-/up-selling is proactive, requiring CSRs to explore unsatisfied customer needs and search for the right offer to be made at the right time (Hash 2010; Minnucci 2009). Inbound customer service has not been designed for that. "Sure, you can hit every caller with the same product or service, but, for most, it will be a waste of time (both yours and the customer's)" says Jay Minnucci (2009), President of a contact center consultancy. Clearly, the efficiency and reliability goals that tend to rule traditional, service-only call centers conflict with the newly introduced revenue generation and relationship enhancement goals (CSO Insights 2007). 
"If there is a lesson to be learned, it is to put people before technology in your priorities" conclude Jim Dickie and Barry Trailer, Managing Partners of CSO Insights (2007). It is not the technology that makes or breaks the conversation, but it is the CSR (Bodine 2011). CSRs' deeply ingrained view that selling is incommensurate with service creates a high mental barrier to blending the two tasks (Eichfeld et al. 2006). Call centers also hire very different skill sets and personality types for service and sales jobs, demonstrating the disparate demands of service and sales tasks (Spherion 2002). For some CSRs, there is also a cultural divide: 'I'm not a salesperson. I'm a customer service representative' (Hash 2010). As a sales consultant notes: "Customer service is giving them [customers] something they want. Sales is getting them to want something you've got" (Hansler 2009). Call centers observe considerable heterogeneity in CSRs' ability to juggle service and sales tasks well and deal with the apparently conflicting demands (ICMI 2007). Moreover, "while companies are eager to drive sales through the service channel, customers aren't always so sure they want to be sold to that way" (Forum 2004 , p. 2). Customers are not always in the 'right' mood and willing to dedicate their time to listening to cross-/up-sell offers (Minnucci 2009). Besides, the prevalent view that service stands for helping people and selling carries the negative connotation of sleazy and dishonest salespeople suggests that service and sales are at odds with each other, such that their conflicting stigmas may put customers off (CSO Insights 2007; Lee, Sandfield, and Dhaliwal 2007; Roux 2008). There are warnings that cross-/up-sell attempts could risk customer hostility and damaged relationships (Eichfeld et al. 2006; Forum 2004). Overall, companies are left with questions as to whether, when, and how their CSRs can effectively leverage inbound customer service calls for relationship enhancement and revenue building. This dissertation aims to find answers to these questions. Therefore, the next sections exploit the academic literature to explore the foundation of this research problem.

\subsubsection{The Research Question}

A considerable amount of marketing literature indicates that both customer service and cross-/up-selling are important tools to enhance customer retention and foster mutually beneficial customer-company relationships (e.g., Christopher, Payne, and Ballantyne 1991; Kamakura et al. 2003; Parvatiyar and Sheth 2001; Zeithaml, Bitner, and Gremler 2006). Customer service creates more value for customers' current products/services, which increases customer satisfaction and repurchase rates (Rust and Chung 2006; Zeithaml et al. 2006). Cross-/up-selling creates more value by satisfying customers' further needs with additional products/services, which generates revenues and enhances customer satisfaction and perceptions of the company's superior ability to serve their needs (Günes et al. 2010; Kamakura et al. 2003). Although the positive implications of customer service and cross-/up-selling have been highlighted extensively, extant marketing literature rarely considers the alignment of these two customer retention tools by CSRs. The few studies that bridge service and sales reveal that CSRs' simultaneous pursuit of service and sales goals involves trade-offs and conflicting demands (e.g., Aksin 
and Harker 1999; Evans, Arnold, and Grant 1999). At the same time, they fail to explain how to resolve and manage them. Alignment in the pursuit of seemingly conflicting goals is reflected in ambidexterity which is a phenomenon studied in the management, strategy, and innovation literature (Raisch and Birkinshaw 2008). Empirical research has shown that ambidextrous companies enjoy superior performance (e.g., Gibson and Birkinshaw 2004). Anecdotal evidence suggests that also managers and employees can be ambidextrous and juggle conflicting tasks (Adler, Goldoftas, and Levine 1999; Mom, van den Bosch, and Volberda 2009). However, extant research does not provide a systematic and profound understanding of employees' ambidexterity (Raisch et al. 2009).

This lack of understanding of CSRs' ambidextrous behavior is a critical impediment to superior value creation for mutually beneficial customer-company relationships, which is a cornerstone for company survival (Boulding et al. 2005; Lusch, Vargo, and O'Brian 2007). Cross-/up-selling during customer service should be a way to nurture relationships that not only reduces costs for both relationship partners by making processes to interact more efficient. It also increases the effectiveness of the identification and satisfaction of customer needs and revenue generation. The alignment of service and sales allows for profitability improvements through both increasing revenues and reducing costs. Such a dual emphasis enables companies to create superior value, thereby enriching and sustaining relationships and gaining a sustainable competitive advantage (Mittal et al. 2005; Ravald and Grönroos 1996). However, whether, when, and how CSRs can effectively align customer service provision and cross-/up-selling and hence act ambidextrously has remained unresolved. This dissertation addresses this theoretically and managerially relevant issue by studying employee-level ambidexterity in the context of CSRs' service-sales alignment.

The premise of mutually beneficial relationships is the creation of value for both company and customer as relationship partners (e.g., Boulding et al. 2005). It is therefore imperative to consider the service-sales alignment from the CSR's and customer's perspective. The alignment essentially takes place during inbound customer service encounters in which CSRs and customers interact as co-creators of value (Vargo and Lusch 2008). CSRs and customers have their own task and relationship related goals, which they want to fulfill during the encounter, and expectations about the partner's role and behavior (Price, Arnould, and Tierney 1995; Solomon et al. 1985). The dyadic nature of these encounters also brings about interdependencies such that each party's behavior influences the other's behavior and the effect of a party's behavior on outcomes depends on the other party (Ma and Dubé 2011). Neglecting the dyadic nature of encounters and relationship characteristics would provide an incomplete understanding of CSRs' servicesales alignment. Thus, it is important to consider not only the outcomes of the servicesales alignment for customers and CSRs (i.e., companies), but also potential influences of customer-CSR interaction contingencies on the effectiveness of CSRs' ambidextrous behavior. Hence, the overall research question that guides this dissertation is:

\section{Which factors facilitate a CSR's ambidextrous behavior and impact its effectiveness?}


To answer this research question and accommodate the dyadic nature of relationships and service encounters, this dissertation draws on several theories and research streams. In the following, we first provide a more detailed analysis of the research question and discuss relevant insights from the literature. This chapter then proceeds with an outline of the contributions this dissertation attempts to make and a brief overview of its content.

\subsection{Theoretical Considerations}

\subsubsection{Customer Service and Cross-/Up-Selling for Relationships}

Enduring mutually beneficial customer-company relationships allow companies to create superior value and contribute to their bottom line (Bolton 1998; Boulding et al. 2005; Heskett et al. 1994; Palmatier et al. 2006; Reinartz and Kumar 2003). They create value for both company and customer (Gwinner, Gremler, and Bitner 1998). For forprofit companies, value equals profitability to which enduring relationships contribute through both cost reduction and increased revenues per customer (e.g., Berry 1995). As to the costs, retaining existing customers is suggested to be cheaper than acquiring new ones (e.g., Reichheld 1996). For example, companies and customers gain more knowledge about each other over time, which allows for more efficient exchanges. As to the revenues, loyal customers tend to engage in more repeat- and cross-buying (e.g., Bolton 1998; Dwyer, Schurr, and Oh 1987) and spread positive word-of-mouth, which helps attract new customers. This is an important benefit as a company cannot survive by relying solely on existing customers (Boulding et al. 2005; Hennig-Thurau, Gwinner, and Gremler 2002). Relationships also create value to customers for whom value is the difference between benefits and costs (i.e., sacrifices; Ravald and Grönroos 1996). Costs can comprise the risk of poor performance of the products/services and their acquisition costs. Benefits relate to confidence/trust (e.g., reduced uncertainty and search costs), social (e.g., personal recognition), and special treatment (e.g., customized offers), amongst others (Gwinner et al. 1998; Hennig-Thurau et al. 2002).

Relationships can consist of multiple exchanges over time but also include discrete exchanges because they are always tied to social and/or legal contracts in some way or another (Vargo and Lusch 2004). Relationships are initiated, maintained, and terminated (Reinartz, Krafft, and Hoyer 2004). Termination can occur at any point in time due to situational and reactional triggers (Gustafsson, Johnson, and Roos 2005). Situational triggers could be changes in customers' life or preferences, which lead to ceased consumption of the product/service. Reactional triggers could be product/service failures which are transgressions of relational terms and norms. Customer service and cross-/up-selling are tools for relationship maintenance to circumvent termination (Reinartz et al. 2004; Zeithaml et al. 2006). Customer service is the service provided in support of the customers' current product/service consumption portfolio, such as answering customers' questions, handling their complaints, and providing recovery to product/service failures (Bolton, Grewal, and Levy 2007; Zeithaml et al. 2006). Customer service is mainly customer-initiated. Cross-/up-selling broadens and deepens customers' 
product/service consumption portfolio by selling additional and higher-value products/ services to them (e.g., Kamakura, Ramaswami, and Srivastava 1991). Companies have typically initiated cross-/up-selling through outbound communication via phone, mail, e-mail, and Internet (Godfrey, Seiders, and Voss 2011).

Customer service and cross-/up-selling are essential for mutually beneficial relationships and their 'survival'. In essence, they are nonsubstitutable and interdependent. For example, customer service reduces the likelihood that customers defect due to reactional triggers and ensures that customers are satisfied and stay with the company at least in the near future. Cross-/up-selling reduces the likelihood that customers defect due to situational triggers and thereby ensures that they stay with the company in the long run. One cannot substitute the other. They are also interdependent. Satisfying unmet customer needs through cross-/up-selling (i.e., selling the right product at the right time) enhances perceptions of service excellence; excellent customer service enhances customer satisfaction and increases sales (Zeithaml 2000; Zeithaml et al. 2006). A successful service-sales alignment by CSRs should result in superior value creation for both companies and customers. The inbound customer service call is an existing customer touch point. Customers already devote attention and time to the company. Other outbound cross-sell messages would consume more of customers' attention and time and a company's resources. Besides, due to the direct interaction between customers and CSRs, customer needs are more transparent and can interactively be scrutinized, which implies more effective revenue generation and customer need satisfaction (Bitner, Booms, and Mohr 1994; Evans et al. 1999).

Both customer retention tools have typically been structurally separated functions in companies (Aksin et al. 2007; Anderson and Ragsdale 2004). A prominent example would be the inbound call center for customer service and outbound call centers for cross-/up-selling. Such a separation allows for specialization and the pursuit of economies of scale (cf. March and Simon 1958). It might also allow for managing the conflicting demands of service and sales. Customer service is considered a cost factor for which efforts are directed at cost reduction and efficiency (Bolton et al. 2007). This conflicts with the sales function that aims to maximize revenues, implying a cost reductionrevenue expansion trade-off (Rust, Moorman, and Dickson 2002). Moreover, due to the nature of services (e.g., heterogeneity, inseparability), customer service involves a productivity-quality trade-off, which arises from the attempt to reconcile customization and standardization (Rust and Chung 2006; Singh 2000). Customization aims to attain high quality in service delivery. Standardization aims to ensure reliable, efficient service and reduce costs (Frenkel et al. 1998; Rust and Chung 2006). Because inbound customer service has a significant labor component, both productivity and quality are important (Singh 2000). Accordingly, inbound call centers typically monitor CSRs' performance on both dimensions efficiency and quality, requiring CSRs to manage this tension (Aksin et al. 2007; Bain et al. 2002). A revenue generation goal which necessitates the search for the right cross/up-sell offers to be made at the right time inevitably introduces variability because it involves failures and uncertainty. Adding a sales goal to customer service therefore leads to productivity-quality-revenue tensions in CSRs' jobs (Aksin et al. 2007; Marinova, Ye, and Singh 2008). 
Although the alignment of customer service and cross-/up-selling promises superior value for customer-company relationships, it is unclear whether, when, and how CSRs can successfully manage the inherent conflicting demands and hence, simultaneously pursue the seemingly conflicting service and sales goals. This dissertation therefore turns to ambidexterity research which we discuss next.

\subsubsection{The Pursuit of Seemingly Conflicting Goals}

Ambidexterity reflects alignment in the pursuit of seemingly conflicting goals and is typically studied at the company level (Raisch and Birkinshaw 2008). Ambidextrous organizations succeed in simultaneously managing today's business efficiently through exploitation and adapting to changes in their environment to ensure future business through exploration, which is essential for company survival (Gibson and Birkinshaw 2004; Levinthal and March 1993; March 1991; Tushman and O'Reilly 1996). The underlying idea is that the demands a company faces in its task environment are always conflicting to a certain degree (e.g., nurturing current projects versus developing new projects) and compete for resources or organizational routines, such that trade-offs need to be made (Gibson and Birkinshaw 2001; Gupta, Smith, and Shalley 2006; March 1991). For example, ambidexterity can refer to the simultaneous engagement in activities that are directed at existing customers and markets (e.g., customer retention) and those that are directed at new customers and markets (e.g., customer acquisition; Arnold, Fang, and Palmatier 2011). Within each type of these activities, there are other conflicting demands. For instance, customer acquisition for a newly developed product can require 'hunting' (e.g., high-volume, transactional selling for immediate gains) and 'farming' (e.g., lowvolume, consultative selling for long-term gains; Sheth and Sharma 2008; Vachhani 2006). Similarly, customer retention can require customer service provision (investments in keeping customers now) and cross-/up-selling (investments in keeping customers in the long-run; this dissertation). All these types of activities compete for resources and involve disparate demands. Ambidextrous organizations successfully manage the conflicting demands, achieve complementarity, and carry out both (Cao, Gedajlovic, and Zhang 2009; Levinthal and March 1993). Because the constituent elements of ambidexterity are nonsubstitutable and interdependent, empirical evidence shows that ambidextrous companies enjoy superior performance (Gibson and Birkinshaw 2004; He and Wong 2004). Despite the confirmed ambidexterity-performance relationship, a few studies suggest that ambidexterity may not be always effective and boundary conditions may arise from the environment in which a company operates (Raisch and Birkinshaw 2008; Raisch and Hotz 2010). However, not much is known about the factors that influence the effectiveness of ambidexterity (Raisch et al. 2009).

For managing the tensions involved in ambidexterity, structural mechanisms have traditionally been proposed. For example, companies might become ambidextrous by developing different subunits that specialize in one or the other activity pattern (Gupta et al. 2006), which appears to be the traditional case for customer service and cross-/up-selling. (Top) managers are then responsible for integrating them to achieve complementarity (Tushman and O’Reilly 1996). Recently, contextual mechanisms, 
such as the creation of supporting organizational contexts (e.g., concurrent discipline, stretch, support, and trust) have been shown to work as well (Gibson and Birkinshaw 2004). These efforts aim to encourage employees to pursue seemingly conflicting goals on their own and provide them with the behavioral capacities to think and behave ambidextrously. The requirement for employees to pursue seemingly conflicting goals simultaneously appears widespread. For example, production workers at Toyota have to be innovative and flexible while performing efficiently their routine tasks (Adler et al. 1999). Ambidextrous professors produce both academically rigorous and managerially relevant, impactful research (Markides 2007). Ambidextrous managers also perform efficiency-oriented routine tasks and variability-increasing nonroutine tasks (Mom et al. 2009). Likewise, CSRs are expected to fulfill service requests efficiently and reliably while also exploring cross-/up-sell opportunities and hence act ambidextrously during service encounters. Because a systematic and profound understanding of employee-level ambidexterity is missing to date (Raisch et al. 2009), chapter 2 of this dissertation studies antecedents and performance consequences of a CSR's ambidextrous behavior. In chapter 3 , the effectiveness of a CSR's ambidexterity comes under scrutiny.

A phenomenon such as ambidexterity can differ in meaning, characteristics, outcomes, and antecedents across organizational levels (Gupta et al. 2006; Gupta, Tesluk, and Taylor 2007). Many things change with different reference levels. This requires some considerations and a clarification of the specifics that are associated with the employee level in relation to CSRs' service-sales alignment. For example, while a company can become ambidextrous by structurally separating conflicting activities in different sub-units, this is no option for the CSR who has to pursue the seemingly conflicting service and sales goals simultaneously during interactions with customers. Dealing with conflicting demands in such a way makes behavioral changes that are necessary for the pursuit of goals more difficult, which increases substantially the need for motivational resources (Baumeister and Vohs 2007). Furthermore, the service-sales alignment aims at long-term mutually beneficial relationships. Relationship length or value is clearly an appropriate performance indicator of ambidexterity at the company level. However, it is inappropriate for a CSR's ambidexterity because customers typically interact with different employees of the company and each of them can affect the state, quality, and length of the relationship (Gutek et al. 1999). Performance outcomes such as customers' satisfaction with their interaction with the CSR and a CSR's sales performance appear to be more suitable.

Moreover, while the market and industry represent the external environment for companies, CSRs' external environment also includes the call center and the service encounter in which they interact with customers. Previous research has shown that employees' characteristics and their environment interact to shape their behavior (for an overview, see Schneider 2007). Therefore, it is important to take the influences and interactions of CSRs' characteristics and their work environment into account. Besides, the contingency view of service encounters suggests that CSRs' micro-environment also influences the effectiveness of their ambidextrous behavior (Weitz 1981). Related factors can arise prior to the service encounter, such as the state of the customercompany relationship or a customer's relationship related goals (Weitz 1981). They can 
also arise directly from the customer-CSR interaction because of the involved behavior and outcome interdependencies (Ma and Dubé 2011). Customers' perceptions of the CSR's behavior are particularly relevant to those interdependencies and influenced by their goals and the state of their relationship with the company (Davidow 2003; Ma and Dubé 2011). Therefore, chapter 3 considers such potential customer-CSR interaction contingencies and their influence on the effectiveness of CSRs' ambidextrous behavior from the customer's perspective. To gain relevant insight, we draw on service encounter research and social cognitive psychology literature, which we discuss in the next section.

\subsubsection{Social Cognition in Service Encounters}

Inbound customer service calls are technology-mediated, voice-to-voice interactions between CSRs and customers. They are "first and foremost social encounters" (McCallum and Harrison 1985, p.85) in which the identities of the CSR and customer, their roles, and goals are relevant to the interaction and encounter outcomes (Czepiel 1990; Solomon et al. 1985; Surprenant and Solomon 1987). In service encounters, customers form impressions of CSRs to determine their identity and predict and assign meaning to their behavior, which is important as service processes and outcomes partly depend on CSRs (Fiske and Neuberg 1990; Ma and Dubé 2011; Solomon et al. 1985). CSRs' behaviors affect customers' impressions which in turn influence their service quality evaluations, satisfaction, and purchase intention (e.g., DeCarlo 2005; Parasuraman, Zeithaml, and Berry 1988; Schneider and Bowen 1995). Because for customers the CSR is the face (or 'voice') of the company in those encounters, their impression of the CSR is informative for their relationship with the company (Bitner, Brown, and Meuter 2000; Schneider and Bowen 1995).

Customers' impression formation begins with categorizing the CSR into a social category (Fiske and Neuberg 1990). When customers have sufficient motivation, ability, and time, they go on with either recategorizing the CSR into a different category when it better fits with the CSR's behavior or individuating the CSR (Fiske, Lin, and Neuberg 1999). Complete individuation is unlikely because inbound service calls are relatively brief and quick interactions in which information about the CSR is limited. When customers use a category based impression for evaluating and predicting the CSR's behavior, they fill gaps in their CSR knowledge with the knowledge they have about the social category (Fiske and Neuberg 1990; Solomon et al. 1985). In other words, they stereotype. A stereotype is a set of beliefs about characteristics (e.g., traits, behaviors, and goals) that are associated with members of a social category (e.g., Hilton and von Hippel 1996; Stangor and Lange 1994). Stereotypes are quick and efficient devices that provide people with a sense of predictability and orderliness of their social environment (Allport 1954; Fiske and Neuberg 1990).

Ambidextrous CSRs are a particularly interesting case for impression formation because they slip from the service provider into the seller role during the service encounter. They therefore provide customers with different bases for social categorization and hence stereotypes. The literature indicates that service and sales stereotypes are quite disparate. While selling is related to the salespeople category which carries quite a 
negative connotation of insincere, deceptive, sales-oriented salespeople, CSRs as service providers are strongly associated with positive motives, helpfulness, and friendliness (Glick, Wilk, and Perreault 1995; Lee et al. 2007). If customers used a stereotype during encounters, their cognitive, affective, and behavioral reactions to their interaction with the CSR and relationship to the company could be biased (Macrae and Bodenhausen 2000). Stereotyping is likely in service recovery encounters which customers initiate when they have experienced a product/service failure. Those failures are reactional triggers that change the state of the relationship and cause distrust regarding the company's intention to live up to relationship terms (Matos, Henrique, and Rossi 2007; Singh and Sirdeshmukh 2000). Product/service failures trigger self-protection goals that motivate customers to stereotype to protect their interests from further threats (Darke, Ashworth, and Main 2010; Darke and Ritchie 2007). Hence, in recovery encounters a CSR's cross-/up-sell attempt could motivate customers to use a negative salesperson stereotype, which potentially renders the CSR's ambidextrous behavior ineffective or even harmful for the customercompany relationship. This raises the question as to whether and how CSRs could prevent this from happening. Because cross-/up-sell attempts typically follow a service recovery interaction, the service employee category and related positive stereotypes have some leeway. In this regard, customer-CSR interdependencies in encounters may provide an answer to that question. However, so far, the literature does not provide an understanding of the factors that determine the stereotype customers would use for the ambidextrous CSR. Chapter 3 of this dissertation is therefore devoted to provide such an understanding and illuminates how customer-CSR interaction contingencies impact the effectiveness of CSRs' ambidextrous behavior in recovery encounters.

\subsection{Theoretical Contributions}

One of the key facilitators for company survival is the ability to form enduring mutually beneficial relationships with customers (Boulding et al. 2005; Lusch et al. 2007). Such relationships require superior value co-creation, which can be achieved by increasing benefits and reducing costs for both relationship partners (e.g., Payne and Frow 2005; Payne, Storbacka, and Frow 2008; Sheth, Sisodia, and Sharma 2000; Sheth and Uslay 2007). The alignment of the two customer retention tools - customer service and cross-/ up-selling - promises to be one such way to create more value. The relationship literature in marketing emphasizes that building mutually beneficial relationships requires collaboration and information sharing between intrafirm functions, such as customer service and sales (e.g., Boulding et al. 2005; Parvatiyar and Sheth 2001). Notably, CSRs' alignment of customer service and sales goes beyond that by uniting these two functions. While customer service and cross-/up-selling have been studied extensively, we lack an understanding of how and when these two customer retention tools can be effectively aligned by CSRs. This dissertation aims to contribute to such understanding. To accommodate the mutuality of benefits in relationships, we address the perspectives of customers and CSRs (i.e., companies), assess value creation for both relationship partners, and consider relationship characteristics and customer-CSR interaction related specifics. 
Beyond providing important insights for the relationship literature in marketing, this dissertation makes specific theoretical contributions to ambidexterity and stereotyping research.

\subsubsection{Ambidexterity}

Prior research has largely focused on ambidexterity at macro-organizational levels (Raisch et al. 2009). Yet recent advances suggest that a company's ambidexterity is rooted in the employee's ability to simultaneously pursue seemingly conflicting goals, which therefore shapes organizational performance. Given the lack and importance of a systematic understanding of ambidexterity at the employee level (Gupta et al. 2006; Raisch and Birkinshaw 2008; Raisch et al. 2009), this dissertation investigates CSRs' pursuit of the seemingly conflicting service and sales goals in an attempt to advance such understanding. Chapter 2 conceptualizes employee-level ambidexterity in the context of CSRs' service-sales alignment and clarifies its specific nature, thereby contributing to an ongoing debate about whether employees can be truly ambidextrous (Gupta et al. 2006; Mom et al. 2009). By considering the specifics of the employee level, this chapter develops and empirically tests a framework of antecedents, their interactions with proximal work environment characteristics, and performance consequences of CSRs' ambidextrous behavior. Because recent ambidexterity literature emphasizes the need for more understanding of the boundary conditions of the ambidexterity-performance relationship (Raisch and Birkinshaw 2008; Raisch et al. 2009), chapter 3 addresses the effect of customer-CSR interaction contingencies on the effectiveness of CSRs' ambidextrous behavior.

\subsubsection{Stereotyping of Ambidextrous CSRs}

Ambidextrous CSRs who provide customer service and then also engage in cross-/ up-selling are multiply categorizable people. Specifically, they reveal multiple social category memberships gradually during a recovery encounter and have the potential to evoke conflicting service employee and salesperson stereotypes (Glick et al. 1995; Lee et al. 2007). Extant stereotyping research into multiply categorizable people examines how people categorize another person who simultaneously reveals multiple social category memberships (Bodenhausen and Macrae 1998; Bodenhausen and Peery 2009). Therefore, this research stream provides an understanding of the factors that determine the initial social category based impression. However, impression formation literature suggests that people can recategorize another person into another social category and hence revise their very first impression (Fiske and Neuberg 1990). Chapter 3 extends stereotyping research into multiply categorizable people by investigating determinants of keeping and revising an initial category based impression when customers are motivated to stereotype CSRs who are first service employees and then turn into salespeople. This chapter also reveals both the deleterious and beneficial consequences of stereotyping. 


\subsection{Dissertation Outline}

To address the overall research question of which factors facilitate a CSR's ambidextrous behavior and impact its effectiveness, this dissertation is based on two sets of empirical studies for which Figure 1.1 provides an integrative overview and Table 1.1 offers a summary.

\section{Figure 1.1 Integrative Overview of Dissertation}

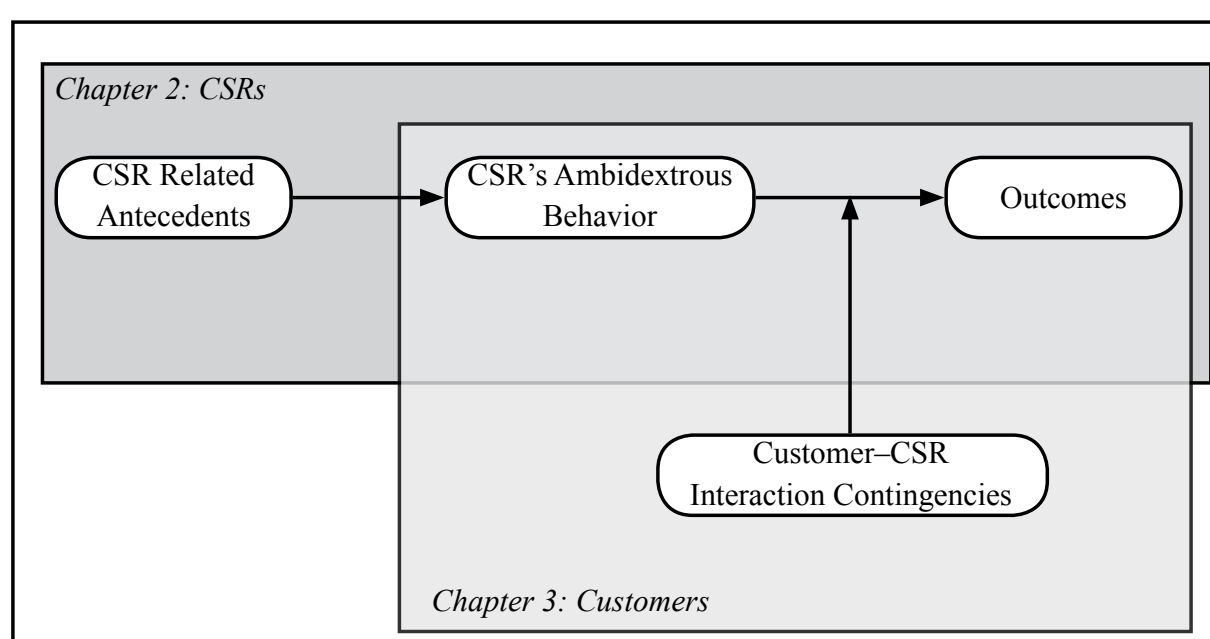

Chapter 2 focuses on the CSR as representing the company in the customercompany relationship. The study considers the self-regulatory and motivational challenge that is posed by the pursuit of seemingly conflicting goals and draws on regulatory mode theory to examine how motivational orientations (i.e., locomotion and assessment orientations) interact to facilitate CSRs' ambidextrous behavior. In addition, the study accommodates the influences of prevalent structural call center contingencies (i.e., team identification and bounded discretion) on these CSR characteristics. The effects of CSRs' ambidextrous behavior on typical call center performance parameters are also assessed to capture the value that is created for the company. In cooperation with a leading, globally operating call center services outsourcing provider, data was collected via surveys among CSRs in inbound call centers. The data served a separate, multi-stage measurement scale development study, which was a basic pre-requisite for the principal study that is mainly described in chapter 2 . Objective sales performance and efficiency data as well as customer satisfaction data collected via a third party provider complemented the survey data.

Chapter 3 focuses on the customer in the customer-company relationship and the service encounter, captures customer reactions to CSRs' ambidextrous behavior directly, and reveals the impact of customer-CSR interaction contingencies on the effectiveness of CSRs' ambidextrous behavior. In particular, this chapter investigates customers' stereotyping of an ambidextrous CSR who provides service recovery and attempts to cross-sell. The developed hypotheses are based on considerations of 
customer-CSR interaction specifics and mechanisms underlying motivated stereotyping during interactions. Five experimental studies using role play scenarios in which students acted as pseudo-customers serve to illuminate the conditions in which cross-sell attempts motivate customers to use a negative salesperson stereotype and how such stereotyping can be circumvented. The studies employed an implicit measure of stereotype activation which does not require verbal report to avoid response and social desirability bias. To capture the value that is created for customers, the downstream consequences of stereotyping were captured with explicit measures of customers' intention to purchase the offered product and satisfaction with the encounter.

Chapter 4 concludes this dissertation by providing a general discussion of the findings against the backdrop of value creation for mutually beneficial relationships and an answer to the overall research question. This chapter also provides directions for further research.

TABLE 1.1 Overview of Studies

\begin{tabular}{|c|c|c|}
\hline & Chapter 2 & Chapter 3 \\
\hline Study & $\begin{array}{l}\text { Generating Sales While } \\
\text { Providing Service - A } \\
\text { Study of Customer Service } \\
\text { Representatives'Ambidextrous } \\
\text { Behavior }\end{array}$ & $\begin{array}{l}\text { Cross-selling in Recovery } \\
\text { Encounters - Staying under } \\
\text { the Customer's Radar to } \\
\text { Avoid Salesperson Stereotype } \\
\text { Activation }\end{array}$ \\
\hline Theoretical focus & $\begin{array}{l}\text { Ambidexterity, regulatory } \\
\text { mode theory }\end{array}$ & $\begin{array}{l}\text { Stereotyping, impression } \\
\text { formation }\end{array}$ \\
\hline Conceptual level & CSR & Service encounter \\
\hline $\begin{array}{l}\text { Focus of the } \\
\text { customer- } \\
\text { company } \\
\text { relationship }\end{array}$ & CSR & Customer \\
\hline \multirow[t]{3}{*}{ Research design } & - Quantitative, correlational & $\begin{array}{l}\text { Quantitative, causal \& } \\
\text { correlational }\end{array}$ \\
\hline & $\begin{array}{l}\text { - Surveys among CSRs in } \\
\text { call centers }\end{array}$ & $\begin{array}{l}\text { Five experiments with } \\
\text { students (pseudo- } \\
\text { customers) based on role- } \\
\text { play scenarios }\end{array}$ \\
\hline & $\begin{array}{l}\text { - Subjective and objective } \\
\text { data }\end{array}$ & $\begin{array}{l}\text { Subjective data: Explicit } \\
\text { and implicit measures }\end{array}$ \\
\hline Analysis strategy & $\begin{array}{l}\text { Structural equation modeling, } \\
\text { OLS regression }\end{array}$ & $\begin{array}{l}\text { Analysis of Variance, OLS } \\
\text { regression, path analysis }\end{array}$ \\
\hline
\end{tabular}




\section{Chapter 2}

\section{Generating Sales While Providing Service: A Study of Customer Service Representatives' Ambidextrous BEHAVIOR}

This chapter is based on:

Jasmand, Claudia, Vera Blazevic, and Ko de Ruyter (2012), "Generating Sales While Providing Service: A Study of Customer Service Representatives' Ambidextrous Behavior," Journal of Marketing, 76 (January).

Reprinted with permission from the American Marketing Association. 


\subsection{Introduction}

Economic and competitive pressures have sparked firms' interest in adding a revenue component to their costly after-sales support. As a consequence, inbound call centers have introduced revenue generation as a strategic priority (CSO Insights 2007). Blending sales with service can reap increased revenues and customer retention rates. A McKinsey \& Co. report points out that inbound call centers have the potential to generate at least $10 \%$ of a firm's total revenues from sales of new products and services (Eichfeld et al. 2006). Yet recent market studies reveal that the actual returns are far below such optimistic estimates (CSO Insights 2007; ICMI 2007). Apparently, firms struggle to create conditions that are conducive to a successful alignment between customer service and sales.

Managerial literature is replete with illustrations of the challenges inbound call centers face (e.g., mycustomer.com, customerthink.com). Among the most commonly cited is CSRs' deeply ingrained view that additional selling is incommensurate with service, which creates a high mental barrier to blending the two tasks. Call centers also observe considerable heterogeneity in CSRs' ability to convert service calls into a crossor up-sale, which complicates the development of policies and guidelines designed to increase average performance (ICMI 2007). Furthermore, the newly introduced revenue generation goals conflict with the efficiency goals that tend to rule traditional, serviceonly call centers (Aksin et al. 2007). Firms clearly need an in-depth understanding of the factors that contribute to CSRs' ability to align their service and sales efforts, as well as the subsequent impact on key performance parameters.

Extant marketing literature rarely considers the simultaneous pursuit of service and sales goals though. Sales literature focuses on the performance effects of sales behaviors in relationship-oriented contexts (e.g., Plouffe, Hulland, and Wachner 2009); services literature centers on the service provider's management of the customer experience (e.g., Price et al. 1995). The few studies that bridge these literature streams highlight the trade-offs involved in service-sales alignment but fail to explain how to resolve them (e.g., Evans et al. 1999). Therefore, we turn to recent research on the phenomenon of ambidexterity, which reflects alignment in the pursuit of seemingly conflicting goals. Ambidextrous firms manage the conflicting demands of exploiting existing competencies and exploring new opportunities, and thus they enjoy superior performance (Raisch and Birkinshaw 2008). Recent theorizing demonstrates that ambidexterity ultimately becomes manifest at the employee level (Raisch et al. 2009). Ambidextrous employees perform contradictory activities in their pursuit of multiple goals, such as efficiencyoriented routine tasks and variability-increasing nonroutine tasks (Mom et al. 2009). In a similar vein, CSRs increasingly are expected to fulfill service requests efficiently and reliably while also exploring cross-/up-selling opportunities. Despite the importance of the employees' ability to pursue seemingly conflicting goals, in-depth understanding of their ambidextrous behavior is lacking (Raisch et al. 2009). To address this theoretically and managerially relevant gap, we develop and empirically validate a framework of the antecedents and performance consequences of CSRs' ambidexterity in relation to the pursuit of service and sales goals.

This study advances ambidexterity theory in three ways. First, we conceptualize 
CSRs' ambidextrous behavior to clarify its specific nature and inherently conflicting demands. Such a clarification is necessary, given the ongoing debate about whether employees can be truly ambidextrous (Gupta et al. 2006; Mom et al. 2009) and the need to understand CSRs' ability to complete seemingly contradictory tasks. Second, we address the observable heterogeneity in individual CSRs' ambidextrous behavior by investigating the hitherto unstudied effects of individual motivations (Raisch et al. 2009). As engaging in ambidextrous behavior poses a self-regulatory and motivational challenge, we draw on regulatory mode theory (Kruglanski et al. 2000) and propose that the joint effect of CSRs' motivational orientations of locomotion and assessment enhances their ambidextrous behavior. We also investigate how prevalent structural call center contingencies, such as team identification (Ashforth and Mael 1989) and bounded discretion (Kelley 1993), may influence the valuable interplay of these two motivational orientations. Third, to the best of our knowledge, this study is the first to assess the performance implications of individual ambidexterity; we conceptualize and empirically test the validity of the ambidexterity-performance tenet at the personal level (Cao et al. 2009). We investigate the specific impact of CSRs' ambidextrous behavior on their performance in terms of customer satisfaction, sales, and efficiency, which are of particular interest because of the commonly observed productivity-quality-revenue trade-offs in frontline jobs (Marinova et al. 2008).

\subsection{Theoretical Background}

The notion of ambidexterity has attracted attention from diverse literature, including strategic management, organizational learning and design, and innovation. For this emerging topic, organizational ambidexterity refers to a firm's ability to pursue the seemingly conflicting goals of exploiting existing competencies and exploring new opportunities (Raisch and Birkinshaw 2008). The objective of exploitation, which includes activities such as refinement, implementation, and execution, is the creation of efficiency and reliability. Exploration instead pertains to activities such as search, discovery, and risk taking and centers on flexibility and creating variability (Levinthal and March 1993; March 1991). ${ }^{1}$ Because these two types of tasks are separate, nonsubstitutable, and interdependent, firms must find ways to achieve complementarity and carry out both (Gibson and Birkinshaw 2004; Levinthal and March 1993). Empirical studies provide support for the tenet that ambidexterity enhances a firm's performance (Raisch and Birkinshaw 2008). Yet the conflicting demands of the two types of activities (e.g., efficiency vs. flexibility) and their frequent competition for limited resources make it difficult to be ambidextrous (Gupta et al. 2006; March 1991).

Traditionally, firms use structural mechanisms to overcome the tensions in their

Exploitation and exploration are prevalent umbrella terms in the organizational literature and refer to various conflicting demands at different organizational levels (e.g., efficiency and flexibility, search scope and search depth). The terms exploitation and exploration appear to have different and inappropriate connotations at the employee level. We therefore decided to use the terms customer service provision and cross-/up-selling for the underlying dimensions of ambidexterity in the context of CSRs' service-sales alignment. 
pursuit of seemingly conflicting goals. They might become ambidextrous by cycling through periods of these types of activities or developing different subunits that specialize in one or the other activity pattern (Gupta et al. 2006). Recent empirical evidence suggests that contextual mechanisms, such as the creation of appropriate organizational contexts (e.g., concurrent discipline, stretch, support, trust) or coordination mechanisms (e.g., cross-functional interfaces), can work as well (Gibson and Birkinshaw 2004; Mom et al. 2009). These efforts aim to encourage employees to pursue apparently conflicting goals and provide them with the behavioral capacities to think and behave ambidextrously. As Raisch et al. (2009) note, these advances suggest that a firm's ambidexterity is rooted in the employee's ability to manage disparate task demands and integrate them for crossfertilization. Accordingly, employees' ambidextrous behavior shapes organizational performance; yet a conceptual and empirically validated understanding of employeelevel ambidexterity is lacking (Raisch et al. 2009).

The requirements for employees to pursue seemingly conflicting goals simultaneously appears widespread, ranging from managers (Mom et al. 2009), to researchers (Markides 2007), to production line workers (Adler et al. 1999). Likewise, CSRs are now asked to provide customer service at constant quality and low cost and, at the same time, to engage in cross-/up-selling to generate revenues during encounters initiated by customer service requests. Firms thus shift the responsibility for managing the dual emphasis on cost reduction and revenue expansion to CSRs, which complicates the existing productivity-quality trade-off in the front line of the organization (Marinova et al. 2008; Rust et al. 2002).

Customer service provision pertains to CSRs' activities that aim to help customers fulfill their needs through their current product/service consumption portfolios. When providing customer service, CSRs respond to incoming customer service requests by implementing available, often prescribed and standardized problem-solving procedures. The large call volumes and frequent recurrence of the same requests enable CSRs to rely on well-practiced processes and leverage routinely used knowledge and skills. The service conversations are typically structured and partly scripted to ensure constant quality and efficiency (Aksin et al. 2007; Deery, Iverson, and Walsh 2002). Moreover, assessments of CSRs' customer service provision usually depend on their performance with regard to efficiency targets, such as call handling time, and reliability and quality targets, measured as customer satisfaction (Deery et al. 2002; Singh 2000).

In contrast, cross-/up-selling refers to CSRs' activities that aim to change (i.e., expanding or replacing parts of) customers' current product/service consumption portfolios, in accordance with their needs that cannot be satisfied by their current portfolios. Thus, during the service encounters, CSRs need to search proactively for customer needs and ways to satisfy them with a new product or service, discover suitable ways to turn the service into a sales conversation, and create and capture sales opportunities (Aksin and Harker 1999; Günes et al. 2010). They also need to leverage dispersed information to generate knowledge beyond what the service conversation usually offers and requires, because effective sales performance depends on an in-depth understanding of customer needs (Evans et al. 1999; Weitz 1978). Furthermore, the customer's purchase willingness depends on many factors, such as previous satisfaction and financial resources (Günes 
et al. 2010). This information may not be readily available to CSRs, which turns cross-/ up-selling into a process with uncertain returns and a high risk of failure. Because cross-/ up-selling requires detecting the right product and time to attempt a sale (Günes et al. 2010), its success necessitates procedural flexibility.

Ambidextrous behavior refers to CSRs' engagement in both customer service provision and cross-/up-selling during service encounters. Because customers' service requests initiate the encounters, CSRs must simultaneously perform customer service and cross-/up-sell activities and/or quickly switch between them to display ambidextrous behavior. Such simultaneous pursuit of service and sales goals requires CSRs to manage fundamentally different, if not conflicting behavioral demands. On the one hand, customer service activities center on explicit service requests, readily available knowledge, and relatively standardized processes, emphasizing implementation and execution, akin to order-taking. They involve the repetitious routine and structure necessary to achieve the goals of reliability and efficiency. On the other hand, cross-/up-selling activities imply proactive, broad, and nonroutine searches for customer needs, knowledge generation, and creation of opportunities, akin to order seeking. They involve risk taking, flexibility, and uncertain returns, because the identification, positioning, and closing of a sale largely depend on the nature of service requests and customers and how the conversation develops. The uncertainty and variability involved in cross-/up-selling are detrimental to the reliability and efficiency focus of customer service provision; the latter may crowd out risk-taking and proactive cross-/up-selling efforts. Furthermore, pursuing service and sales goals often requires CSRs to trade off the allocation of their time, effort, and attention to both types of activities (Aksin and Harker 1999; Evans et al. 1999).

Several researchers have questioned the compatibility of the constituent dimensions of ambidexterity at the employee level (Gupta et al. 2006; March 1991), though others have observed that employees can simultaneously and sequentially attend to them (Adler et al. 1999; Mom et al. 2009). For CSRs, we predict compatibility. Prior literature indicates that service and sales activities are compatible because they share common ground. A common set of abilities, such as diagnostic behavior, empathy, and interpersonal adaptation, underlies both of them (e.g., Evans et al. 1999; Gwinner et al. 2005; Saxe and Weitz 1982). Previous research further suggests that people can simultaneously perform routine tasks using automatic processes and rely on controlled processes for their nonroutine tasks (Wegner and Bargh 1998). Thus, some customer service activities might be performed in automatic mode to free up cognitive and attentional resources for cross-/up-selling. Consequently, we posit that it is possible for CSRs to engage, simultaneously and/or sequentially, in customer service provision and cross-/up-selling during a service encounter.

Although service and sales goals are not completely incompatible in their requirements for underlying abilities, they appear conflicting in their behavioral demands and often compete for CSRs' resources. As such, engaging in ambidextrous behavior requires CSRs to manage seemingly conflicting task demands, which poses a substantial self-regulatory and motivational challenge in the process of pursuing multiple goals.

Research into self-regulation has examined how people direct attention, resources, and action in goal pursuit by dealing with change (i.e., making progress toward 
the goal) and comparison (i.e., monitoring the progress, e.g., Carver and Scheier 2010). In this literature, the two regulatory mode orientations of locomotion and assessment have emerged to reflect the motivational capacity of people to guide themselves effectively toward important goals (Higgins, Kruglanski, and Pierro 2003). Regulatory mode theory views self-regulation as consisting of two independent dimensions. Locomotion denotes movement away from a current state, which is independent of the value of the current state and its relationship to goals, while assessment refers to evaluations of current states, goals, and means and comparisons among them (Kruglanski et al. 2000). Empirical studies show that people reliably differ in their preferences for locomotion and assessment, which influences the manner in which they approach tasks, pursue goals, make decisions, evaluate themselves and others, and deal with challenges (Kruglanski et al. 2010). These studies also demonstrate that a desire for movement and progress is unrelated to the preference for critical evaluation and comparison, such that a person can be high on both locomotion and assessment or high or low on one or the other. Previous research into these motivational orientations indicates that in combination, they lead to superior self-regulation in challenging and difficult endeavors, such as demand for ambidextrous behavior (Kruglanski et al. 2000; Pierro, Kruglanski, and Higgins 2006). We therefore study the effects of CSRs' locomotion and assessment orientations in regulating their behavior toward seemingly conflicting goals. By investigating such individual differences, our study complements existing research that focuses on the effects of supporting contextual factors on ambidexterity (Gibson and Birkinshaw 2004; Mom et al. 2009).

We also consider CSRs' responses to prevalent structural call center characteristics because self-regulation and motivation in goal pursuit are intertwined with social, situational, and environmental conditions (e.g., Fitzsimons and Bargh 2004). Inbound call centers typically organize CSRs around team structures to encourage the creation of a collective team identity that motivates performance, cooperation, and mutual support (Ashforth, Harrison, and Corley 2008; Deery et al. 2002). Moreover, call center operations focus on standardization, routines, and efficiency. Therefore, work is generally formalized with standards and rules that provide guides for workflows, tasks, and procedures to encourage CSRs to exercise bounded discretion (Aksin et al. 2007; Kelley 1993). Because team identification and bounded discretion may create conditions that interfere with the functionality of the motivational orientations, we consider these interactions.

Finally, we investigate the performance implications of CSRs' ambidextrous behavior. To the best of our knowledge, this study is the first to assess the validity of the ambidexterity-performance tenet at the employee level. The tenet rests on the assumption that customer service provision and cross-/up-selling are complementary (Cao et al. 2009). Complementarity may be reflected differently in various performance parameters (for a similar view, see Raisch and Birkinshaw 2008), particularly given the observed trade-offs among performance outcomes of business units with frontline service jobs (Marinova et al. 2008). Therefore, we consider the effects of ambidextrous behavior on the CSR's performance in terms of customer satisfaction, sales, and efficiency, which are critical performance parameters in inbound call centers that aim to align service and sales. 
We provide our conceptual framework in Figure 2.1.

\section{Figure 2.1 Conceptual Framework of Antecedents and Consequences of CSR's Ambidextrous Behavior}

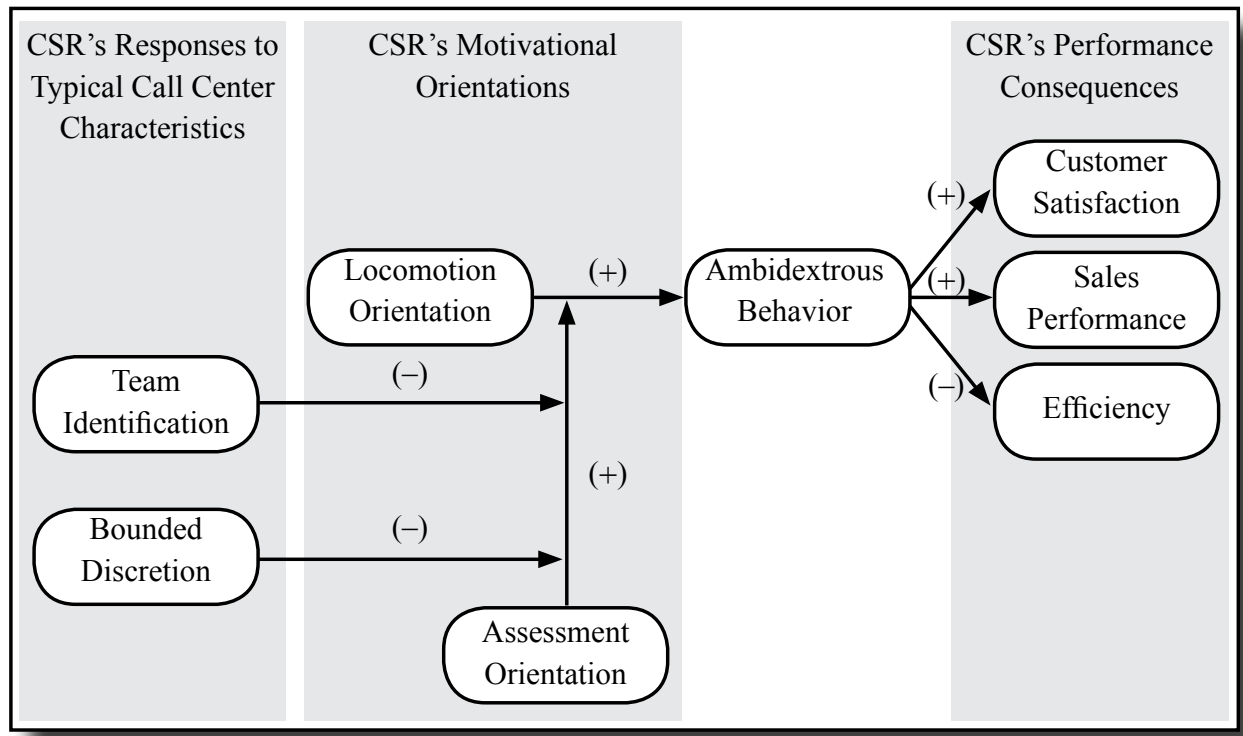

\subsection{Hypotheses Development}

\subsubsection{Effects of Locomotion and Assessment Orientations on Ambidextrous Behavior}

Locomotion orientation. A locomotion orientation constitutes a preference for movement away from a current state (in either an experiential or psychological sense) when pursuing goals. This preoccupation with moving forward reflects the desire to choose any activity to work on rather than standing still and waiting to commence the activity (Higgins et al. 2003; Kruglanski et al. 2000). Locomotion-oriented people prefer to get started on a task and expend effort to move quickly on to the next one, and they enjoy being in motion, rather than critically evaluating to determine whether the course of action is in the right direction. In other words, their focus is on 'getting on with it' in order to make things happen (Kruglanski et al. 2010). They are intrinsically motivated to engage in activities and tend to perceive such actions as ends in themselves rather than means (Higgins et al. 2003). For them, the greater the sense of movement, the more they feel intrinsically rewarded (Avnet and Higgins 2003). The popular Nike slogan 'Just do it' is an apt reflection of this orientation (Kruglanski et al. 2000).

Ambidextrous behavior is inevitably linked with the motivation to deal, simultaneously and/or sequentially, with disparate task demands in the pursuit of multiple service and sales goals. High locomotion-oriented CSRs, with their desire for action and change, may be more motivated to do so. Previous research indicates that high locomotion- 
oriented people welcome changing conditions and new experiences, react positively to changes in their task environment, and prefer a broad variety of tasks, possibly because doing very different rather than similar things gives them a greater sense of progress and movement (Avnet and Higgins 2003; Kruglanski et al. 2007; Pierro et al. 2006). Thus, high locomotion-oriented CSRs should be more likely to seek switching between (or simultaneously engaging in) fundamentally different activities, such as closely listening to a customer's service request and searching for a sales opportunity, than repeatedly doing the same type of activity.

In addition, locomotion-oriented people pay less attention to the potential consequences of their decisions and actions, because they prefer to get started quickly on tasks and make swift decisions to 'make something happen' and keep moving forward (Higgins et al. 2003; Pierro et al. 2008). Thinking less about the implications of activity engagement should decrease awareness of potentially conflicting outcomes and weaken perceptions of incompatibility of activities and goals. Therefore, high locomotionoriented CSRs may be less sensitive and receptive to trade-offs and conflicting demands, which is conducive to engaging in ambidextrous behavior. Finally, previous research suggests that people attend more to motivationally salient cues and tend to see what they desire to see (Balcetis and Dunning 2006; Lang, Bradley, and Cuthbert 1997). For locomotion-oriented people, every cue that signals an opportunity to do something is motivationally salient. Because of their urge to make use of such opportunities in relative disregard of personal benefits and costs (Higgins et al. 2003), locomotion-oriented CSRs should be more likely to engage simultaneously and sequentially in customer service and cross-/up-sell activities regardless of situational obstacles, difficulties, or constraints. We thus expect high locomotion-oriented CSRs to be more likely to engage in ambidextrous behavior.

$\mathrm{H}_{1}$ : A CSR's locomotion orientation is positively related to his or her ambidextrous behavior.

Assessment orientation. An assessment orientation refers to a preference for critical comparison of alternative states, means, and goals to judge their relative worth (Kruglanski et al. 2000). It reflects a desire for careful analysis to be accurate and make the ideal choice (Higgins et al. 2003). In contrast with locomotors, assessment-oriented people prefer to wait and evaluate all possible choices thoroughly before deciding how to act. In other words, they have a tendency to keep thinking without leaping. In decision-making, for example, assessors favor a strategy that allows them to make as many comparisons as possible without reducing the set of alternatives to arrive at the best decision (Avnet and Higgins 2003). An assessment orientation is reflected in the popular phrase 'do the right thing' (Kruglanski et al. 2000).

Previous research indicates that assessment-oriented people have strong selfevaluative concerns; they continuously compare themselves with external standards, such as goals, norms, and other people, and worry about how their performance will be perceived by others (Higgins et al. 2003). An assessment orientation signifies great sensitivity to feedback and discrepancies of any kind. Empirical studies show that high 
assessment-oriented people are better at detecting errors and deficiencies, while also coming up with more alternative means to eliminate such imperfections (Kruglanski et al. 2000). Given this enhanced sensitivity to standards, feedback, and discrepancies, high (vs. low) assessment-oriented CSRs should be more aware of their multiple service and sales goals and inclined to assess continuously how their performance measures up to these standards. With their desire for critical comparison and evaluation of alternatives, they should be preoccupied with determining the right means, courses of action, and time needed to achieve each of these goals, because doing so would reflect positively on them. We expect this enhanced sensitivity to performance gaps in service and sales goals and concern with ideal choice to purposefully guide high locomotion-oriented CSRs' resource investments into customer service and cross-/up-selling activities in the direction of the multiple job goals. Such assessment-oriented guidance should result in high locomotionoriented CSRs achieving superior levels of ambidextrous behavior.

We do not expect an assessment orientation to affect ambidextrous behavior directly however. Previous studies indicate that high assessment-oriented people primarily form behavioral intentions that lead to successful goal attainment only if they also have high locomotion concerns (Higgins et al. 2003). Research demonstrates that the combined effect of locomotion and assessment orientations results in successful self-regulation in challenging and difficult endeavors (Kruglanski et al. 2010). Effective self-regulation in the pursuit of seemingly conflicting service and sales goals requires CSRs to be eager to initiate continuously and keep on performing customer service and cross-/up-selling activities, while also wisely managing their effort and resources.

$\mathrm{H}_{2}$ : There is a positive interaction effect of locomotion and assessment orientations on ambidextrous behavior, such that the higher a CSR's assessment orientation, the stronger is the relationship between a CSR's locomotion orientation and ambidextrous behavior.

\subsubsection{Moderating Effects of CSRs' Responses to Typical Call Center Characteristics}

Team identification. Team identification refers to a CSR's perception of oneness with or belongingness to the team (Ashforth and Mael 1989). The CSRs who strongly identify with their team perceive the team's goals, norms, and values as their own (Dutton, Dukerich, and Harquail 1994; Van Knippenberg 2000). This sense of oneness with the team guides CSRs to behave in team-typical ways to endorse their team congruent identity (Haslam, Powell, and Turner 2000). When the team congruent identity is salient, CSRs use the team's goals, norms, and values in regulating their behavior, with the aim to conform to a shared team consensus, enhance well-being, and thereby feel a high belongingness to the team (Ashforth et al. 2008). Such conformity to consensus reduces the range of means that can potentially be employed in goal attainment. The CSRs then engage in team convergent thinking and reduce active consideration of other possible alternatives in their pursuit of goals. While team identification limits the continuous questioning of alternative options, assessment orientation needs active deliberation and critical reflection to purposefully guide locomotion behavior, which results in greater variability 
in judgment (Kruglanski et al. 2010). High levels of team identification therefore disrupt the continuous, considerate deliberation of alternatives, which is central to the assessment orientation. We thus expect that strong team identification reduces the effectiveness of an assessment orientation in guiding high locomotion-oriented CSRs' engagement toward ambidextrous behavior.

$\mathrm{H}_{3}$ : A CSR's team identification weakens the positive interaction effect of the locomotion and assessment orientations on ambidextrous behavior, such that the positive relationship between locomotion orientation and ambidextrous behavior is strongest when a CSR's assessment orientation is high and team identification is weak.

Exercise of bounded discretion. Employees exercising bounded discretion perform their job tasks by relying on (self-)developed routines that are largely based on organizationally prescribed standards, processes, and rules (Kelley, Longfellow, and Malehorn 1996). Employees use bounded discretion when they choose a possible action from a prescribed list. For example, in call center settings, organizational trainings, manuals, and other colleagues provide employees with routine procedures for many tasks. This differentiates bounded discretion from stronger types of discretionary behavior, such as creative or deviant discretion, in which employees develop alternative means that are not formally specified or even engage in counter-role behavior (Kelley 1993). Exercising bounded discretion refers to the rather strict enactment of routines and implies a structured, well-practiced approach to the work tasks (Kelley 1993). In a self-regulation context, bounded discretion means the deployment of a restricted and pre-defined number of means in goal pursuit (March and Simon 1958). Because of the limited choice of alternative actions (in contrast with 'free format' work practice), bounded discretion involves only a minimal level of active deliberation (Kelley et al. 1996). The CSRs exercising high bounded discretion want to ascertain the flow of activity, while reducing cognitive effort. This is a common phenomenon in a highly standardized service environment. Yet, when CSRs strictly follow routines, their assessment orientation is disrupted and inhibited. Prior research has shown that high assessment-oriented people enjoy a maximum amount of options in goal pursuit and prefer critical comparative evaluations (Avnet and Higgins 2003). They want their task flow to be disrupted by continually considering what their options are, instead of relying on actions based on pre-described routines. If these people now strictly follow the routines and, thus, only have a limited set of options, they are less likely to use their assessment orientation, and critical evaluations to find the optimal course of action are inhibited. We thus expect that high levels of bounded discretion reduce the effectiveness of the assessment orientation for purposefully guiding high locomotion-oriented CSRs' engagement in ambidextrous behavior.

$\mathrm{H}_{4}$ : The exercise of bounded discretion weakens the positive interaction effect of the locomotion and assessment orientations on ambidextrous behavior, such that the positive relationship between locomotion orientation and ambidextrous behavior is strongest when a CSR's assessment orientation is high and exercise of bounded discretion is low. 


\subsubsection{Performance Consequences of CSRs' Ambidextrous Behavior}

For the ambidexterity-performance tenet to hold at the employee level, customer service provision and cross-/up-selling should be complementary in their effects on performance. To provide a first, fine-grained validity test of the ambidexterity-performance tenet for CSRs, we focus on customer satisfaction, sales performance, and efficiency. Customer satisfaction refers to customers' level of contentment with the service encounters supplied by the CSR. Sales performance pertains to the proportion of a CSR's service encounters during which the CSR successfully extends a customer's product portfolio in terms of its size and/or value. Efficiency refers to the average total time a CSR spends per customer, such that efficiency decreases with increasing expenditure of time per customer.

Customer satisfaction. We expect cross-/up-selling to enhance the effectiveness of customer service provision with regard to customer satisfaction for several reasons. First, cross-/up-selling leads to increased knowledge about products and their benefits, which enables CSRs to address service requests better or faster. Enhanced product knowledge helps CSRs determine when a new product is a better solution to the customer's problem or when it augments solution quality. Knowledge about the product benefits customers seek can enhance CSRs' understanding of the severity of certain problems for customers, such that they can select more appropriate means to address these problems and better adapt to customers' emotional states, which implies greater service quality and customer satisfaction (Brady and Cronin 2001; Hennig-Thurau et al. 2006). Second, the large call volumes and repetitive nature of customer service provision may cause CSRs to fall into an assembly line mode of dealing with customers (Evans et al. 1999). Customers perceive lower service quality when treated this way (Brady and Cronin 2001). However, cross-/up-selling attempts require CSRs to deal more intensively with customers, listen more closely, and acquire a deeper understanding of their needs and experience (Evans et al. 1999). In turn, customers might perceive the CSR as more attentive, responsive, and authentic, enhancing their quality perceptions and satisfaction (Smith, Bolton, and Wagner 1999). We expect cross-/up-selling to contribute to the effectiveness of customer service provision in shaping customer satisfaction.

$\mathrm{H}_{5}$ : A CSR's ambidextrous behavior is positively related to customer satisfaction.

Sales performance. Customer service provision should contribute to the effectiveness of cross-/up-selling with regard to sales performance. First, customer service provision involves communication with customers and access to customer information (e.g., database records), which may reveal potentially sales-relevant information and enhance understanding of the customers' needs and experience (Evans et al. 1999). Such insight is important for effective selling (Weitz, Sujan, and Sujan 1986). Customer service provision also could create an elaborate knowledge structure of customer types and product consumption portfolios. This knowledge would facilitate the categorization of customers and situations and the identification of potential sales opportunities, enhancing sales effectiveness (Weitz et al. 1986). Second, the adequate handling of service requests may produce favorable customer perceptions of the CSR's credibility, competence, and 
capability to address their needs. Such perceived characteristics can serve as bases of influence that underlie commonly employed influence tactics in sales situations (Weitz 1981). Moreover, proper responses to customer service requests can induce positive customer reactions (Bitner, Booms, and Tetreault 1990), such as reciprocal behaviors that feature increased sharing of information and listening to the CSR, creating a fertile ground for sales efforts to flourish. We therefore expect customer service provision to contribute to the effectiveness of cross-/up-selling efforts.

$\mathrm{H}_{6}$ : A CSR's ambidextrous behavior is positively related to sales performance.

Efficiency. In contrast, we expect efficiency losses to result from ambidextrous behavior for CSRs, which is detrimental to inbound call centers' priority parameters (Aksin et al. 2007). Prior literature indicates that cross-/up-selling activities, in addition to customer service provision, lengthen customer-CSR interactions and reduce efficiency at the CSR level (e.g., Aksin and Harker 1999). Moreover, Marinova et al. (2008) find that employees in service occupations prioritize quality over efficiency. Accordingly, we expect that ambidextrous behavior leads to efficiency losses for CSRs.

$\mathrm{H}_{7}$ : A CSR's ambidextrous behavior is negatively related to efficiency.

\subsection{Methodology}

\subsubsection{Research Setting and Data Collection}

We conducted an empirical study in cooperation with a national branch of a global call center provider (i.e., the company provides call center outsourcing services to client companies). We collected data through an online survey of CSRs at two call center sites. These CSRs work for several business lines of a client company that provides telecommunication services. As such, there are differences in the product/service portfolios these CSRs represent and the customer mix they serve. The CSRs handle typical inbound customer service tasks, such as answering incoming questions and responding to complaints. Technology-supported, standardized instructions define the process for handling most types of customer service requests and problems. As part of their daily jobs, these CSRs also should make cross-/up-sale offers to customers. For many calls, they receive product suggestions from the system, but they have latitude in their choice of product and when and how to offer it (i.e., the sales process is not scripted and largely unspecified). As is common in the call center industry, the representatives, who perform their tasks individually, are organized in teams of 8 to 15 CSRs, each led by a team manager. Individual team members and team managers often initiate team-building activities. Management sets customer satisfaction, sales performance, and efficiency goals for the CSRs and the teams. The set goals result from the call center provider's negotiations with the different business lines of the client company, considering industry standards and benchmarks. Team managers regularly monitor CSR-customer interactions and evaluate the CSRs' performance in one-on-one meetings and team performance in 
group meetings. The latter also serve as a platform to share learning experiences and exchange best practices among team members.

For the survey and performance data collection, we obtained approval from the national headquarters and call center site managers. During this approval process, we received helpful suggestions about our questionnaire and data collection. The author team sent e-mail invitations with the link to the online survey in two waves, to which 202 CSRs were randomly assigned. We guaranteed complete anonymity and confidentiality. Both waves lasted two and a half weeks and took place consecutively. In each wave, a reminder e-mail followed one and a half weeks later. To express our gratitude for the CSRs' participation in the survey, we raffled ten individual shopping vouchers and one team voucher, which a CSR could win for his or her team, among the respondents. One month after the survey study, we obtained performance data from the two call center sites. The performance data included weekly average call handling time, conversion rate, and customer satisfaction (through customer surveys) for the CSRs who were invited to participate in the study. They covered a period of seven weeks, spanning a window of about one week before and one week after the survey study. We matched the performance and survey data using code numbers, which guaranteed anonymity.

We obtained answers from 119 CSRs, for a response rate of $58.9 \%$. The sample consists of 68 female CSRs (57.1\%). The age distribution in the sample (in years) is as follows: $18-25$ (32.8\%), 26-35 (33.6\%), 36-45 (19.3\%), and >46 (14.3\%). The CSRs have worked, on average, 2.52 years $(\mathrm{SD}=2.53)$ in the call center industry, .90 years (SD $=1.38)$ in the current team, and 1.61 years $(\mathrm{SD}=1.51)$ as CSRs with cross-/up-selling responsibilities. A comparison of the profile of the CSR sample with profiles reported in other studies (e.g., Gwinner et al. 2005; Singh 2000) and the general CSR population at the call center provider suggests the representativeness of our sample. The respondents are almost equally distributed between the two call center sites (45.4\% and $54.6 \%)$, and come from 25 teams. On average, we had 4.76 respondents per team.

\subsubsection{Measures}

Independent variables. Because measures for customer service provision and cross-/upselling were not available in existing literature, we developed new scales in a separate, extensive, multistage study, following established procedures (Netemeyer, Bearden, and Sharma 2003). We developed initial item pools based on (1) an extensive review of sales and services literature; (2) interviews with ten CSRs, five team managers, and three customer experience managers working at one call center site involved in the current study, as well as in two other sites; and (3) intensive on-site fieldwork, including listening in on service and sales calls. The items underwent sorting and judgment tasks, aided by six academic experts and two practitioners, to achieve trimmed and refined item pools. We subjected the remaining items to a quantitative study among the CSRs with cross-/upselling responsibilities at three call center sites to assess the psychometric properties. The analysis provided evidence of convergent and discriminant validity of the two constructs. The confirmatory factor analysis with the twelve items for customer service provision and cross-/up-selling (see Appendix A) provided indexes which indicate adequate model 
fit $\left(\chi^{2}(53)=68.074\right.$, comparative fit index $[\mathrm{CFI}]=.977$, Tucker-Lewis index $[\mathrm{TLI}]=$ .972 , root mean square error of approximation [RMSEA] $=.046$, standardized root mean square residual $[\mathrm{SRMR}]=.046)$. Factor loadings ranged from .663 to .828 and were significant $(p<.01)$. All items loaded on their designated factor with no significant crossloadings. Construct reliabilities (CR) for customer service provision (.90) and cross-/ up-selling (.88) were above the recommended threshold (Bagozzi and Yi 1988). Average variances extracted (AVE) for customer service provision (.61) and cross-/up-selling (.55) were greater than the .50 criterion (Fornell and Larcker 1981). Their square roots exceed the correlation between the two constructs $(\mathrm{r}=.058, p>.05)$, and thus passed the Fornell and Larcker's (1981) test, indicating discriminant validity. We also assessed the extent to which the two constructs are distinct from other types of sales and service behavior: Customer-oriented selling $(\mathrm{AVE}=.61)$ and selling orientation $(\mathrm{AVE}=.62$; Periatt, LeMay, and Chakrabarty 2004; Saxe and Weitz 1982), and interpersonal adaptive behavior (AVE $=.56$ ) and service-offering adaptive behavior (AVE $=.55$; Gwinner et al. 2005). The square roots of all AVEs exceed the inter-construct correlations (cross-/ up-selling with customer-oriented selling: $\mathrm{r}=.215, p<.05$, and with selling orientation: $\mathrm{r}=.047$, n.s.; customer service provision with interpersonal adaptive behavior: $\mathrm{r}=-.110$, n.s., and with service-offering adaptive behavior: $\mathrm{r}=.227, p<.05)$. As expected, these results show that customer service provision and cross-/up-selling are empirically distinct from other types of service and sales behaviors.

For the other study constructs, we relied on existing scales. Appendix A provides an overview of the items and corresponding references. To control for possible effects on our dependent variables, we also measured the CSR's job satisfaction ("All in all, I am satisfied with my job"), work experience as a CSR with cross-/up-selling responsibilities (e.g., 2.5 years), and general demographics.

Dependent variables. A third-party provider that randomly surveys customers after their interaction with a CSR collected the customer satisfaction data. Customers rated their satisfaction with the encounter supplied by the CSR on a five-point Likert scale ranging from "extremely dissatisfied" to "extremely satisfied." We received weekly averages of customer satisfaction per CSR. For sales performance and efficiency, we received conversion rate and call handling time data from the call center sites. The conversion rate reflects the number of calls during which the CSR sold a product relative to the total number of calls handled by the CSR (per week), expressed as a percentage. It does not consider value or type of products sold. Call handling time is the average number of minutes a CSR spent per customer (call length plus post-processing time) per week. For all three data types, we averaged the weekly scores per CSR. To account for variations in performance due to call center site and business line characteristics (e.g., nature of products and services, customer mix, and markets), we adjusted these average scores by the goals set for the CSRs, as follows: [(achieved score - goal)/goal]. For efficiency, we reversed the sign of this ratio. The final performance measures represent positively increasing scales for customer satisfaction, sales performance, and efficiency.

Checks. To rule out the possibility of systematic effects on our data and hypothesis testing, we took several measures. We probed for selection and nonresponse bias by comparing (1) early and late respondents on our key study variables and respondent 
profiles, (2) the performance levels of respondents and nonrespondents according to the matched performance data, (3) first- and second-wave respondents, and (4) respondents from the two call center sites. None of these comparisons revealed any differences.

To minimize common method variance, we followed Podsakoff, MacKenzie, and Podsakoff's (2003) suggestions: We obtained measures for the dependent variables and other variables from different sources. We psychologically separated the measures of the independent variables from those of customer service provision and cross-/upselling by placing them into different thematic sections in the questionnaire, such that they appeared unrelated. Finally, we protected the CSRs' anonymity, clarified that the study's purpose was not to evaluate them in any way, and emphasized our interest in their personal perceptions, opinions, and behavior. Accordingly, we aimed to reduce evaluation apprehension and demands for social desirability.

\subsubsection{Measurement Model and Analysis Approach}

The relatively small sample size $(n=119)$ and large number of items $(>40)$ produced a highly unfavorable item-to-cases ratio. We therefore relied on the partial disaggregation approach (Bagozzi and Heatherton 1994) to minimize any loss of information in the latent factors, increase the accuracy of the parameter estimates (compared with total aggregation), and improve ratio of sample size to parameter estimates (Coffman and MacCallum 2005). An assumption underlying all methods used to form parcels is unidimensionality. Our exploratory factor analyses with the original number of items for each construct provided evidence that the items loaded on the appropriate factors. We then formed parcels with a random item-to-parcel assignment (Bagozzi and Edwards 1998). Appendix A lists the items that form the respective parcels for each construct. We did not parcel the items for customer service provision and cross-/up-selling, which are new scales. To prevent our parceling strategy from affecting our model estimations, we repeated all the analyses with new item-to-parcel combinations. The analyses did not reveal any differences in fit for the measurement model or in the pattern of significant structural parameter estimates.

Mardia's normalized estimate indicates significant multivariate kurtosis (z $=3.799, p<.01$ ); we rely on maximum likelihood robust estimation (MLR) for our confirmatory factor analysis. The indexes suggest adequate fit of the measurement model $\left(\chi^{2}(193)=226.223, \mathrm{CFI}=.979, \mathrm{TLI}=.975, \mathrm{RMSEA}=.038, \mathrm{SRMR}=.053\right)$. All factor loadings are substantive $(>.717)$ and significant $(p<.01)$. There are no cross-loadings, and CRs range between .82 and .95 , above the recommended threshold (Bagozzi and Yi 1988). AVEs are greater than .50, and their square roots exceed the correlations of all construct pairs. Together, these findings indicate the convergent and discriminant validity of our constructs (Fornell and Larcker 1981). Consistent with our conceptualization and previous studies on ambidexterity (e.g., Cao et al. 2009; Gibson and Birkinshaw 2004), we multiplied the customer service provision and cross-/up-selling measures to construct a measure for ambidextrous behavior that reflects the nonsubstitutability and interdependence of its elements. Table 1 provides a summary of the descriptive statistics, correlations, AVEs and their square roots, and CRs of the constructs.

We used Mplus 6.0 to test our hypotheses. This software estimates models 


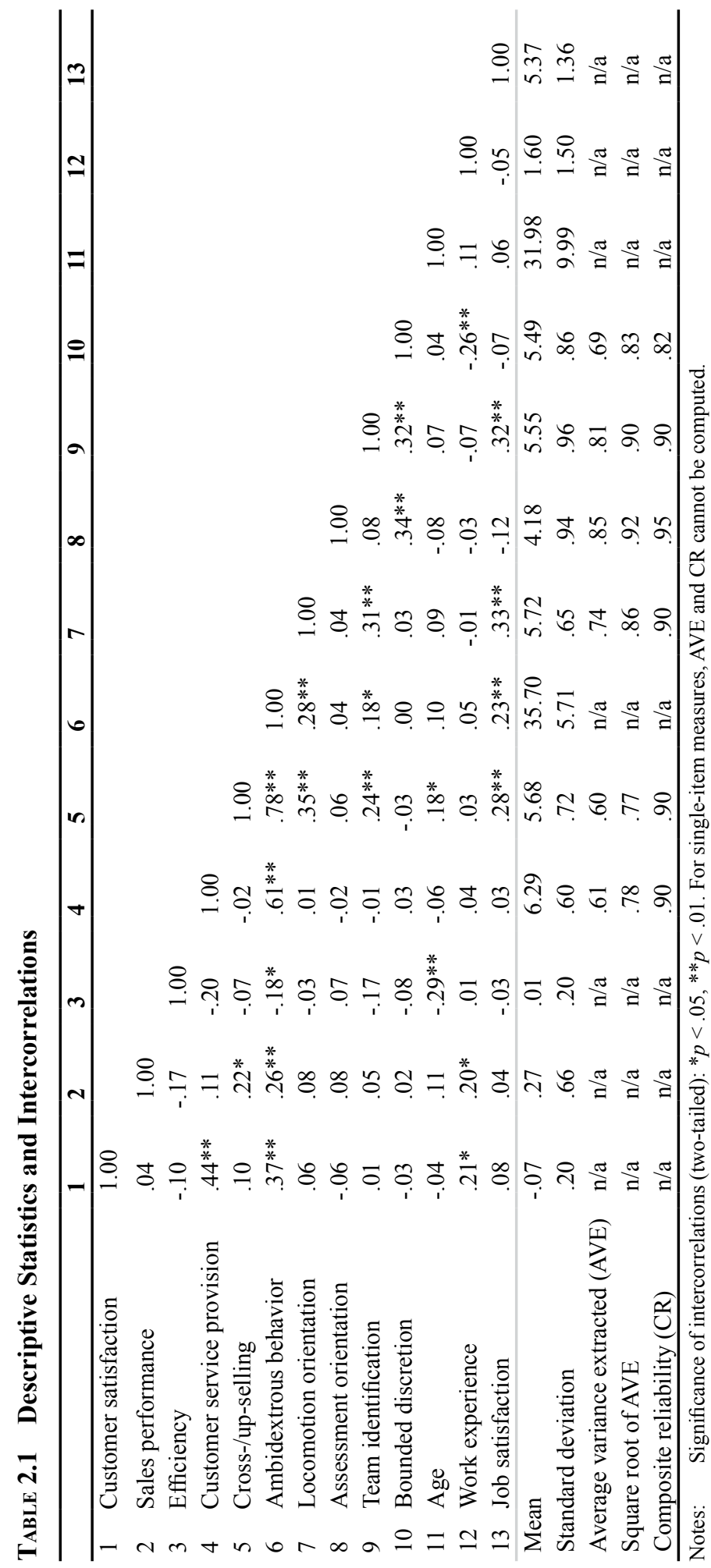


involving latent variable interactions with MLR and a version of the latent moderated structural equations method that explicitly considers the type of nonnormality implied by latent variable interactions and provides standard errors robust to nonnormality (Klein and Moosbrugger 2000; Muthén and Muthén 1998-2009). To test our hypotheses, we used a nested model approach. We compared the models with the Satorra-Bentler scaled chi-square difference test, based on the log-likelihood values of the models (Satorra and Bentler 1999).

\subsection{Results}

We provide an overview of the results in Table 2.2. Model 1 includes the effects of the control variables, the first-order effects of the variables involved in the two- and threeway interactions, and the effects of ambidextrous behavior on the performance outcomes. We add all two-way interactions in Model 2 , which results in improved model fit $\left(\Delta \chi_{\mathrm{SB}}^{2}(5)\right.$ $=11.152, p<.05)$. In Model 3, we insert the three-way interactions. Adding these interaction terms improves model fit significantly $\left(\Delta \chi_{\mathrm{SB}}^{2}(2)=19.314, p<.01\right)$.

In support of $\mathrm{H}_{1}$, the effect of the locomotion orientation on ambidextrous behavior is significant and positive $(\mathrm{b}=2.353, p<.05)$. $\mathrm{In}_{2}$, we predicted that this positive effect would strengthen with increasing levels of assessment orientation. Consistent with our prediction, the locomotion $\times$ assessment orientation interaction is significant and positive $(\mathrm{b}=2.826, p<.05)$. Furthermore, Model 3 reveals a significant, negative three-way interaction with team identification $(b=-2.136, p<.05)$, in support of $\mathrm{H}_{3}$. With Figure 2.2, we probe further into this three-way interaction. When CSRs' team identification is weak (Panel A), there is a positive interaction between locomotion and assessment orientations. This positive interaction disappears when CSRs strongly identify with their team (Panel B). A comparison of both panels shows that CSRs' locomotion orientation has the most positive impact on ambidextrous behavior when assessment orientation is high and team identification is weak (Panel A).

In support of $\mathrm{H}_{4}$, we find a significant, negative three-way interaction of bounded discretion, locomotion orientation, and assessment orientation $(\mathrm{b}=-5.066, p<.01)$. In Figure 2.3, we depict the positive interaction effect of the two motivational orientations on ambidextrous behavior when the exercise of bounded discretion is low (Panel A). Yet this interaction weakens when the exercise of bounded discretion is high (Panel B). Consistent with our expectation, CSRs' locomotion orientation has the most positive effect on ambidextrous behavior when their assessment orientation is high and exercise of bounded discretion is low (Panel A).

In support of $\mathrm{H}_{5}, \mathrm{H}_{6}$, and $\mathrm{H}_{7}$, we find significant, positive effects of ambidextrous behavior on customer satisfaction $(\mathrm{b}=.013, p<.01)$ and sales performance $(\mathrm{b}=.029, p<$ $.01)$ and a significant negative effect on efficiency $(b=-.006, p<.05)$. Because the effects of our multiplicative ambidexterity measure as an exogenous variable are potentially biased (Edwards 1994), we explicitly estimated the interaction effects of customer service provision and cross-/up-selling on the performance outcomes while controlling for their main effects. Table 2.3 shows the results. We find that adding the two-way interaction 


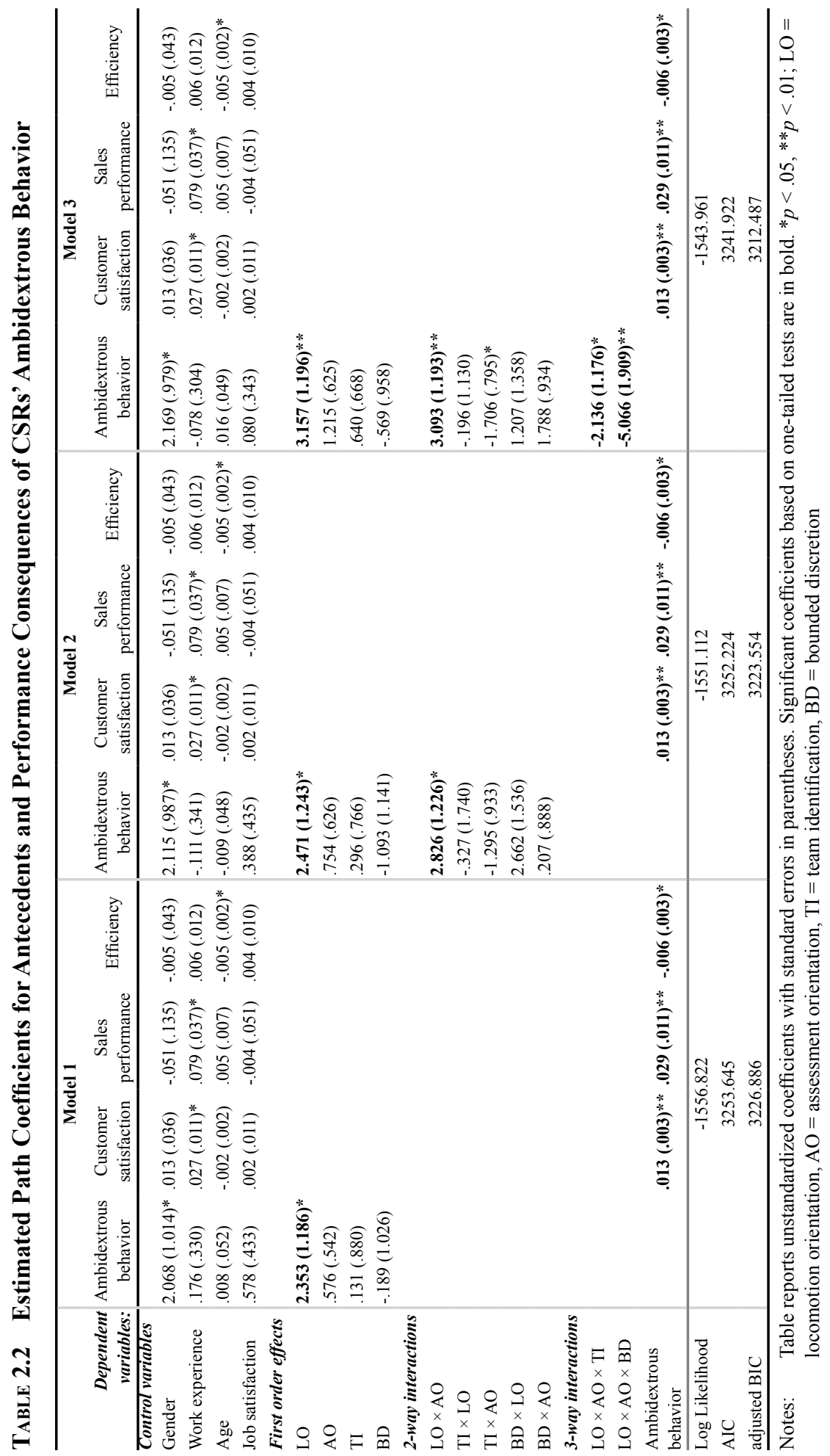


Figure 2.2 The Moderating Effect of Team Identification

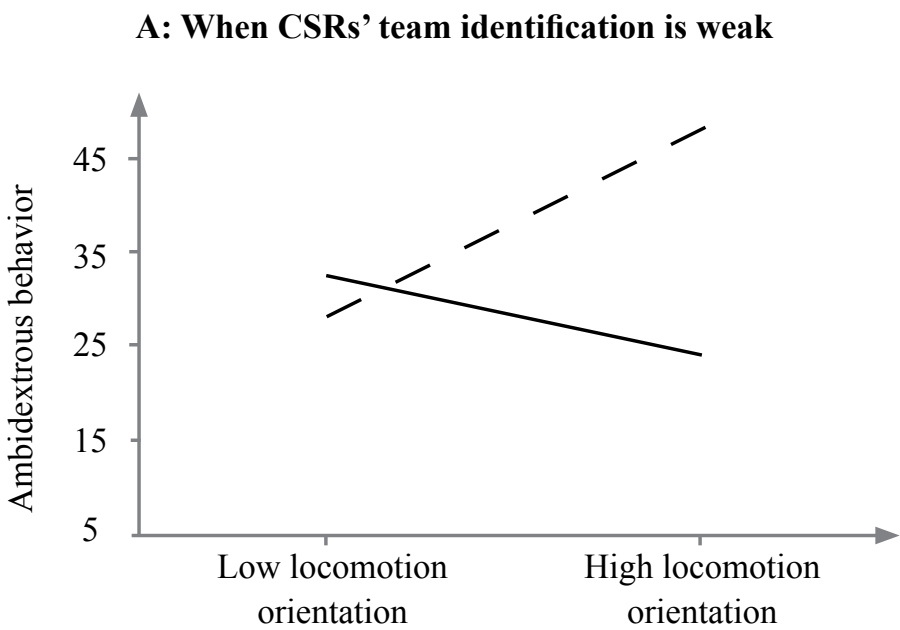

B: When CSRs' team identification is strong

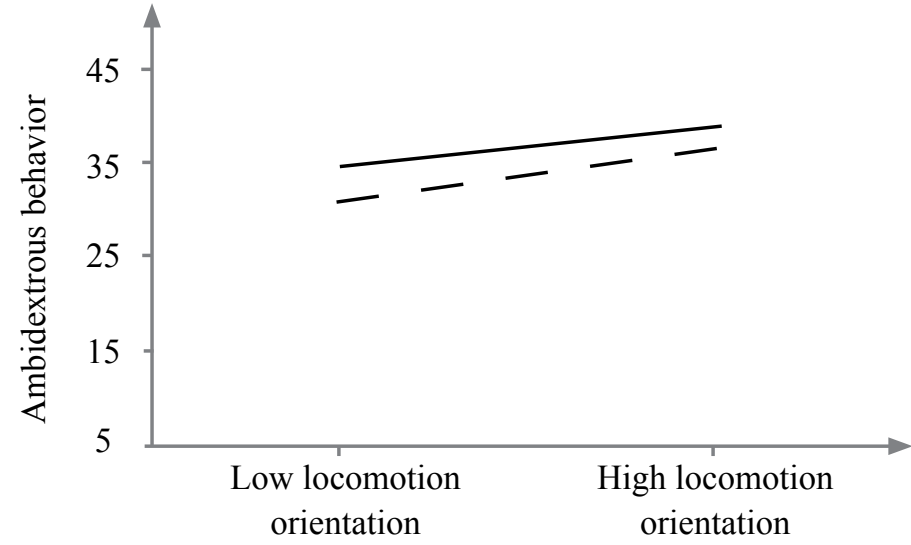

Low assessment orientation

- - High assessment orientation

Notes: Figure shows the simple slopes of locomotion orientation at 1.5 standard deviations above and below the means of assessment orientation and team identification. The intercepts of the simple slopes represent male CSRs and would shift by 2.169 for female CSRs. 
Figure 2.3 The Moderating Effect of the Exercise of Bounded Discretion

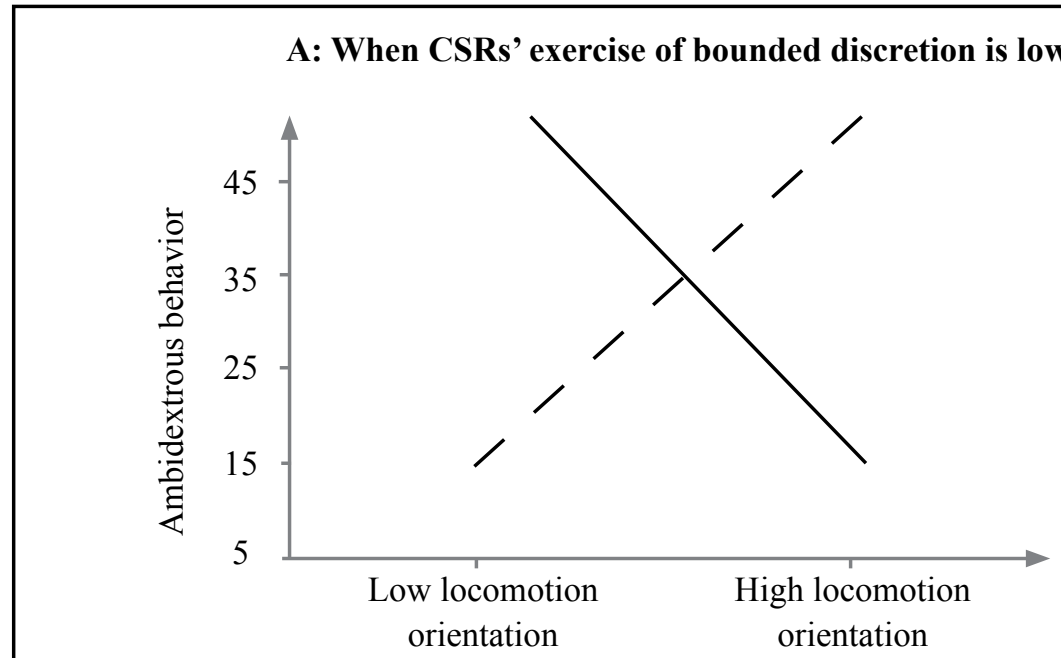

\section{B: When CSRs' exercise of bounded discretion is high}

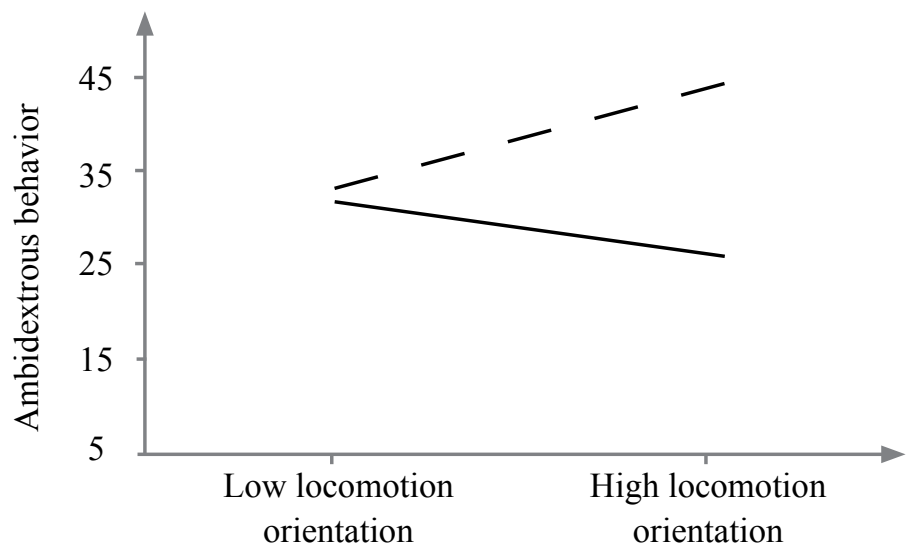

Low assessment orientation

- - High assessment orientation

Notes: $\quad$ Figure shows the simple slopes of locomotion orientation at 1.5 standard deviations above and below the means of assessment orientation and bounded discretion. The intercepts of the simple slopes represent male CSRs and would shift by 2.169 for female CSRs.

of customer service provision and cross-/up-selling significantly improves model fit $\left(\Delta \chi_{\mathrm{SB}}^{2}(3)=17.788, p<.01\right)$. The results also reveal significant interaction effects of customer service provision and cross-/up-selling on customer satisfaction $(\mathrm{b}=.174, p<$ $.01)$, sales performance $(\mathrm{b}=.548, p<.05)$, and efficiency $(\mathrm{b}=-.121, p<.05)$, providing strong support for $\mathrm{H}_{5}, \mathrm{H}_{6}$, and $\mathrm{H}_{7}$. 
TABLE 2.3 Interaction Effects of Customer Service Provision and Cross-/UpSelling on Customer Satisfaction, Sales Performance, and Efficiency

\begin{tabular}{|c|c|c|c|c|c|c|}
\hline Dependent variables: & $\begin{array}{c}\text { Customer } \\
\text { satisfaction }\end{array}$ & $\begin{array}{c}\text { Sales } \\
\text { performance }\end{array}$ & Efficiency & $\begin{array}{c}\text { Customer } \\
\text { satisfaction }\end{array}$ & $\begin{array}{c}\text { Sales } \\
\text { performance }\end{array}$ & Efficiency \\
\hline \multicolumn{7}{|l|}{ Control variables } \\
\hline Work experience & $.026(.010)^{*}$ & $.079(.037)^{*}$ & $.007(.012)$ & $.027(.010)^{* *}$ & $.082(.036)^{*}$ & $.006(.012)$ \\
\hline Age & $-.001(.002)$ & $.005(.007)$ & $-.006(.002)^{* *}$ & $-.001(.002)$ & $.006(.006)$ & $-.006(.002)^{* *}$ \\
\hline \multicolumn{7}{|l|}{ First order effects } \\
\hline Customer service provision (CSP) & $.173(.026)^{* *}$ & $.149(.109)$ & $-.085(.034)^{*}$ & $.137(.029)^{* *}$ & $.022(.132)$ & $-.058(.036)$ \\
\hline Cross-/up-selling (CUS) & $.030(.031)$ & $.261(.109)^{*}$ & $-.006(.026)$ & $.029(.030)$ & $.254(.112)^{*}$ & $-.006(.028)$ \\
\hline \multicolumn{7}{|l|}{ 2-way interaction } \\
\hline adjusted BIC & & 2809.114 & & & 2800.187 & \\
\hline
\end{tabular}

Notes: Table reports unstandardized coefficients with standard errors in parentheses. Significant coefficients based on one-tailed tests are in bold. ${ }^{*} p<.05,{ }^{*} p<.01$.

With Figure 2.4, we probe further into these interaction effects on customer satisfaction and sales performance to depict the nature of complementarity between customer service provision and cross-/up-selling. Panel A illustrates that high levels of cross-/up-selling augment the effect of customer service provision on customer satisfaction. Similarly, Panel B shows that cross-/up-selling has a strong positive effect on sales performance when customer service provision is high. Yet, at low customer service provision levels, cross-/up-selling tends to harm sales performance. Together, the results in Table 2.3 and Figure 2.4 support our expectation that customer service provision and cross-/up-selling enhance each other in terms of effectiveness for customer satisfaction and sales performance.

Given the relatively small sample size for the estimation of latent variable interactions, we conducted four hierarchical OLS regression analyses to verify the robustness of our findings. At first, ambidextrous behavior is regressed on the antecedents and control variables, and higher-order terms are entered in separate steps: Locomotion orientation $(\beta=.217, p<.05)$, locomotion $\times$ assessment orientation $(\beta=.199, p<.05)$, three-way interactions with team identification $(\beta=-.172, p<.05)$, and bounded discretion $(\beta=-.268, p<.05), \mathrm{R}^{2}=.285$. In the other regression analyses, each performance measure is regressed on the control variables, customer service provision, and cross-/up-selling in the first step and ambidextrous behavior in the second step: The effects of ambidextrous behavior on customer satisfaction: $\beta=.256, p<.01\left(\mathrm{R}^{2}=.299\right)$, sales performance: $\beta$ $=.183, p<.05\left(\mathrm{R}^{2}=.132\right)$, and efficiency: $\beta=-.158, p<.10\left(\mathrm{R}^{2}=.152\right)$. We find that the pattern and direction of significant coefficients are nearly identical, in support of our hypotheses. 
Figure 2.4 Interaction Effects of Customer Service Provision and Cross-/UpSelling on Customer Satisfaction and Sales Performance

\section{A: Customer satisfaction}

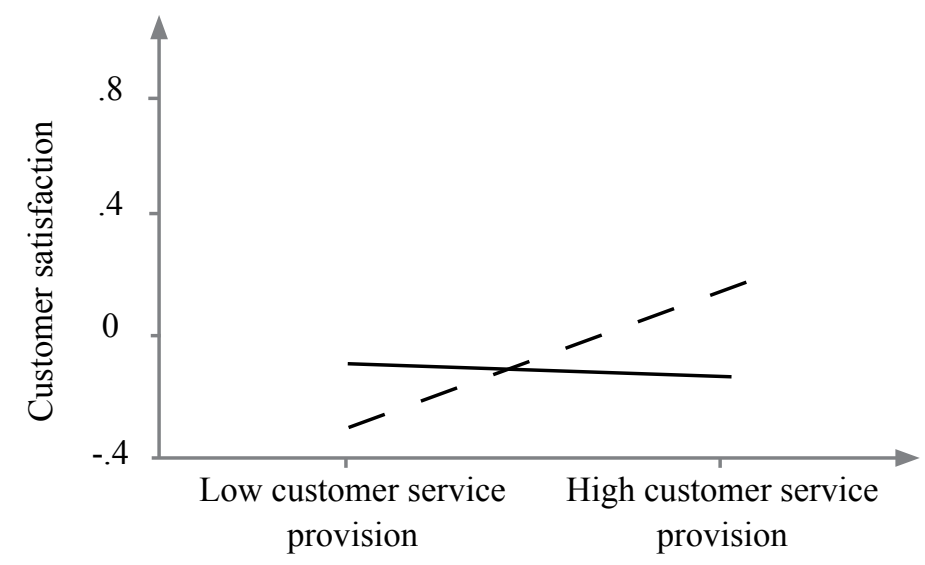

Low cross-/up-selling

- - High cross-/up-selling

\section{B: Sales performance}

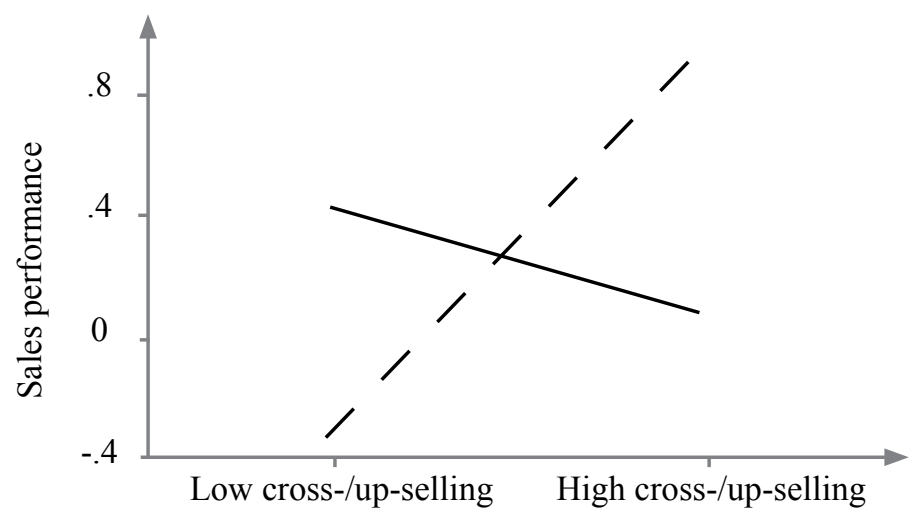

Low customer service provision - - High customer service provision

Notes: Figure shows the simple slopes of customer service provision (Panel A) and cross-/up-selling (Panel B) at 1.5 standard deviations above and below the means of cross-/up-selling (Panel A) and customer service provision (Panel B). 


\subsection{Discussion and Implications}

Considering the challenges that managers face in their effort to create conditions conducive to CSRs' successful service-sales alignment, as well as the prevalence of employee requirements for ambidextrous behavior, it is surprising that individuallevel ambidexterity has not been investigated more systematically (Raisch et al. 2009). Our study addresses this theoretically and managerially relevant gap by investigating antecedents and performance consequences of CSRs' ambidextrous behavior in relation to the pursuit of service and sales goals.

\subsubsection{Theoretical Discussion}

Employee-level ambidextrous behavior. Whereas prior research has focused on ambidexterity at organizational levels, our study advances the understanding of employeelevel ambidexterity. Theoretical work on ambidexterity regards its constituent dimensions as mutually exclusive at the individual level (Gupta et al. 2006; March 1991); our review of the literature suggests that they are not completely incompatible in the context of CSRs' service-sales alignment. In support of our proposition, Table 2.1 shows that customer service provision and cross-/up-selling are essentially uncorrelated. Employees can engage in nonnegligible levels of ambidextrous behavior; $10 \%$ of our sample scored in the upper $15 \%$ on the measure of ambidextrous behavior. Recent empirical research also has indicated that managers can engage in ambidextrous behavior by addressing disparate task demands during a one-year period (Mom et al. 2009), and our study further highlights a context in which employees simultaneously engage in seemingly conflicting tasks and/ or switch between them at "minute intervals" to become ambidextrous. The prevalence and diversity of contexts in which people are required to act ambidextrously leaves much to be clarified regarding how ambidexterity becomes manifest at the employee level (e.g., cycling, simultaneity, or both), and why and when it does so.

Facilitators of ambidextrous behavior. Previous research has focused on organizational and contextual factors that may enable and support employees to become ambidextrous (e.g., Gibson and Birkinshaw 2004; Mom et al. 2009). Yet, eventually employees need to tackle the self-regulatory and motivational challenge posed by the pursuit of seemingly conflicting goals on their own. Our study underscores the indispensable role of motivational orientations with regard to how to pursue goals as an explanation of ambidextrous behavior. In particular, our results show a positive effect of the locomotion orientation on CSRs' ambidextrous behavior. This effect becomes considerably enhanced when CSRs are also highly assessment oriented. Thus, the joint presence of these motivations to experience movement and "do the right thing" is conducive to CSRs' ambidextrous behavior. Conceptual work cites the importance of the motivation to pursue conflicting activities and goals (Mom et al. 2009). Our study highlights that the locomotion and assessment orientations jointly embody such motivational capacity for CSRs' pursuit of service and sales goals. In addition, previous empirical research by Kruglanski and colleagues $(2000 ; 2007)$ highlights the relevance of these motivational orientations for employees who need to master challenging, increasingly complex, and 
changing job demands. We therefore expect the valuable interaction of these orientations, with their joint emphasis on "just do the right thing", to generalize to other contexts in which people must act ambidextrously. Other factors might facilitate ambidextrous behavior. For example, our control variables suggest that gender has a significant impact (see Table 2.2). Post-hoc analyses reveal that female CSRs engage more in ambidextrous behavior $(\mathrm{t}(117)=-2.546, p<.05)$ and cross-/up-selling $(\mathrm{t}(117)=-3.132, p<.01)$. Our study of antecedents of individual-level ambidextrous behavior invites further extension studies.

Structural contingencies as moderators. Our study reveals that CSRs' responses to typical structural call center controls in terms of team identification and bounded discretion create motivational conditions that impair the functionality of the motivational orientations for ambidextrous behavior. These findings underscore the importance of considering the impact of contextually relevant factors on the motivational capacity to self-regulate towards ambidextrous behavior at the personal level.

First, whereas extant literature largely highlights the positive implications of organizational and workgroup identification for firms (see Ashforth et al. 2008), our study reveals that strong team identification impairs the effective interplay of CSRs' locomotion and assessment orientations, making ambidextrous behavior less likely. When team identification is weak (Figure 2.2, Panel A), the locomotion orientation positively affects ambidextrous behavior for high assessment-oriented CSRs. Yet, when team identification is strong, convergent thinking and conformity to shared consensus reduce active deliberation and critical questioning. Accordingly, the assessment orientation loses its virtue, and the positive impact of the locomotion orientation declines, if not disappears (Panel B). Although these findings highlight a detrimental effect of team identification, we also note that strong team identification appears to neutralize the negative effect of the locomotion orientation for low assessment-oriented CSRs. The psychological attachment to the team and the resulting desire to enhance the team's well-being make task engagement purposeful but fail to guide a locomotion orientation toward ambidextrous behavior. However, in the case team members identify specifically with the team as an ambidextrous unit, with the consensus being that every member should be engaged, the results could be quite opposite, which additional research would need to explore.

Second, we find an impairing effect of high bounded discretion, as the reduced cognitive effort involved in the routinized flow of activity inhibits the functionality of an assessment orientation. Only when the exercise of bounded discretion is low (Figure 2.3, Panel A) does the assessment orientation purposefully guide high locomotion-oriented CSRs' task engagement in the direction of their service and sales goals, leading to ambidextrous behavior. When CSRs exercise high levels of bounded discretion (Panel B), the assessment orientation becomes ineffective, and the ambidexterity-enhancing effect of the locomotion orientation disappears. However, a high level of bounded discretion also seems to buffer against a negative impact of the locomotion orientation when assessment orientation is low. Routinized compliance with organizational prescriptions and routines seems to channel high locomotion-oriented CSRs' task engagement, but in a way seemingly unrelated to ambidextrous behavior. Thus, locomotion and assessment orientations operate at full force only at low levels of bounded discretion. 
Accordingly, our study highlights the intricacy involved in shaping ambidextrous behavior at the employee level, as well as the importance of considering how employees' motivational orientations interact with their responses to proximal work environment characteristics. We focus on team identification and the exercise of bounded discretion as CSRs' responses to prevalent call center characteristics; therefore, our study invites further research to study the role of other environmental aspects. An important extension of our study would be to examine factors that might compensate for low levels of the assessment or locomotion orientation and foster individual ambidextrous behavior. For example, when explicit reward and compensation plans are in place and structured in the right way, a locomotion orientation in the absence of assessment concerns might become functional to promote goal attainment and ambidexterity.

Performance consequences of ambidextrous behavior. To the best of our knowledge, our study is the first to investigate the validity of the ambidexterity-performance tenet at the employee level. Our findings reveal the importance of considering various performance parameters for studying the effects of employees' ambidextrous behavior. We find that CSRs' ambidextrous behavior leads to superior customer satisfaction and sales performance, highlighting the complementary effects of customer service provision and cross-/up-selling. However, ambidextrous behavior also results in efficiency losses for CSRs, reflecting the apparent tensions among revenue expansion, quality, and efficiency that previous studies have highlighted for macro-organizational levels (Marinova et al. 2008; Rust et al. 2002). Does this finding provide counter-evidence for the validity of the tenet that ambidexterity leads to superior performance? We think not. First and foremost, a post-hoc analysis with standardized coefficients reveals that ambidextrous behavior increases customer satisfaction $(\beta=.361, p<.01)$ and sales performance $(\beta=.249, p<$ $.01)$ more than it decreases efficiency $(\beta=-.163, p<.05)$. Thus, the overall performance effect is positive, which confirms the validity of the ambidexterity-performance tenet at the employee level. Second, the gains in customer satisfaction and sales performance potentially outweigh the efficiency losses at the firm level because customer satisfaction and cross-/up-selling result in positive long-term benefits, such as enhanced customerfirm relationships (e.g., Bolton 1998). Third, a successful service-sales alignment could lead to efficiency gains at the firm level, greater than the sum of the CSRs' efficiency losses, because it allows for reduced investments in traditional cross-/up-selling channels (e.g., outbound call centers), as well as capitalization on customer-initiated touch points. Overall, our discussion suggests that individual ambidextrous behavior can have positive performance implications for various organizational levels. Further research should study the levels and conditions at which the performance-enhancing effects of employee-level ambidexterity unfold.

\subsubsection{Limitations}

We recognize that our study is not without limitations, some of which highlight avenues for further research in addition to those already outlined. Our empirical study is based on a relatively small sample of CSRs, which may limit the generalizability of our findings. Yet a comparison of our sample profile with those in other studies and industry norms suggests 
the representativeness of our sample. Although small samples tend to reduce statistical power and inflate Type II errors, we still find strong support for all our theory-grounded hypotheses. Furthermore, we conducted our empirical study in a single company setting and therefore ruled out any effects based on company differences, but this study should be replicated to generalize our findings. Our effort to collect data in two call center sites and develop the measurement scales with a separate study should alleviate some concerns about single-domain effects.

Another avenue for research is the study of CSRs' ambidextrous behavior in different after-sales support settings. We focused on one-time customer-CSR interactions; studying ambidextrous behavior in service relationships in which customers repeatedly interact with the same CSR would be worthwhile. Furthere research might also explore the nature of the service-sales alignment in industries that market highly complex products, such as turbines, in which the complexity of service and selling might be increased to such an extent that it shifts the organizational level at which ambidexterity can be pursued. Another promising extension of our study could explore how customer or relationship related factors, such as reciprocity and trust, interact with the variables in our model.

\subsubsection{Managerial Implications}

For managers who want to tap the full potential of a service-sales alignment in customer service channels, our study offers useful insights and several recommendations. The commonly cited observation that CSRs view customer service provision as incommensurate with selling seems to reflect their struggle with conflicting task demands. An awareness of the conflicting demands that CSRs face should encourage service-sales alignment. Our study of motivational orientations explains some of the heterogeneity observed in CSRs' ability to convert service calls to cross-/up-selling. During personnel selection, call centers may find it valuable to assess the motivational orientations of their job candidates. Because CSRs who are locomotion and assessment oriented engage in more ambidextrous behavior, they seem the best-suited candidates for a service-sales job. Such a person-job fit has additional positive outcomes, such as job satisfaction (Kristof-Brown, Zimmerman, and Johnson 2005), which can increase customer satisfaction (Harter, Schmidt, and Hayes 2002). In designing CSR training modules, it seems advisable to stimulate self-regulation skills. In training sessions, CSRs should be given the opportunity to elaborate on their personal motivations and to reflect on and discuss how they invest effort and attempt to meet performance standards in the context of service-sales alignment. Furthermore, assessing the motivational orientations of already-employed CSRs would provide valuable information for intelligent routing. Customers with higher cross-buying probability could be routed to CSRs with high locomotion and assessment orientations; those with low cross-buying potential should talk with CSRs who are less successful at aligning their service and sales. Such routing might mitigate efficiency losses for call centers.

Our study also reveals that CSRs' responses to typical call center characteristics impair the valuable interplay of locomotion and assessment orientations, which complicates the creation of conditions conducive to successful alignment. Regarding the 
negative effect of team identification, we consider the idea of abolishing team structures or reducing team-building efforts in call centers premature. Teams have administrative advantages and offer social and task support to team members. Interventions to prevent overidentification may be valuable however. When observing strong team consensus and conformity, team managers may want to spur critical reflection, divergent thinking, and questioning among team members during regular team meetings or ad-hoc individual 'stop-and-think' sessions. Managers could stimulate teams to develop a team norm that highly values active deliberation of alternatives. The exercise of bounded discretion also has a negative effect. In service-only call centers, a certain degree of bounded discretion seems appropriate for the relatively standardized nature of service offerings (Kelley 1993). However, service-sales alignment requires greater latitude and more customized service encounters, so encouraging more appropriate forms of discretion among CSRs, which also allow for critical thinking and comparative evaluations, is worthwhile.

Finally, our study provides some encouraging findings regarding the performance implications of service-sales alignment. When CSRs focus on both customer service provision and cross-/up-selling, they produce increased customer satisfaction and revenues. The satisfaction-enhancing effect of aligned sales and customer service provision is noteworthy and helps prove that the fear that sales efforts may put customers off is unfounded (Eichfeld et al. 2006). However, the resulting efficiency losses imply the need for higher staff levels, which lead to more costs for inbound call centers. Multi-skill call centers, which combine inbound and traditional outbound cross-/up-selling, might offset such costs by revising their staffing levels for outbound activities. Nevertheless, the traditional focus on efficiency as the key performance parameter in inbound call centers is an antithesis to the goals firms try to achieve with service-sales alignment. Firms should reconsider a strong focus on efficiency because increased customer satisfaction and successful cross-/up-selling may lead to long-term benefits, such as enhanced customer retention and loyalty. When assessing the profitability of a service-sales alignment, firms should consider long-term implications in addition to immediately visible efficiency losses. 



\section{Chapter 3}

Cross-Selling in Service Recovery Encounters: Staying Under the Customer's Radar to Avoid SALEsPerson Stereotype ACTIVATION 


\subsection{Introduction}

The recent introduction of restrictive telemarketing legislation (e.g., "do not call" registries) to curb fraudulent sales practices and customer privacy violations has heavily restrained outbound calling (commonly referred to as 'cold calling') for crosssell campaigns. In response, an increasing number of companies is experimenting with leveraging customer-initiated service calls as a source of revenue generation and relationship expansion (ICMI 2007). Managerial literature asserts that customer service representatives (CSRs) who are often viewed as helpful and caring problem-solvers are in an excellent position to explore additional customer needs and suggest propositions that meet these needs (Domanski 2002). By solving and anticipating customer problems in a sincere and attentive manner, CSRs' high-touch response proves that the company cares about customers' re-patronage, thereby enhancing customer confidence and satisfaction (Matos et al. 2007; Tripp and Grégoire 2011). The caring and trustworthy atmosphere in these encounters contrasts sharply with cold calling by telemarketers and has the potential to further enhance customer relationships by proposing a cross-sell as a proactive service that expresses a genuine interest in the customer (Anderson and Ragsdale 2004; Beaujean et al. 2006). However, CSRs' cross-sell attempts after service delivery have also been shown to lead to customer hostility and damaged relationships (Günes et al. 2010; Hash 2010). The prevalent view that service stands for helping people and selling carries the negative connotation of sleazy salespeople who are fast-talking and use dishonest misinformation suggests that service and sales are at odds with each other such that their conflicting stigmas may put customers off (CSO Insights 2007; Lee et al. 2007; Roux 2008). Hence, cross-selling during inbound calls may easily backfire and render problem solving ineffective. As a result, companies clearly need an in-depth understanding of how to handle this double-edged sword without hurting themselves.

In order to develop such an understanding, we turn to consumer research that has revealed how consumers resort to stereotype-based impressions and judgments in their brief interactions with salespeople and service employees (e.g., Folkes and Patrick 2003; Main, Dahl, and Darke 2007). A stereotype is a set of beliefs about members of a social category (Hilton and von Hippel 1996; Stangor and Lange 1994). It is a quick and efficient device to make sense of other people, providing a sense of predictability and orderliness (Allport 1954; Fiske and Neuberg 1990). Typical behaviors of a social category can activate stereotypes which color judgment and behavior (e.g., Bargh, Chen, and Burrows 1996; Devine 1989). Motivated stereotyping research shows that people stereotype others when it serves their goals (Sinclair and Kunda 1999). In the case of product failures self-protection goals are triggered that motivate customers to stereotype to protect their interests from further threats (Darke et al. 2010; Darke and Ritchie 2007). As providing service recovery is typical for helpful service people and selling for distrustworthy salespeople, a CSR's service recovery behavior may motivate customers to use a positive service employee stereotype and their subsequent cross-sell attempt may trigger a negative salesperson stereotype. Hence, such a CSR is a multiply categorizable person with the potential to evoke conflicting stereotypes in different phases of an interaction with a customer. Extant research into multiply categorizable targets has 
examined how people categorize a person who reveals multiple identities simultaneously upon initial target exposure, and shows that one category becomes activated, while others are inhibited. Yet an initially activated category has also been shown to dissipate during an interaction (Kunda et al. 2002). Hence, we lack an understanding of the situation in which people learn a person's other conflicting category memberships after their first categorization. The literature that deals with conflicting cues focuses on single-category targets and suggests cognitive capacity to affect impression revision; yet the empirical results are inconclusive (Macrae and Bodenhausen 2000). While some studies suggest that ample cognitive capacity leads to impression revision when conflicting cues are present (e.g., Macrae et al. 1999), others suggest this not to be the case (Wegener, Clark, and Petty 2006), and others, in turn, point to the idea that cognitive capacity effects depend on people's goals (e.g., Spencer et al. 1998). Thus, two important questions are largely unsolved: (1) What determines which stereotype people are motivated to use when facing a multiply categorizable person who gradually reveals conflicting category memberships? and (2) When does cognitive capacity impact impression revision?

Our study addresses these questions in the context of recovery encounters in which customers interact with CSRs who first provide recovery and then attempt to crosssell, with the purpose of illuminating the conditions under which recovery encounters can be leveraged effectively for cross-selling. Our study contributes to the stereotyping literature in the following ways. First, we extend research into multiply categorizable people by investigating determinants of keeping and revising an initial impression when customers are motivated to stereotype CSRs who are first service employees and then turn into salespeople. Such investigation is important, as conflicting category memberships that emerge in different stages of an interaction could lead to impression revision and hence the use of a different stereotype with opposing downstream consequences for customer behavior. We propose that self-protection goal fulfillment and stereotype instrumentality determine whether customers use a service employee or salesperson stereotype. We also identify 'warmth', which signals a person's good-will or ill-will (Cuddy, Fiske, and Glick 2008), as the driver of the instrumentality of these stereotypes for their self-protection goal. Second, to clarify further the role of cognitive capacity for impression revision and stereotyping, we propose that cognitive capacity requirements for revising and keeping an initial impression are eliminated because service employee and salesperson stereotype cues can be easily processed and judged. Hence, we show that even if customers are cognitively busy, which they tend to be in interactions with marketers (e.g., Campbell and Kirmani 2000), they can easily and quickly detect good-will and ill-will signals in CSRs' behavior. Accordingly, our five studies demonstrate that CSRs may easily fall prey to a negative salesperson stereotype which renders cross-sell efforts and adequate service recovery ineffective, unless they relate closely to customers such that their service recovery evokes a positive stereotype that allows cross-sell attempts and the negative salesperson stereotype to stay 'under the radar'. 


\subsection{Theoretical Background}

\subsubsection{Impression Formation and Stereotyping}

Recovery encounters are social exchanges in which customers form impressions of the CSRs who are the face of the company and embody a substantial part of the service (Czepiel 1990; Grandey et al. 2005). Impression formation begins with categorizing a person into a social category based on simple cues (Fiske and Neuberg 1990). Formed impressions can range from being entirely social category based to individualized, attribute based (Fiske et al. 1999). A stereotype is a set of beliefs about characteristics such as traits, behaviors, and goals that are associated with members of a social category (e.g., Hilton and von Hippel 1996; Stangor and Lange 1994). A cue, such as behavior typical for a category, can activate the corresponding stereotype (e.g., Fiske et al. 1999; Macrae, Bodenhausen, and Milne 1995). This is especially likely in voice-to-voice recovery encounters where visual cues are absent and stereotypes help fill informational gaps (Wang et al. 2009). Stereotype activation signifies the increased cognitive accessibility of category associations. Application implies that the activated stereotype guides cognitive, affective, and behavioral responses (Kunda and Spencer 2003; Macrae and Bodenhausen 2000).

Numerous studies document the negativity of the salesperson stereotype (e.g., Lee et al. 2007; Roux 2008). Although there are sub-types, such as telemarketers (Roux 2008) or clothing salespeople (Sujan, Bettman, and Sujan 1986), the general salesperson stereotype has associations such as insincerity, pushiness, selfishness, rudeness, annoyance, sales-orientation, deceptive and persuasive practices (e.g., Babin, Boles, and Darden 1995; Hartman 2006; Lee et al. 2007; Main et al. 2007). A CSR's sales attempt can easily trigger the negative salesperson stereotype because salespeople are most strongly associated with the motive of selling (Campbell and Kirmani 2000). Besides, selling over the phone is strongly linked to annoying and deceptive telemarketers (Roux 2008). In contrast, generally held beliefs of service employees are rather positive, comprising associations such as helpfulness, friendliness, caring, courtesy, and attentiveness (Folkes and Patrick 2003; Glick et al. 1995; Hess, Ganesan, and Klein 2007). In general, there is a positivity bias in services such that customers infer from a CSR's positive behavior that the company's other CSRs similarly behave in a positive manner (Folkes and Patrick 2003; Hess et al. 2007). Negative behavior does not generalize. Hence, good service behavior can trigger a positive service employee stereotype.

A CSR providing service recovery and subsequently engaging in cross-selling represents a multiply categorizable person having the potential to evoke conflicting service employee and salesperson stereotypes in different phases of an interaction with a customer. Extant research into multiply categorizable people addresses initial categorization by studying how people categorize a person who exhibits multiple category memberships simultaneously upon initial exposure to that person (Bodenhausen and Macrae 1998). So far, this research is silent as to the many situations in which people learn a person's other category memberships after the first categorization, as is the case with cross-sell attempts during inbound service recovery calls. Most stereotyping studies focus on a 
single social category and highlight motivation (goals) and ability (cognitive capacity) as factors determining stereotype activation and application (Bodenhausen and Peery 2009; Kulik, Roberson, and Perry 2007).

\subsubsection{Motivation and Cognitive Capacity}

Literature suggests that stereotyping is goal-dependent (e.g., Macrae and Bodenhausen 2000). For example, accuracy goals can undermine stereotyping because they motivate the formation of veridical impressions (cf. Fiske et al. 1999). In contrast, many other goals motivate people to use stereotypes (e.g., Kunda and Spencer 2003). For instance, people use stereotypes that support their desired impressions of others to enhance their selfesteem (Sinclair and Kunda 1999), and customers use stereotypes after product failures to protect their interests from further threats (Darke et al. 2010; Darke and Ritchie 2007). So far, however, leading research strategies focus on demonstrating the effect of a goal by making available a single goal-relevant category (e.g., deceptive marketers). This leaves unaddressed the question as to how customers would stereotype CSRs who gradually reveal goal-relevant, conflicting service employee and salespeople category cues during a recovery encounter.

The stereotype literature that deals with conflicting cues suggests that cognitive capacity affects whether customers keep or revise their initial category based impression (Macrae and Bodenhausen 2000). When conflicting cues are salient, people can resolve the conflict by either recategorizing the person into a better fitting category or forming an individualized, attribute based impression (Fiske and Neuberg 1990; Macrae and Bodenhausen 2000). Such impression revision through conflict resolution requires cognitive capacity because high cognitive load impairs the processing of conflicting information (Dijksterhuis and van Knippenberg 1995; Macrae et al. 1999). This would imply that cognitively busy customers would be more likely to keep an initial service employee category based impression despite conflicting sales cues. Yet, other studies point to the idea that cognitive capacity effects depend on the specific goal people have (see also Kunda and Spencer 2003). For example, Sherman et al. (1998) found that cognitively busy people with an accuracy goal attend more to conflicting information. Besides, although stereotype activation requires cognitive capacity (Gilbert and Hixon 1991), this is not the case when stereotyping serves to enhance one's self-image (Spencer et al. 1998).

\subsubsection{Stereotyping in Interactions}

Despite the goal-dependency of stereotyping and cognitive capacity effects, extant stereotyping research has not explicitly considered whether and when people's goals are satisfied (see also Gollwitzer and Moskowitz 1996). Yet goals can shift during interactions (Kunda et al. 2002). Research into goal pursuit suggests that once customers' self-protection goal is fulfilled during their interaction with CSRs, it no longer affects their information processing and behavior and they turn to other goals (Bargh, Green, and Fitzsimons 2008; Fishbach and Ferguson 2007; Förster, Liberman, and Higgins 2005). 
As long as their goal is not fulfilled, customers continue their goal pursuit or resume it once the opportunity is available (Bargh et al. 2001). Self-protection motivated customers fulfill their goal through stereotyping and thus stereotypes must be instrumental to serve as means for goal fulfillment. Instrumentality is determined by how strongly a stereotype is associated with the goal-relevant attribute (Kunda and Spencer 2003). The goal literature suggests that people tend to use the most instrumental means for goal fulfillment (Shah and Kruglanski 2003). Consequently, customers would resort to the stereotype that is most strongly associated with the attribute which is relevant for their self-protection goal.

Besides, customers must also have sufficient confidence in their stereotype based impression of the CSR to obtain a sense of goal fulfillment (Chaiken, Giner-Sorolla, and Chen 1996; Gollwitzer and Moskowitz 1996). The literature suggests that people can gain sufficient confidence in the validity of their impression (i.e., strong impression) when they have ample cognitive capacity to engage in enhanced, effortful thinking about the other person (Barden and Petty 2008; Chaiken et al. 1996). A recent study shows that people who are not cognitively busy form strong stereotype based impressions which they do not revise, but instead defend, when facing conflicting information. In contrast, cognitively busy people form weak stereotype based impressions which they revise as soon as they have sufficient cognitive capacity (Wegener et al. 2006). This study suggests that impression revision is a function of confidence in the initial impression and hence goal fulfillment. Yet sufficient confidence may not only depend on the level of thinking, but also on the ease with which customers can process and judge service and sales stereotype cues. Research has shown that heightened ease of processing increases people's confidence in the validity of their judgment (e.g., Schwartz 2004; Tormala, Petty, and Brinol 2002). Hence, even cognitively busy customers would gain sufficient impression confidence and fulfill their self-protection goal when they can easily process and judge goal-relevant service employee and salesperson category cues.

Based on the above discussion, we propose that stereotype instrumentality and goal fulfillment determine which stereotype customers activate and apply in recovery encounters in which CSRs provide recovery and then attempt to cross-sell. Specifically, they would use the most instrumental stereotype to fulfill their self-protection goal. This should also hold true for cognitively busy customers when they can easily process and judge goal-relevant stereotype cues, implying effortless conflict resolution (i.e., recategorization) and goal fulfillment.

\subsection{Stereotyping in Recovery Encounters}

Failures, such as unavailability of core services or errors in transactions and billing, are expectation-disconfirming experiences which involve economic and social/psychological losses for customers (Smith et al. 1999). They provoke uncertainty and distrust regarding the company's intention to live up to the terms of the exchange relationship, and hence the company's reliability and integrity (Boon and Holmes 1999; Matos et al. 2007; Singh and Sirdeshmukh 2000). When initiating recovery encounters customers are self-protection motivated and selectively process information to protect their interests from further 
threats (Chaiken et al. 1996; Darke et al. 2010; Darke and Ritchie 2007). They also want to know whether they are a valued, respected customer for whom the company is willing to keep up to relational norms and fulfill obligations (Aaker, Fournier, and Brasel 2004; DeWitt, Nguyen, and Marshall 2008; Wan, Hui, and Wyer 2011). ${ }^{2}$ Hence, customers are particularly sensitive to signals of the company's (positive and negative) intention towards them and the relationship, as conveyed by CSRs.

For these self-protection motivated customers, we propose that warmth drives the instrumentality of stereotypes. Warmth is a fundamental dimension underlying person judgment and stereotypes (Cuddy et al. 2008). The warm-cold dimension is reflected in traits such as trustworthiness, friendliness, sincerity, and righteousness. Importantly, it signals the valence of a person's intention towards others - intent for good versus ill (Fiske, Cuddy, and Glick 2002). Hence, the more warmth or coldness stereotypes reflect, the more instrumental they are for self-protection motivated customers. The salesperson stereotype being associated with insincerity, rudeness, distrustworthiness, ulterior motives, and deceptive practices strongly reflects coldness and conveys negative intent, making it highly instrumental for the self-protection goal. Being sensitive to such intention signals, customers should perceive a cross-sell attempt as a threat to their social/ psychological and material interests and activate and apply the negative salesperson stereotype to protect themselves from further threats.

However, cross-sell attempts typically follow a service recovery interaction between customers and CSRs, giving leeway to the service employee category. Having experienced a failure event, customers expect CSRs to provide adequate recovery (e.g., DeWitt et al. 2008; Smith et al. 1999). Adequate recovery refers to the resolving of complaints in a quick, competent, helpful, and friendly manner such that the problem is solved. CSRs providing adequate recovery belong to a service employee category which is relevant for the self-protection goal because it signals the company's intention to comply with the relationship terms and fulfill its obligations. Yet, differences in beliefs about service employees may arise from the specific way CSRs relate to customers. Interaction quality pertains to customers' perceptions of the CSR's demeanor on dimensions such as attentiveness, responsiveness, empathy, friendliness, and assurance (Blodgett, Hill, and Tax 1997; Brady and Cronin 2001; Davidow 2003; Parasuraman et al. 1988). These dimensions are inherently reflective of warmth. Thus, CSRs demonstrating very responsive, empathetic, and attentive demeanor (high interaction quality) should convey more warmth and a stronger signal of goodwill and positive intent towards the customer than CSRs who do less so (henceforth called moderate interaction quality). ${ }^{3}$

Because moderate interaction quality triggers a goal-relevant service employee stereotype that does not strongly convey positive intent, it is less likely to sufficiently fulfill the self-protection goal and eliminate the sensitivity to intention signals. The

2 In contrast to previous studies (e.g., Darke et al. 2010), the self-protection goal in recovery encounters does not imply unidirectionality for selective information processing and judgment bias. As Kunda and Spencer (2003) note, a self-protection goal can comprise the needs to maintain, enhance, and protect the self.

3 We do not consider low interaction quality because it represents a recovery failure (i.e. a 'double deviation', Bitner et al. 1990). For the sake of completeness, we would expect low interaction quality to signal low warmth and negative intent. 
salesperson stereotype provides a stronger intention signal, making it more instrumental for the self-protection goal. Hence, upon receipt of the cross-sell offer, customers should be likely to recategorize the CSR and apply the negative salesperson stereotype to protect themselves from further threats. In contrast, high interaction quality should trigger a positive service employee stereotype that is highly instrumental for the selfprotection goal. Literature asserts that warm treatment is highly desirable from a social and emotional perspective, strengthens and nurtures relationships, conveys sincerity, and cues trustworthiness inferences (Aaker et al. 2004; Liao 2007). Trust and the feeling of having a caring and committed partner eliminate the need to self-protect (Jarvenpaa, Knoll, and Leidner 1998; Mayer, Davis, and Schoorman 1995; Murray, Holmes, and Griffin 2000). Warm interpersonal treatment reaffirms customers' desired self-beliefs of being valued and respected and validates the decision to have entered the relationship. Therefore, customers should be highly motivated to view the CSR in a positive light and apply the positive service employee stereotype. Because self-protection goal fulfillment eliminates sensitivity to intention signals, cross-sell attempts are unlikely to trigger the otherwise highly instrumental salesperson stereotype and should be perceived through the lens of the positive stereotype.

We expect these effects to occur independent of cognitive load. Literature suggests that judging a person's warmth is essential and primary, as it determines whether he/she is a friend (warm) or a foe (cold; Fiske, Cuddy, and Glick 2007). Empirical evidence shows that people judge warmth-related traits faster and more reliably than other traits (for a review, see Cuddy et al. 2008). The ease and rapidity with which warmth is processed and judged increases the salience of stereotypes strongly reflecting warmth or coldness and enhances impression confidence. Hence, we expect that even customers with high cognitive load will revise their impression through recategorizing the CSR (moderate interaction quality) and gain sufficient confidence in the validity of their impression, leading to goal fulfillment (high interaction quality).

$\mathrm{H}_{1}$ : In case of moderate interaction quality during recovery provision, a CSR's cross-sell attempt evokes a negative salesperson stereotype (regardless of cognitive load).

$\mathrm{H}_{2}$ : In case of high interaction quality during recovery provision, the activation and application of a positive service employee stereotype prevents a cross-sell attempt from triggering a negative salesperson stereotype (regardless of cognitive load).

Consistent with research into stereotyping, we expect that activated stereotypes guide customers' reaction to the product offered by the CSR. However, the specific way in which they do so should depend on the level of cognitive load. Dual process models suggest that persuasion can occur through heuristic, shallow processing (e.g., using simple cues such as a trustworthy message source) and systematic, elaborate processing (e.g., enhanced processing of message arguments; Chaiken et al. 1996; Petty and Cacioppo 1986). Low cognitive load is a prerequisite for systematic, elaborate processing, while 
high load forces the reliance on heuristics and spontaneous or impulsive reactions (Strack and Deutsch 2004). Similar to previous research (Darke and Ritchie 2007; Wegener et al. 2006), we expect that when cognitive load is high, stereotypes serve as a heuristic that directly determines customers' reaction to the offered product because elaboration and thinking is curtailed. When cognitive load is low, stereotypes will bias cognitive responses to the cross-sell offer, whereby the bias is in the self-protective direction. While the negative salesperson stereotype should color thoughts related to the cross-sell offer negatively, the positive service employee stereotype should introduce a positive bias into cross-sell offer related thoughts. These biased cognitive responses then affect customers' intention to purchase the product.

$\mathrm{H}_{3}$ : When cognitive load is high, activated stereotypes mediate the effect of interaction quality on purchase intention.

$\mathrm{H}_{4}$ : When cognitive load is low, activated stereotypes bias cognitive responses, which mediates the effect of interaction quality on purchase intention.

\subsection{Pre-Studies}

Two pre-studies served as the basis for five experimental scenario-based studies. The first was a field study in two inbound call centers. We listened into service-sales calls and interviewed CSRs and their managers to learn about typical service-sales calls, service failures, service recovery and cross-selling procedures, and conversational styles. We used this insight to develop realistic scenarios. The second pre-study aimed to investigate the content of service employee and salesperson stereotypes because stereotype content can be culture-specific. Following established procedures (e.g., Babin et al. 1995; Lee et al. 2007), we conducted a two-stage study to identify the most associated characteristics of these groups. First, a projective word association task asked 151 students to list words that immediately come to their mind when thinking about salespeople and service employees. Synonymous answers were subsequently classified under one label. Second, the final list of 37 most associated characteristics was subjected to a study in which 118 students rated the valence and typicality of the characteristics for service employees and salespeople. We retained the characteristics that were significantly typical and atypical. Following Lee et al. (2007), we conducted Principal Component Analysis to identify typical profiles for service employees and salespeople. Results revealed one negative salesperson stereotype and two positive service employee stereotypes that differed significantly. To distinguish them, we labeled them as the 'positive' and 'ordinary' service employee stereotypes because the former scored higher on warmth-related traits than the latter. Results also showed that service employees are typically perceived as female, whereas salespeople tend to be male. The three profiles served as a basis for the stereotype activation measures used in our studies. 


\subsection{Study 1}

\subsubsection{Method}

Design and Procedure. Study 1 employed a 2 (cognitive load: low vs. high) $\times 2$ (interaction quality: moderate vs. high) between-subjects design. 126 students $(54.8 \%$ female) participated in multiple sessions each comprising 8 to 12 students. Participants were assigned randomly to the conditions. Our scenarios asked participants to envision themselves being the person in the interaction described. In contrast to previous studies (e.g., Campbell and Kirmani 2000), participants were not instructed to form an impression because such instruction would make trait inferences more likely (Bassili and Smith 1986) and activate an instructional goal that could interfere with the self-protection goal triggered by a service failure. The instructions explained that participants would engage in a second task, which served our cognitive load manipulation, and emphasized that good performance on both tasks was important. Participants were introduced to the cognitive load manipulation and then exposed to the scenario and purchase intention question. Afterwards they performed a lexical decision task (LDT) which was our measure of stereotype activation and then received a battery of questions comprising manipulation checks, control variables, demographics, and a surprise memory task about facts mentioned in the scenario.

Manipulations and measures. The scenario described a student coming home from university, experiencing a malfunctioning Internet connection, and an interaction with a female CSR of his/her Internet service provider's customer service hotline. After restoring the Internet connection, the CSR offers an online movie flat rate 'Watch/on' which is a fictitious brand. We obtained information from various websites that offer similar products to provide a realistic product description. The description of the crosssell attempt did not involve strong persuasion or influence tactics, such as flattery or promises, and was held constant across conditions. Appendix B presents the scenarios.

The high interaction quality scenario described a very responsive, empathetic, and attentive CSR: Responsiveness in terms of willingness and feeling responsible to help the customer, e.g., "I am there to solve your problem and answer your questions" (Brady and Cronin 2001; Parasuraman et al. 1988), empathy in terms of caring for and understanding of the customers' point of view and needs, e.g., "This unpleasant problem" (Brady and Cronin 2001; Parasuraman et al. 1988), attentiveness in terms of respect, effort, and concern, e.g., "problem will most likely be solved with a port reset which I could initiate immediately. Would it be okay with you if I did so?" or "Katja explains why this could help to restore the Internet connection" (Blodgett and Tax 1993; Davidow 2003; Sparks and McColl-Kennedy 1998). The recovery interaction ended with "I said in the beginning that my ambition was to help you solve this problem. Now, I would like to ask whether you think I solved the problem to your satisfaction." (attentiveness) and participants had to provide their answer $(1=$ No! Not at all; $9=$ Yes! Very much $)$. For the moderate interaction quality scenario, these text passages were removed or replaced with neutral descriptions (e.g., "While you wait, you can hear Katja typing on her keyboard and clicking with her mouse"). For the manipulation checks, we asked the participants to 
evaluate the CSR's responsiveness, empathy, and attentiveness $(1=$ strongly disagree; 9 $=$ strongly agree; $\alpha=.78$ ). A qualitative pre-test with five students and three colleagues confirmed that the scenarios were realistic and understandable, differed in interaction quality as intended, and included a product offer that was appropriate in terms of price and benefits.

Consistent with previous studies (e.g., Gilbert and Hixon 1991; Shiv and Fedorikhin 1999), participants had to rehearse either an eight-digit number (high cognitive load) or a two-digit number (low cognitive load) while reading the scenario and indicating their purchase intention. As manipulation checks, we included questions about the difficulty of remembering the number ( $1=$ not at all difficult, $9=$ very difficult $)$ assuming that it is more difficult to remember an eight-digit than a two-digit number, and the extent to which participants focused on the interaction with the CSR $(=1)$ or remembering the number (=9), assuming that participants in the low cognitive load condition should score lower on this measure (Campbell and Kirmani 2000; Zemborain and Johar 2007).

We measured stereotype activation by means of the LDT in which faster responses to stereotype-related words signifies increased stereotype activation (Macrae et al. 1995; Sinclair and Kunda 1999). The task included 8 target words for the salesperson stereotype (e.g., dishonest, sneaky, deceptive, manipulative), 9 target words for the positive service employee stereotype (e.g., attentive, caring, responsive, trustworthy), 20 neutral words (e.g., attractive, youthful, forgetful, sarcastic), and 30 non-words (e.g., telp, trasty, ontifot, burd). The target words were based on the stereotype profiles identified in the pre-study. For each presented letter string, participants had to indicate as fast as possible whether it was a word (left-shift key) or a non-word (right-shift key). The letter strings appeared on the screen in random order, separated by a blank screen and a "+" sign, and were preceded by 10 practice trials ( 5 neutral and 5 non-words). Response latencies were recorded in milliseconds. We computed averages to obtain summary response latencies for the negative salesperson stereotype words, the positive service employee stereotype words, and neutral words. These were then log-transformed to reduce the skewness of the response distribution, following recommendations in the literature (Fazio 1990).

Purchase intention was measured with one item $(1=$ very low, $9=$ very high). The surprise memory task included nine forced-choice questions about the interaction and product with two response options (true, false). We included a realism check with two items that measure the extent to which the scenario was perceived as realistic and credible $(1=$ not at all, $9=$ very much). We also measured involvement (i.e., to what extent participants imagined themselves in the scenario described; $1=$ not at all, $9=$ very much) as an additional control.

\subsubsection{Results}

Manipulation checks. A $2 \times 2$ analysis of variance (ANOVA) revealed only a significant main effect of the interaction quality manipulation on perceived interaction quality $(\mathrm{F}(1$, $122)=8.59, p<.01)$. High interaction quality $(\mathrm{M}=6.99, \mathrm{SD}=.90)$ produced higher quality perceptions than moderate interaction quality $(\mathrm{M}=6.52, \mathrm{SD}=.90)$. For the 
cognitive load manipulation, ANOVA results showed only significant main effects of the manipulation on the difficulty to rehearse the number $(\mathrm{F}(1,122)=234.40, p<.001)$ and on participants' focus $(\mathrm{F}(1,122)=41.75, p<.001)$. Participants in the high cognitive load condition found it more difficult to remember the number $(\mathrm{M}=4.92, \mathrm{SD}=1.55)$ and focused more on remembering the number $(\mathrm{M}=4.69 \mathrm{SD}=1.40)$ than participants in the low cognitive load condition $\left(\mathrm{M}_{\text {difficulty }}=1.51, \mathrm{SD}=.79 ; \mathrm{M}_{\text {focus }}=3.13, \mathrm{SD}=1.28\right)$. The scenario realism check was successful (test value $=5, \mathrm{t}(125)=18.56, p<.001$ ) with no differences between conditions $(\mathrm{F}(3,122)=.40$, n.s. $)$. Conditions did not differ in memory performance $(\mathrm{F}(3,122)=.32$, n.s. $)$ and involvement $(\mathrm{F}(3,122)=.34$, n.s. $)$.

Purchase intention. Results of a $2 \times 2$ ANOVA showed a significant main effect of interaction quality $(\mathrm{F}(1,122)=45.22, p<.001)$ which was qualified by a significant interaction quality $\times$ cognitive load interaction $(\mathrm{F}(1,122)=9.19, p<.01)$. Results are shown in Figure 3.1. Purchase intention was higher when interaction quality was high (M $=5.25, \mathrm{SD}=2.16)$ than when it was moderate $(\mathrm{M}=2.89, \mathrm{SD}=1.82)$. In the moderate interaction quality condition, cognitive load negatively affected purchase intention $\left(\mathrm{M}_{\text {high }}\right.$ load $\left.=2.38, \mathrm{SD}=1.50 ; \mathrm{M}_{\text {low load }}=3.42, \mathrm{SD}=1.99 ; \mathrm{F}(1,122)=4.54, p<.05\right)$. This effect was reversed in the high interaction quality condition $\left(\mathrm{M}_{\text {high load }}=5.76, \mathrm{SD}=2.03 ; \mathrm{M}_{\text {low load }}\right.$ $=4.70, \mathrm{SD}=2.20 ; \mathrm{F}(1,122)=4.65, p<.05)$. Besides, for low cognitive load, purchase intention differed significantly between the interaction quality conditions $(\mathrm{F}(1,122)=$ $6.61, p<.05)$. The effect of the interaction quality manipulation on purchase intention was stronger for high cognitive load.

Figure 3.1 Purchase Intention as a Function of Interaction Quality and Cognitive Load

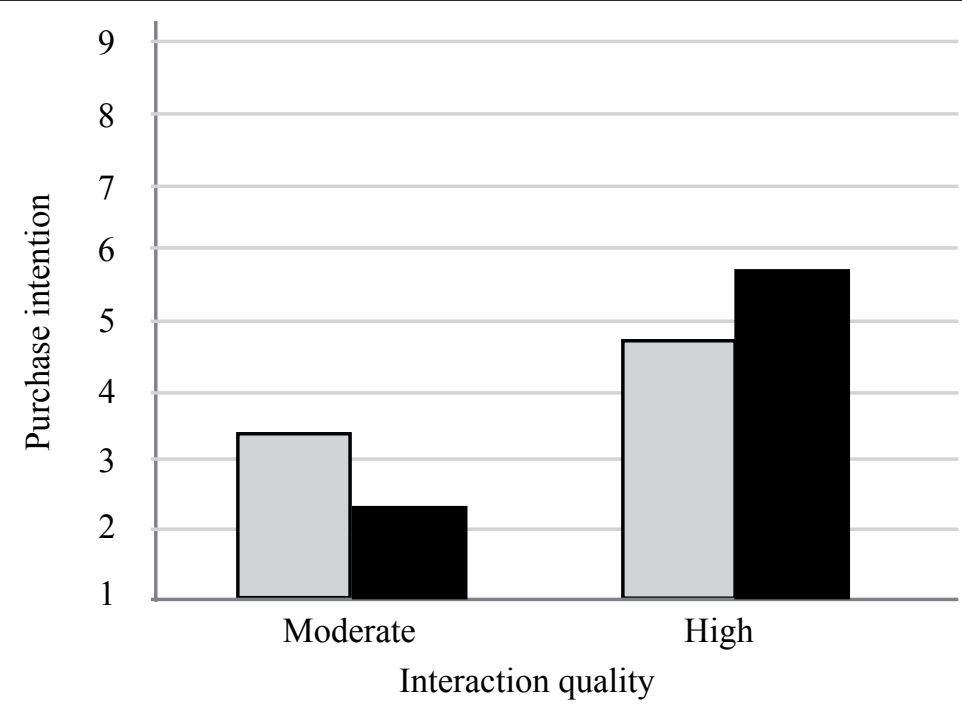

$\square$ Low cognitive load $\square$ High cognitive load 
Stereotype activation. We conducted separate $2 \times 2$ ANCOVAs for salesperson stereotype activation and service employee stereotype activation. To control for interperson variability in latencies (Fazio 1990), we included average response times to neutral words as a covariate which was significant in both analyses. For ease of interpretation, Figure 3.2 depicts the results as the deviations of average response times to target words from those to neutral words in milliseconds. The ANCOVA on reaction times to salesperson stereotype words only revealed a significant main effect of interaction quality $(\mathrm{F}(1,121)=139.65, p<.001)$. Participants in the moderate interaction quality condition reacted faster to the salesperson stereotype words than those in the high interaction quality condition (Figure 3.2 A). Participants in the moderate interaction quality condition reacted significantly faster to the salesperson stereotype words than to neutral words (high cognitive load: $\mathrm{t}(31)=-7.839, p<.001$; low cognitive load: $\mathrm{t}(30)=$ $-7.840, p<.001$ ), indicating negative salesperson stereotype activation in support of $\mathrm{H}_{1}$. No such activation was found in the high interaction quality condition. The ANCOVA on reaction times to positive service employee stereotype words only showed a significant main effect of interaction quality $(\mathrm{F}(1,121)=209.88, p<.001)$. Participants in the high interaction quality condition reacted faster to the service employee stereotype words than those in the moderate interaction quality condition (Figure 3.2 B). High interaction quality produced faster responses to service employee stereotype words than to neutral words (high cognitive load: $\mathrm{t}(32)=-12.188, p<.001$; low cognitive load: $\mathrm{t}(29)=-11.137 ; p$ $<.001$ ), indicating positive service employee stereotype activation in support of $\mathrm{H}_{2}$. The experimental conditions did not differ significantly in response times to neutral words.

Mediation analyses. To test the mediational role of stereotype activation, we constructed a single stereotype activation index by subtracting average response times to service employee words from average response times to salesperson words. Negative (positive) scores on this index represent the activation of the salesperson (service employee) stereotype. Scores around zero reflect very low activation levels of both stereotypes, because the correlation between the activation levels of the two stereotypes was negative $(\mathrm{r}=-.578, p<.001)$, making the concurrent activation of both stereotypes unlikely. Regression analyses showed that for high cognitive load, interaction quality significantly affected stereotype activation $(\beta=.865, p<.001)$ and purchase intention $(\beta=.693, p<.001)$. The effect of interaction quality on purchase intention became insignificant $(\beta=.249$, n.s.) when controlling for the effect of stereotype activation on purchase intention $(\beta=.513, p<.01)$. Following recommendations in the literature (Preacher and Hayes 2008), we used bootstrapping with bias-corrected intervals and 5000 resamples to estimate the indirect effect. In contrast to the products-of-coefficients approach ('Sobel-test'), bootstrapping as a nonparametric resampling procedure does not assume standard normal sampling distribution of the indirect effect. Its use is therefore appropriate for small sample sizes (Shrout and Bolger 2002). Results revealed that the indirect effect was significant (.444), with a 95\% confidence interval (CI) excluding zero (.229 to .658). These results support $\mathrm{H}_{3}$. In the low cognitive load condition, interaction quality also significantly affected stereotype activation $(\beta=.866, p<.001)$ and purchase intention $(\beta=.296, p<.05)$. Yet stereotype activation $(\beta=.378$, n.s. $)$ did not significantly affect purchase intention when controlling for the effect of interaction quality on purchase 
intention.

Figure 3.2 Reaction Times to Negative Salesperson and Positive Service Employee Stereotype Words

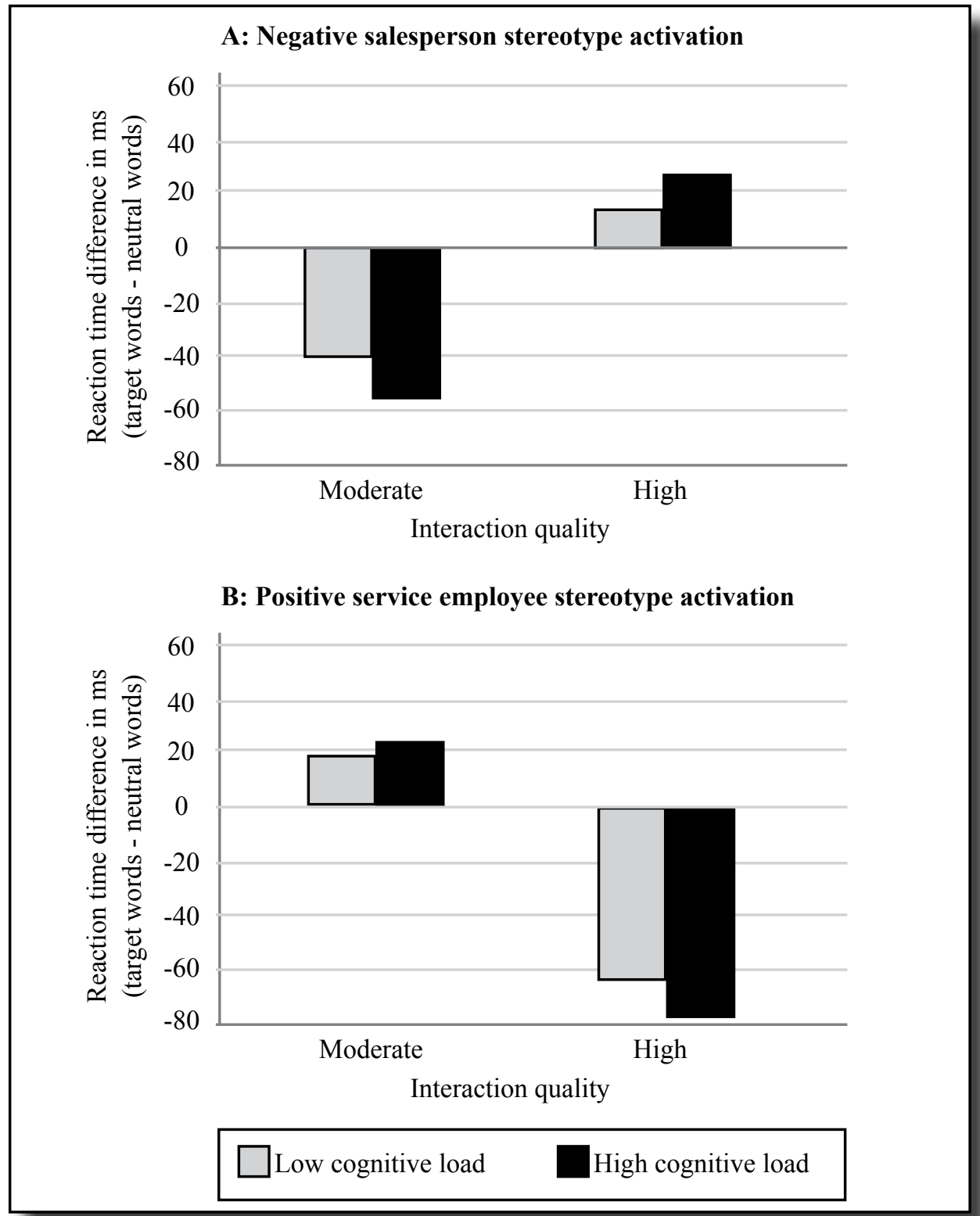

\subsubsection{Discussion}

Study 1 provides support for $\mathrm{H}_{1}$ to $\mathrm{H}_{3}$. Results show that whether a cross-sell attempt triggers a negative stereotype strongly depends on the level of interaction quality during recovery provision. Results support our expectation that high interaction quality evokes 
the positive service employee stereotype that prevents a cross-sell attempt from triggering a negative salesperson stereotype. Yet when interaction quality is moderate, the crosssell attempt triggers the negative salesperson stereotype. As expected, we observe this pattern of stereotype activation in both cognitive load conditions. The LDT results do not show any cognitive traces of the salesperson stereotype in the high interaction quality condition, providing some support for our argument that the positive service employee stereotype fulfills sufficiently the self-protection goal.

Furthermore, study 1 shows that interaction quality during recovery provision positively affects purchase intention. For high cognitive load, the positive effect is due to the activated stereotypes that mediated the effect of the interaction quality manipulation on purchase intention. ${ }^{4}$ As expected, we do not find such mediation for low cognitive load. Besides, high cognitive load increased the effect of interaction quality on purchase intention, which suggests that the heuristic way in which the stereotypes were used leads to more biased purchase intentions than the more elaborate way under low cognitive load. However, because study 1 cannot rule out that stereotype activation was a mere byproduct when cognitive load was low, study 2 subjects $\mathrm{H}_{4}$ to a direct test.

\subsection{Study 2}

Study 2 examined whether the observed effects in study 1 would generalize to a different context (mobile communications provider), a failure of a non-core service, a product offer with monetary benefits for the customer and being unrelated to the object of the failure, a male CSR, and a cross-sell attempt that more 'naturally' arises from recovery provision. These changes were partly designed to make the cross-sell attempt less blatant than in study 1, which could have increased the likelihood of salesperson stereotype activation in the moderate interaction quality condition. For example, research has shown that people judge service employees which violate gender expectations more extreme (e.g., a female vs. male financial analyst; Matta and Folkes 2005). Our pre-study suggests that stereotypical CSRs are female and stereotypical salespeople are male. In study 1, the female CSR was counter-stereotypical for the sales behavior, but stereotypical for recovery provision. Although this could explain the salesperson stereotype activation and reduced purchase intention in the moderate interaction quality condition, it cannot account for the non-activation of the salesperson stereotype in the high interaction quality condition. Nevertheless, to rule out that counter-stereotypicality due to gender drives our findings, study 2 employs a male CSR. Study 2 also incorporated changes to provide a direct test for $\mathrm{H}_{4}$.

\subsubsection{Method}

Design and Procedure. 147 students (47.6\% female) participating in this experiment were

4 Because we measured the mediator after purchase intention, the proposed causality could be questioned. However, we believe that beliefs about the CSR (i.e. stereotype activation) are more likely to affect behavioral intentions (i.e. purchase intention) than the reverse. It seems more plausible to assume that the interaction quality manipulation affects purchase intention (in part) because it activates the stereotypes. 
randomly assigned to the experimental conditions. The basic design and procedures were the same as in study 1 with the following exceptions. The scenario describes a student identifying a mistakenly double-charged monthly fee in the bill from his/her mobile communications provider and the subsequent interaction with a male CSR. Because the failure does not concern the core service, it is less severe than in study 1 . The CSR provides recovery by initiating the refund of the wrongly charged fee. Afterwards, he informs the student about a new service package 'Surf/on' - an Internet flat rate for mobile phones (fictitious brand). The scenario describes the product offer as arising out of the recovery process. Specifically, while the CSR searches the customer's bills to check the billing mistake, he identifies an unsatisfied need of the customer which he/she is not aware of. In contrast to study 1, the adoption of the service 'Surf/on' provides the customer with monetary benefits. The scenarios were pre-tested with 42 students. Results confirmed that the scenarios were realistic and understandable, the interaction quality manipulation worked as intended, and the product offer was appropriate. Appendix C presents the scenarios (parts I- III).

Measures and Manipulations. We used the manipulations and measures of study 1 with the following changes. The interaction quality manipulation was slightly adapted to the new context. To test $\mathrm{H}_{4}$, we included a thought-listing task which asked participants to describe the thoughts they had while reading the scenario. The LDT preceded the thought-listing task to circumvent inefficiency of the LDT to capture stereotype activation and prevent thought-listings from biasing activated associations. Two coders, blind to the experimental conditions, independently coded the thoughts that were related to the cross-sell offer and classified them as positive (e.g., "10€ for the Internet flat rate is not much"), negative (e.g., "It is too expensive"), or neutral (e.g., "difficult to know whether Surf/on is really worth $10 € "$ ). Inter-coder reliability was $91 \%$. The coders resolved the disagreements. Similar to Darke and Ritchie (2007), we calculated a valenced thought index by subtracting the number of negative thoughts from the number of positive thoughts and dividing this difference score by the total number of thoughts. The surprise memory task comprised five open questions of which three were about the product offer. Answers were coded as correct and incorrect.

\subsubsection{Results}

Manipulation checks. A $2 \times 2$ ANOVA on perceived interaction quality revealed only a significant main effect of the interaction quality manipulation $(\alpha=.85 ; \mathrm{F}(1,143)=32.60$, $p<.01)$. High interaction quality led to higher perceived interaction quality $(\mathrm{M}=6.71$, $\mathrm{SD}=.97)$ than moderate interaction quality $(\mathrm{M}=5.73, \mathrm{SD}=1.10)$. For the cognitive load manipulation, ANOVA results showed only significant main effects of the manipulation on the difficulty to remember the number $(\mathrm{F}(1,143)=624.80, p<.001)$ and participants' focus $(\mathrm{F}(1,143)=68.11, p<.01)$. Participants in the high cognitive load condition found it more difficult to remember the number $(\mathrm{M}=4.80, \mathrm{SD}=.95)$ and focused more on remembering the number $(\mathrm{M}=4.08, \mathrm{SD}=1.11)$ than those in the low cognitive load condition $\left(\mathrm{M}_{\text {difficulty }}=1.38, \mathrm{SD}=.69 ; \mathrm{M}_{\text {focus }}=2.45, \mathrm{SD}=1.27\right)$. Additional analysis revealed that the scenario realism check was successful (test value $=5, \mathrm{t}(146)=41.83, p$ 
$<.001)$ with no differences between conditions $(\mathrm{F}(3,143)=1.18$, n.s. $)$. Conditions did not differ in memory performance $\left(\chi^{2}(3,147)=.55\right.$, n.s. $)$ and involvement $(F(3,143)=$ .08 , n.s.).

Purchase intention. Results of a $2 \times 2$ ANOVA on purchase intention revealed a significant main effect of interaction quality $(\mathrm{F}(1,143)=48.82, p<.001)$ which was qualified by a significant interaction quality $\times$ cognitive load interaction $(F(1,143)=8.79$, $p<.01)$. Purchase intention was higher in the high interaction quality - high cognitive load condition $(\mathrm{M}=6.65, \mathrm{SD}=1.48)$ than in the high interaction quality - low cognitive load condition $(\mathrm{M}=5.71, \mathrm{SD}=1.93 ; \mathrm{F}(1,143)=4.76, p<.05)$. In the latter condition, purchase intention was significantly higher than in the moderate interaction quality low cognitive condition $(\mathrm{M}=4.47, \mathrm{SD}=2.17 ; \mathrm{F}(1,143)=8.38, p<.01)$, which in turn revealed higher purchase intention than the moderate interaction quality - high cognitive load condition $(\mathrm{M}=3.59, \mathrm{SD}=1.78 ; \mathrm{F}(1,143)=4.06, p<.05)$. As in study 1 , the interaction quality manipulation resulted in a greater difference in purchase intention when cognitive load was high.

Stereotype activation. A $2 \times 2$ ANCOVA on reaction times to negative salesperson stereotype words only revealed a significant main effect of interaction quality on salesperson stereotype activation $(\mathrm{F}(1,142)=153.13, p<.001)$. Reaction times to salesperson stereotype words were significantly faster when interaction quality was moderate $(\mathrm{M}=6.46 \approx 635 \mathrm{~ms}, \mathrm{SD}=.01)$ than when it was high $(\mathrm{M}=6.58 \approx 723 \mathrm{~ms}, \mathrm{SD}$ $=.01)$. Participants in the moderate interaction quality condition reacted significantly faster to salesperson stereotype words than to neutral words (high cognitive load: $\mathrm{t}(33)$ $=-7.315, p<.001$; low cognitive load: $\mathrm{t}(37)=-7.735, p<.01)$, supporting $\mathrm{H}_{1}$. No such activation was found in the high interaction quality condition. An ANCOVA on reaction times to positive service employee stereotype words only revealed a significant main effect of interaction quality $(\mathrm{F}(1,142)=154.34, p<.001)$. Reaction times to positive service employee stereotype words were significantly faster when interaction quality was high $(\mathrm{M}=6.44 \approx 624 \mathrm{~ms}, \mathrm{SD}=.01)$ than when it was moderate $(\mathrm{M}=6.57 \approx 712 \mathrm{~ms}$, $\mathrm{SD}=.01)$. As in study 1 , participants in the high interaction quality condition reacted significantly faster to positive service employee stereotype words than to neutral words (high cognitive load: $\mathrm{t}(36)=-9.957, p<.001$; low cognitive load: $\mathrm{t}(37)=-9.336 ; p<$ $.001)$. No such activation was found in the moderate interaction quality condition. These results support $\mathrm{H}_{2}$. Conditions did not differ significantly in response times to neutral words.

Valenced thoughts. The ANOVA only revealed a significant main effect of interaction quality $(\mathrm{F}(1,143)=28.15, p<.001)$. Participants in the moderate interaction quality condition had a higher proportion of negative thoughts $(\mathrm{M}=-.38, \mathrm{SD}=.60)$ than those in the high interaction quality condition $(\mathrm{M}=.13, \mathrm{SD}=.55)$. As expected, low cognitive load resulted in more thoughts $(\mathrm{M}=1.96, \mathrm{SD}=1.24)$ than high cognitive load $(\mathrm{M}=1.03, \mathrm{SD}=.74 ; \mathrm{F}(1,143)=29.40, p<.001)$.

Mediational analyses. Similar to Darke and Ritchie (2007), we computed separate path analyses for each cognitive load condition. As in study 1, we constructed a single stereotype activation index. In multiple mediator models, we simultaneously estimated the paths interaction quality $\rightarrow$ valenced thoughts $\rightarrow$ purchase intention and 
interaction quality $\rightarrow$ stereotype activation $\rightarrow$ purchase intention. Figure 3.3 provides an overview of the findings. For high cognitive load (Figure 3.3 A), analyses revealed a significant effect of interaction quality $(\beta=.820, p<.001)$ on stereotype activation which in turn significantly affected purchase intention $(\beta=.893, p<.001)$. The direct effect of interaction quality on purchase intention was insignificant $(\beta=-.084$, n.s.; without mediators: $\beta=.690, p<.001)$. Bootstrapping revealed that the specific indirect effect was significant (.732), with a $95 \% \mathrm{CI}$ excluding zero (.598 to .866). The effect of interaction quality on valenced thoughts $(\beta=.360, p<.01)$ was significant and the effect of valenced thoughts on purchase intention $(\beta=.117, p=.068)$ was marginally significant. This specific indirect effect was not significant (.042) with a 95\% CI including zero (-.002 to

\section{Figure 3.3 Path Analyses for the Effects of the Interaction Quality Manipulation on Purchase Intention}

\section{A: High cognitive load}

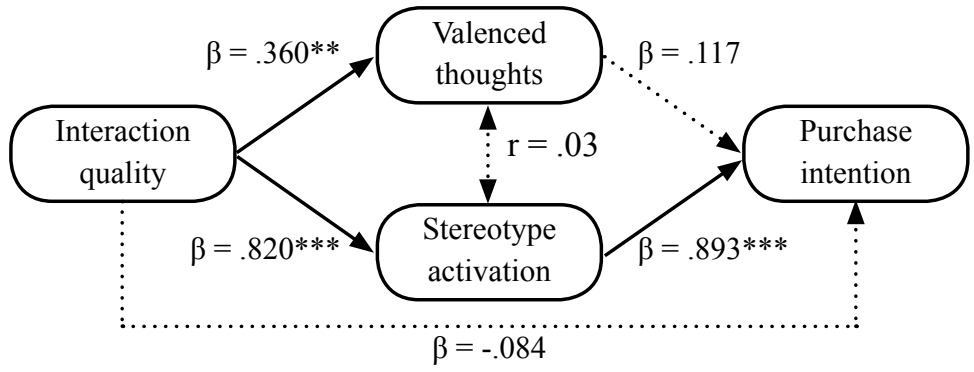

B: Low cognitive load
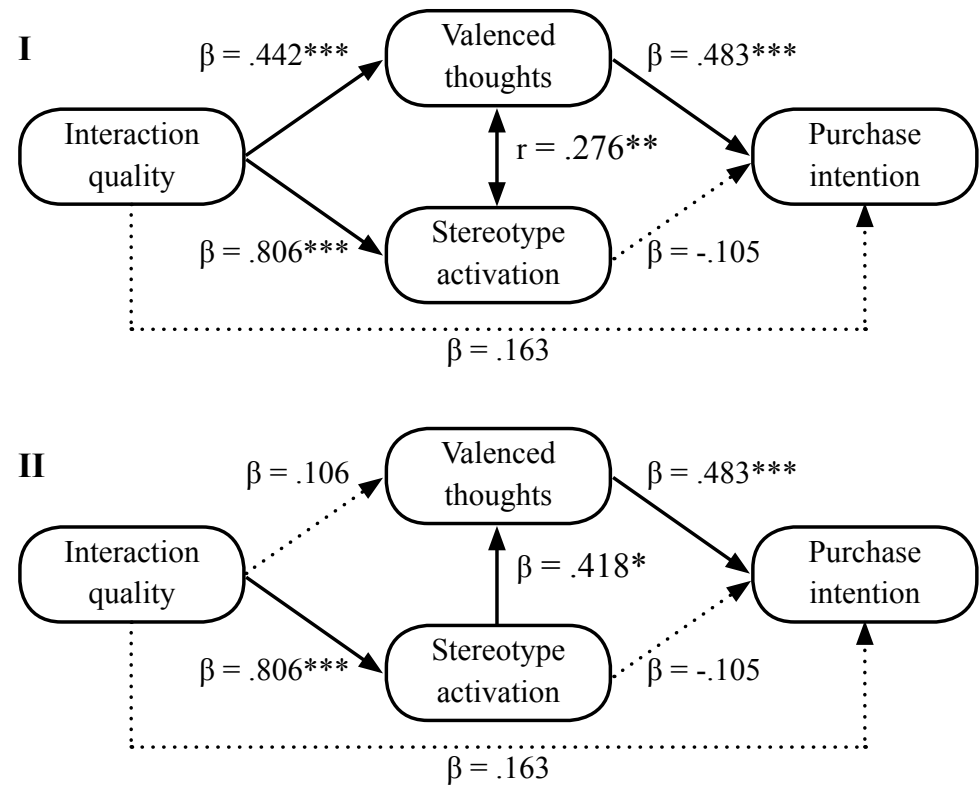

Notes: $\quad$ Figure reports standardized estimates. $* p<.05, * * p<.01, * * * p<.001$. 
.079). The correlation between stereotype activation and valenced thoughts $(r=.030$, n.s. $)$ was not significant. These results support $\mathrm{H}_{3}$.

For low cognitive load (Figure 3.3 B.I), the path analysis showed a significant effect of interaction quality on stereotype activation $(\beta=.806, p<.001)$ which in turn did not affect purchase intention $(\beta=-.105$, n.s.), replicating study 1 . Interaction quality also significantly impacted valenced thoughts $(\beta=.442, p<.001)$ which in turn significantly influenced purchase intention $(\beta=.483, p<.001)$. The direct effect of interaction quality on purchase intention was not significant in this model $(\beta=.163$, n.s.; without mediators: $\beta=.291, p<.01)$. Because stereotype activation and valenced thoughts were correlated significantly $(\mathrm{r}=.276, p<.01)$, we added the proposed stereotype activation $\rightarrow$ valenced thoughts path to the model (see Figure 3.3 B.II). While this path was significant $(\beta=.418$, $p<.05)$, the effect of interaction quality on valenced thoughts $(\beta=.106$, n.s.) was not significant anymore. All other path coefficients remained the same. The indirect effect (interaction quality $\rightarrow$ stereotype activation $\rightarrow$ valenced thoughts $\rightarrow$ purchase intention) was significant (.163; 95\% CI: .045 to .281). These results support $\mathrm{H}_{4}$.

\subsubsection{Discussion}

Study 2 demonstrates the two different ways in which the activated stereotypes influenced purchase intention. Results of the mediation analyses show that the stereotypes triggered in the interaction quality conditions enacted their influence by biasing low cognitive load participants' valenced thoughts about the cross-sell offer which in turn influenced their intention to purchase the product. ${ }^{5}$ For high cognitive load participants, the effect of activated stereotypes on purchase intention was direct in nature. While the latter replicates the findings of study 1 , study 2 shows that stereotype activation was not a mere by-product in the low cognitive load condition but exerted its influence on cognitive responses to the cross-sell offer. We again found smaller differences in purchase intention between moderate and high interaction quality when cognitive load was low. It appears that under enhanced levels of thinking and elaboration on the cross-sell offer, product related arguments have some leeway to exert their influence on the purchase decision.

Replicating study 1, results show that high interaction quality evokes the positive service employee stereotype, whereas the negative salesperson stereotype is triggered as soon as interaction quality is lowered. Study 2 provides some support for the generalizability of these effects. For example, the pattern of effects did not change with the gender of the CSR, which allows us to rule out that (in)congruity between gender and salesperson stereotype or service employee stereotype drives our findings. In addition, although communal traits are more associated with women than with men (e.g., Kurt,

\footnotetext{
We do not believe that reverse causality could be assumed. First, stereotype activation was measured before cross-sell offer related thoughts, and it is reasonable to assume that beliefs about the CSR (stereotype activation) affect beliefs about the cross-sell offer (not vice versa). Study 3 will show that high interaction quality during recovery provision activates the positive service employee stereotype and hence precedes the cross-sell offer and related thoughts, providing some support for the proposed causal relationship. Second, concerning the effect of thoughts on purchase intention, we believe that it is unreasonable to assume that activated stereotypes affect cross-sell offer related thoughts in part because of purchase intention. Besides, respondents were asked to list thoughts they had while (not after) interacting with the CSR.
} 
Inman, and Argo 2011), we find that high interaction quality provided by a male CSR triggers the positive service employee stereotype. Besides, study 2 reveals that even if the cross-sell attempt naturally arises from recovery provision and the offered product provides monetary benefits for the customer, a cross-sell attempt coupled with moderate interaction quality during recovery provision triggers the negative salesperson stereotype which elicits negative reactions to the cross-sell attempt. Similarly, although study 2 did not involve the failure of the core service (i.e., less severe failure than in study 1), potentially resulting in a weaker need to self-protect, moderate interaction quality did not act as a buffer against negative salesperson stereotype activation.

In general, the results of the first two studies support our argument that both high interaction quality and a cross-sell attempt when interaction quality is moderate trigger stereotypes that are very high and low in warmth, which makes them more instrumental for the self-protection goal than the service employee category that should be triggered by moderate interaction quality. The observed stereotype activation pattern implies goal fulfillment in the high interaction quality condition and recategorization in the moderate interaction quality condition, irrespective of cognitive load. However, so far, we can only infer recategorization from the observed salesperson stereotype activation in the moderate interaction quality condition. Because our arguments base upon warmth as the driver of the instrumentality of the stereotypes and the primacy of warmth judgment, study 3 was designed to provide evidence for recategorization under high cognitive load. Study 4 investigates high cognitive load participants' evaluations of the CSR along the dimension of warmth and aims to show that recategorization does not consume cognitive resources. Finally, study 5 attempts to provide converging evidence for our argument that is the ease of warmth judgment that allows high cognitive load participants to have sufficient impression confidence for goal fulfillment in the high interaction quality condition. The following studies will therefore focus on high cognitive load.

\subsection{Study 3}

Study 3 employed scenarios that present a recovery encounter without a cross-sell attempt. The purpose was two-fold. First, measuring stereotype activation directly after the recovery interaction should provide insight that better explains the stereotype activation pattern found in the previous studies. To provide evidence for recategorization, moderate interaction quality should not trigger the negative salesperson stereotype but instead the ordinary service employee stereotype identified in our pre-study. Yet, as $\mathrm{H}_{2}$ proposes, high interaction quality during recovery provision without a cross-sell attempt should trigger the positive service employee stereotype, ruling out recategorization and hence providing indirect support for goal fulfillment. Second, the manipulation checks for interaction quality may have been biased in the previous studies. Although we only manipulated CSR behavior during recovery provision, it is possible that negative stereotype activation led to an overestimation of the difference in perceived interaction quality. Measuring perceived interaction quality directly after the recovery provision provides accurate estimates, enhancing confidence in the validity of our manipulation checks. 


\subsubsection{Method}

90 students participated in this experiment. The basic design, procedures, manipulations, and measures were the same as in study 2 with the following exceptions. We used the scenarios of study 2 but removed the description of the cross-sell attempt. Participants received parts I-II of the scenarios (Appendix C) and were subjected to the high cognitive load manipulation. We also included a control group which only performed the LDT. This group served as the baseline, allowing us to rule out alternative explanations such as differences in difficulty or word length between neutral and target words for our findings. We only employed the manipulation checks of study 2 and measured stereotype activation. In the LDT, we used the same target words as in the previous studies to measure activation of the positive service employee stereotype and negative salesperson stereotype. To measure the ordinary service employee stereotype, we relied on our pre-study which identified that this stereotype was somewhat lower in warmth (reliable, friendly, competent, helpful) and conducted a brief additional study to verify this category. 27 students read the first part of the scenario which described the service failure (part I, Appendix B). Participants indicated the CSR they would expect to interact with in this situation (via thought-listing and rating scales). Thoughts were coded, ranked based on frequency of mentions, and compared to the assessments of the trait ratings and the findings of the pre-study. Results confirmed that the CSR would be reliable, friendly, competent, and helpful. We included these four words in the LDT to assess the activation of the ordinary service employee stereotype.

\subsubsection{Results}

Manipulation checks. An ANOVA on perceived interaction quality $(\alpha=.85)$ revealed a significant main effect of the manipulation $(\mathrm{F}(1,59)=16.47, p<.001)$. Perceived interaction quality was lower in the moderate interaction quality condition $(\mathrm{M}=5.95$, $\mathrm{SD}=1.04)$ than in the high interaction quality condition $(\mathrm{M}=6.93, \mathrm{SD}=.84)$. These means are comparable to those obtained in study 2 . We are therefore confident that the manipulation of interaction quality was not over- or underestimated in the previous studies. As expected, participants in the moderate and high interaction quality conditions did not differ significantly in their experienced difficulty to remember the eight-digit number $\left(\mathrm{M}_{\text {moderate }}=4.77, \mathrm{SD}=1.20 ; \mathrm{M}_{\text {high }}=4.80, \mathrm{SD}=1.32 ; \mathrm{F}(1,59)=.00\right.$, n.s. $)$ and their focus on the interaction versus remembering the number $\left(\mathrm{M}_{\text {moderate }}=4.23, \mathrm{SD}=1.54 ; \mathrm{M}_{\text {high }}=4.17\right.$, $\mathrm{SD}=1.76 ; \mathrm{F}(1,59)=.019$, n.s. $)$. Because there are no differences between the groups and the means are very similar to those observed in the high cognitive load conditions of studies 1 and 2, we conclude that the cognitive load manipulation was successful.

Stereotype activation. An ANCOVA on reaction times to ordinary service employee stereotype words revealed differences between conditions $(\mathrm{F}(2,86)=5.48$, $p<.01)$. In both interaction quality conditions, reaction times to the ordinary service employee stereotype words were faster compared to the control group $\left(\mathrm{M}_{\text {control }}=6.53\right.$ $\approx 686 \mathrm{~ms}, \mathrm{SD}=.02 ; \mathrm{M}_{\text {moderate }}=6.46 \approx 640 \mathrm{~ms}, \mathrm{SD}=.02 ; \mathrm{F}(1,86)=6.19, p<.05 ; \mathrm{M}_{\text {high }}$ $=6.44 \approx 628 \mathrm{~ms}, \mathrm{SD}=.02 ; \mathrm{F}(1,86)=9.93, p<.01)$. Besides, reaction times to ordinary 
service employee stereotype words were also faster than those to neutral words (moderate interaction quality: $\mathrm{t}(30)=-3.31, p<.01$; high interaction quality: $\mathrm{t}(29)=-3.80, p<.01)$. These results show that both interaction quality conditions triggered associations with the ordinary service employee stereotype.

An ANCOVA on reaction times to positive service employee stereotype words also revealed a significant effect of condition $(\mathrm{F}(2,86)=11.31, p<.001)$. Reaction times were significantly faster in the high interaction quality condition $(\mathrm{M}=6.44 \approx 627 \mathrm{~ms}, \mathrm{SD}$ $=.01)$ than in the control condition $(\mathrm{M}=6.51 \approx 669 \mathrm{~ms}, \mathrm{SD}=.01 ; \mathrm{F}(1,86)=12.86, p<$ $.01)$. Moderate interaction quality $(\mathrm{M}=6.52 \approx 679 \mathrm{~ms}, \mathrm{SD}=.01)$ and control conditions did not differ $(\mathrm{F}(1,86)<.72$, n.s. $)$. Reaction times to positive service employee stereotype words were also faster than those to neutral words in the high interaction quality condition $(\mathrm{t}(29)=-5.74, p<.001)$. These findings provide additional support for $\mathrm{H}_{2}$.

The analysis of reaction times to negative salesperson stereotype words indicated unanticipated differences between the conditions $(\mathrm{F}(2,86)=4.39, p<.05)$. Reaction times in the control condition $(\mathrm{M}=6.51 \approx 670 \mathrm{~ms}, \mathrm{SD}=.01)$ were significantly faster than in the high interaction quality condition $(\mathrm{M}=6.54 \approx 694 \mathrm{~ms}, \mathrm{SD}=.01 ; \mathrm{F}(1,86)=8.45$, $p<.01)$ and moderate interaction quality condition $(\mathrm{M}=6.53 \approx 686 \mathrm{~ms}, \mathrm{SD}=.01 ; \mathrm{F}(1$, $86)=3.91, p=.05)$. Compared to neutral words, reaction times to salesperson stereotype words were significantly slower in the high interaction quality condition $(\mathrm{t}(29)=2.72, p$ $<.05)$ but not in the moderate interaction quality condition $(\mathrm{t}(30)=1.46, \mathrm{n} . \mathrm{s}$. $)$ and control condition $(\mathrm{t}(28)=-1.39$, n.s.). Reaction times to neutral words did not differ significantly between conditions.

\subsubsection{Discussion}

These results provide further insight into $\mathrm{H}_{1}$ and $\mathrm{H}_{2}$ by disentangling the effects of interaction quality and the cross-sell attempt. The activation of the ordinary service employee stereotype in the moderate interaction quality condition implies that participants with high cognitive load indeed recategorized the CSR when confronted with a cross-sell attempt in studies 1 and 2. These findings support our argument that recategorization can occur fairly effortless. Further, they imply that the salesperson stereotype is more instrumental than the ordinary service employee stereotype for the self-protection goal. Moreover, study 3 clearly demonstrates that the activation of the positive service employee stereotype is the result of high interaction quality during recovery provision. We can therefore rule out that factors such as the combination of high interaction quality and the cross-sell attempt produced the results in study 1 and 2 . This finding further suggests that even under high cognitive load, the positive service employee stereotype produces confidence levels that sufficiently fulfill the self-protection goal and hence, obscures the link between the cross-sell attempt and the otherwise highly instrumental salesperson stereotype. We also found the simultaneous increased accessibility of associations with the ordinary and positive service employee stereotype in the high interaction quality condition. It is possible that both service employee stereotypes are related subtypes.

As expected, results show no activation of the negative salesperson stereotype in any of the conditions. The decreased accessibility of salesperson stereotype associations in 
the interaction quality conditions compared to the control group points to inhibition. Such inhibition might be the result of the opposite valence of the associations. The negative salesperson stereotype associations would possibly interfere with those of the service employee stereotypes and therefore become inhibited. We note that the comparison of reaction times to salesperson stereotype words with those of the control group and those to neutral words results in two different conclusions - inhibition and non-activation - in the moderate interaction quality condition. Although inhibitory effects do not pertain to the core of our hypotheses, the inconclusive comparisons may cast doubt on the selection of the LDT words. Yet, all other comparisons of reaction times to target words with those of the control group and those to neutral words led to consistent results which were always in line with our expectations. We therefore believe that factors such as differences in word length or difficulty did not affect the patterns of stereotype activation we found in the previous studies.

\subsection{Study 4}

The objective of study 4 was three-fold. First, we aimed to provide support for our arguments that warmth drives the instrumentality of the stereotypes and the effects observed also hold true for high cognitive load due to the ease with which warmth can be judged. Thus, study 4 assesses customers' evaluations of the CSR along the dimension of warmth under high cognitive load. To support our arguments, the pattern of warmth evaluations should mirror the pattern of stereotype activation we observed in studies 2 and 3 . We argued that the positive service employee and the negative salesperson stereotypes are more instrumental for the self-protection goal than the ordinary service employee stereotype, because they signal warmth (coldness) more strongly. Given high interaction quality triggers the positive service employee stereotype that fulfills the self-protection goal, warmth evaluations should be highest when interaction quality is high irrespective of a cross-sell attempt. Moderate interaction quality without a cross-sell attempt should result in lower warmth evaluations, because it evokes the ordinary service employee stereotype. Lowest warmth evaluations should result from a cross-sell attempt coupled with moderate interaction quality because it triggers the negative salesperson stereotype.

Second, if recategorization occurs effortless due to the ease with which warmth can be judged, it should not consume significant cognitive resources. Although the results of the manipulation checks in the previous studies provide initial support for this expectation, an objective measure instead of the self-report measures would provide stronger evidence. Study 4 compared performance in correctly recalling the eight-digit number across conditions. If recategorization consumed cognitive resources, it would draw attention away from rehearsing the eight-digit number and hence result in reduced recall performance.

Third, the first two studies showed the consequences of stereotype activation and application for cross-selling performance. In study 4, we wanted to probe further the consequences for service performance in terms of customer satisfaction with the encounter and asked: Would there be serious dilution effects such that cross-sell attempts 
render service recovery ineffective? And could cross-sell attempts increase customers' satisfaction with the recovery encounter?

\subsubsection{Method}

104 undergraduates participated in this experiment. This study employed a 2 (interaction quality: moderate vs. high) $\times 2$ (cross-sell attempt: present vs. absent) between-subjects design and the scenarios of studies 2 and 3 (Appendix C: cross-sell attempt present (absent): parts I - III (I - II)). While reading the scenario, answering the satisfaction questions, and evaluating the CSR's warmth, all participants rehearsed an eight-digit number. Manipulation checks and control questions followed. Satisfaction with the encounter was measured with three items tapping satisfaction with the performance of the CSR, the service received, and the interaction (Mohr and Bitner 1995) on 9-point scales ( 1 = very dissatisfied, 9 = very dissatisfied). Participants rated the CSR's warmth on five items (sincere, helpful, trustworthy, friendly, and had my best interest at heart) on a 9-point scale $(1=$ strongly disagree, 9 = strongly agree; Cuddy, Fiske, and Glick 2004; Fiske et al. 2002; Judd et al. 2005). Similar to Gilbert, Brett, and Douglas (1988), we developed an index for recall performance of the eight-digit number. One point was given for every number recalled correctly. Another point was given if the place of the number within the sequence was recalled correctly. The index was computed as the points obtained divided by the maximum 16 points obtainable. We included the surprise memory task of study 2 for the participants in the cross-sell attempt condition as an additional check of shifting cognitive resources. Finally, because the scenarios with and without a cross-sell attempt differed considerably in length, which affects how long participants had to rehearse the eight-digit number, we recorded the time taken (in seconds) for reading the scenario and answering the dependent measures for each participant. We included this time measure as an additional check in the analyses.

\subsubsection{Results}

Manipulation checks. Results of a $2 \times 2$ ANOVA revealed only a significant main effect of the interaction quality manipulation on perceived interaction quality $(\alpha=.80 ; \mathrm{F}(1,100)$ $=60.25, p<.01)$. Participants in the high interaction quality condition $(\mathrm{M}=6.94, \mathrm{SD}=$ .71) perceived the CSR to provide higher interaction quality than those in the moderate interaction quality condition $(\mathrm{M}=5.74, \mathrm{SD}=.86)$. For the cognitive load manipulation, ANOVA results showed no significant effects. The means for perceived difficulty and focus are very similar to those found in the previous studies (difficulty: $\mathrm{M}_{\text {moderate }- \text { no cross-sale }}$ $=4.73, \mathrm{SD}=1.37 ; \mathrm{M}_{\text {moderate }- \text { cross-sale }}=5.00, \mathrm{SD}=1.19 ; \mathrm{M}_{\text {high }- \text { no cross sale }}=4.88, \mathrm{SD}=1.42 ;$ $\mathrm{M}_{\text {high - cross-sale }}=4.74, \mathrm{SD}=1.10$; focus: $\mathrm{M}_{\text {moderate - no cross-sale }}=4.38, \mathrm{SD}=1.33 ; \mathrm{M}_{\text {moderate - cross- }}$ $\underset{\text { sale }}{\stackrel{1}{=}}=4.04, \mathrm{SD}=1.14 ; \mathrm{M}_{\text {high }- \text { no cross sale }}=4.27, \mathrm{SD}=1.34 ; \mathrm{M}_{\text {high }- \text { cross-sale }}=4.37, \mathrm{SD}=1.04$ ).

Recall performance. An ANOVA on recall performance revealed no significant differences between the experimental conditions $(\mathrm{F}(3,100)=.69$, n.s. $)$. Average recall performance of the eight-digit number was $87 \%$. A comparison of memory performance between moderate and high interaction quality conditions with the cross-sell attempt 
also revealed no significant difference $(\mathrm{z}=-.59$, n.s.). These findings indicate that recategorization did not consume significantly more cognitive resources.

Warmth evaluation. An ANOVA on warmth evaluations $(\alpha=.89)$ showed significant main effects of interaction quality $(\mathrm{F}(1,100)=299.64, p<.001)$ and cross-sell attempt $(\mathrm{F}(1,100)=15.93, p<.001)$ and a significant cross-sell attempt $\times$ interaction quality interaction $(\mathrm{F}(1,100)=25.03, p<.001)$. As Figure 3.4 shows, the cross-sell attempt did not affect warmth evaluations when interaction quality was high ( $\mathrm{M}_{\text {cross-sale }}$ $=7.54, \mathrm{SD}=.63 ; \mathrm{M}_{\text {no cross-sale }}=7.39 ; \mathrm{SD}=.76 ; \mathrm{F}(1,100)=.52$, n.s. $)$. Yet it decreased perceived warmth in the moderate interaction quality condition; participants who received a product offer judged the CSR as less warm $(\mathrm{M}=4.10, \mathrm{SD}=.95)$ than those who did not $(\mathrm{M}=5.49, \mathrm{SD}=.78 ; \mathrm{F}(1,100)=39.69, p<.001)$.

\section{Figure 3.4 Perceived Warmth as a Function of Interaction Quality and Cross-Sell} Attempt

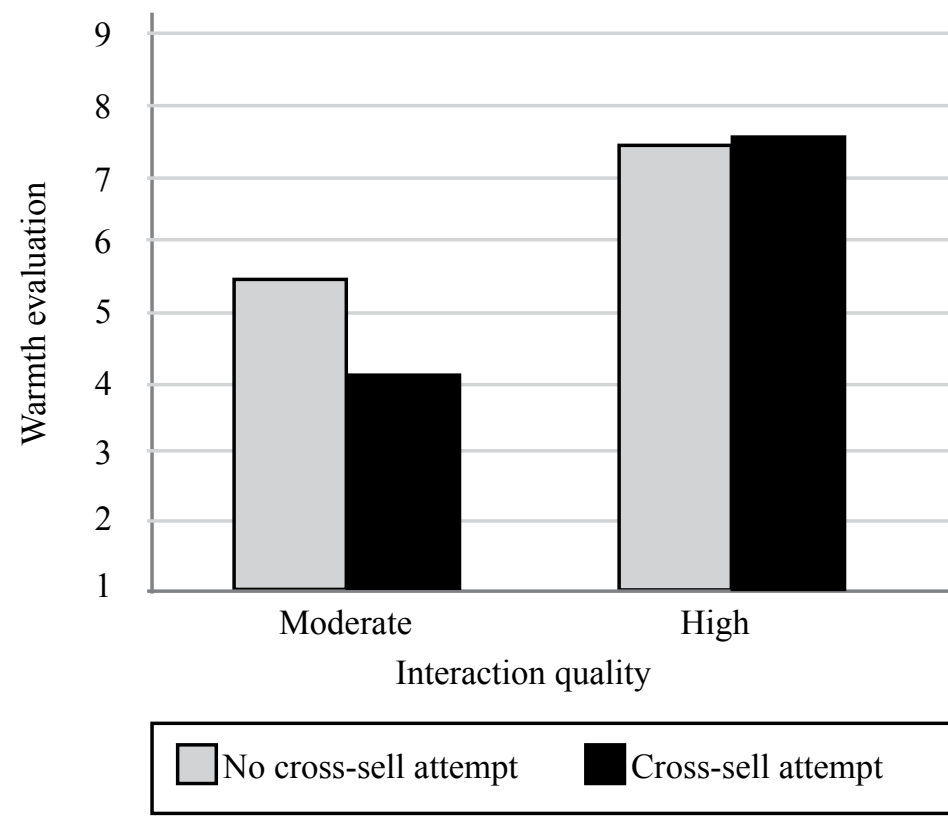

Encounter satisfaction. An ANOVA on satisfaction $(\alpha=.94)$ showed significant main effects of interaction quality $(\mathrm{F}(1,100)=169.31, p<.001)$ and cross-sell attempt $(\mathrm{F}(1,100)=13.69, p<.001)$ and a significant interaction quality $\times$ cross-sell attempt interaction $(\mathrm{F}(1,100)=42.38, p<.001)$. A cross-sell attempt increased satisfaction when interaction quality was high $\left(\mathrm{M}_{\text {cross-sale }}=8.32, \mathrm{SD}=.80 ; \mathrm{M}_{\text {no cross-sale }}=7.83, \mathrm{SD}=.73 ; \mathrm{F}(1\right.$, $100)=4.03, p<.05)$ but decreased satisfaction when interaction quality was moderate $\left(\mathrm{M}_{\text {cross-sale }}=4.93, \mathrm{SD}=.98 ; \mathrm{M}_{\text {no cross-sale }}=6.71, \mathrm{SD}=.99 ; \mathrm{F}(1,100)=51.14, p<.001\right)$.

Time. We included time as a covariate in all of the analyses. As a covariate, time only had a marginally significant effect on perceived difficulty to remember the number 
$(\mathrm{F}(1,99)=3.44, p=.066)$, but controlling for this effect did not change any of the results reported for this manipulation check. We did not find any other significant effects of time or any interactions with the experimental factors on the other dependent variables.

\subsubsection{Discussion}

Study 4 provides support for our argument that recategorization can occur fairly effortless. Results show that recall performance is not impaired in the moderate interaction quality - cross-sell attempt present condition compared to the other conditions. There are also no performance differences in memory about the scenarios. Study 4 also supports our argument that warmth drives the instrumentality of the stereotypes. Results show that the differences in warmth evaluations mirror the pattern of stereotype activation in the previous studies. Warmth evaluations are highest when high interaction quality triggers the positive service employee stereotype. When interaction quality is moderate, a crosssell attempt leads to a huge drop in warmth evaluations, indicating recategorization from the ordinary service employee into the negative salesperson category. Although we cannot rule out that the warmth difference is due to interaction quality in the cross-sell attempt absent condition, the drop in warmth evaluations when interaction quality is moderate can only be explained by the cross-sell attempt activating the negative salesperson stereotype. Study 4 also reveals that cross-selling in recovery encounters can do harm and good. Encounter satisfaction is seriously harmed by the cross-sell attempt when interaction quality is moderate. Yet, when high interaction quality evokes the positive employee stereotype, a cross-sell attempt increases encounter satisfaction.

\subsection{Study 5}

Study 5 assesses the robustness of the effect that high interaction quality triggers the positive service employee stereotype that helps the negative salesperson stereotype to stay 'under the radar'. It is possible that we only observed this effect so far because high interaction quality was always presented with high recovery outcome quality. We were interested in whether we could replicate this finding even if recovery outcome quality was lower (i.e., the customer's problem is not definitely solved). This should be particularly interesting for high cognitive load for which we argued that we observe this effect because of the primacy of warmth judgment. A replication of our findings with outcome quality being lower would provide converging evidence for warmth to be the factor that underlies the findings of the previous studies. As to the outcomes, we focused on encounter satisfaction to allow for a direct comparison with satisfaction levels observed in study 4 .

\subsubsection{Method}

118 students $(51.7 \%$ female) participated in this study which employed the design of study 4 . The change in the description of the recovery provision pertained to the solution of the problem. In this study, the CSR does not initiate the refund for the double-charged fee himself, but transfers the handling of the problem to colleagues responsible for billing 
and accounts, leaving the status of the problem solution in uncertainty (see Appendix C). We used the same design, measures, and manipulations as in study 4, but added the purchase intention question (study 2) again to the cross-sell present condition.

\subsubsection{Results}

Manipulation checks. Results of a $2 \times 2$ ANOVA on perceived interaction quality $(\alpha=$ .86) revealed only a significant main effect of the interaction quality manipulation $(\mathrm{F}(1$, $114)=31.74, p<.001)$. Perceived interaction quality was higher in the high $(\mathrm{M}=6.66$, $\mathrm{SD}=1.07)$ than in the moderate $(\mathrm{M}=5.50, \mathrm{SD}=1.14)$ interaction quality condition. The four conditions did not differ in the level of cognitive load and corresponding means are very similar to those found in studies 1 to 4 (difficulty: $\mathrm{M}_{\text {moderate }- \text { no cross-sale }}=4.69, \mathrm{SD}=$ $1.46 ; \mathrm{M}_{\text {moderate - cross-sale }}=4.65, \mathrm{SD}=1.85 ; \mathrm{M}_{\text {high - no cross-sale }}=4.59, \mathrm{SD}=1.74 ; \mathrm{M}_{\text {high - cross-sale }}=$ 4.93, $\mathrm{SD}=1.65$; focus: $\mathrm{M}_{\text {moderate }- \text { no cross-sale }}=4.42, \mathrm{SD}=1.53 ; \mathrm{M}_{\text {moderate }- \text { cross-sale }}=4.58, \mathrm{SD}=$ $1.34 ; \mathrm{M}_{\text {high - no cross-sale }}=4.00, \mathrm{SD}=1.63 ; \mathrm{M}_{\text {high - cross-sale }}=4.38, \mathrm{SD}=1.66$ ).

\section{Figure 3.5 Encounter Satisfaction as a Function of Interaction Quality and Cross-} Sell Attempt

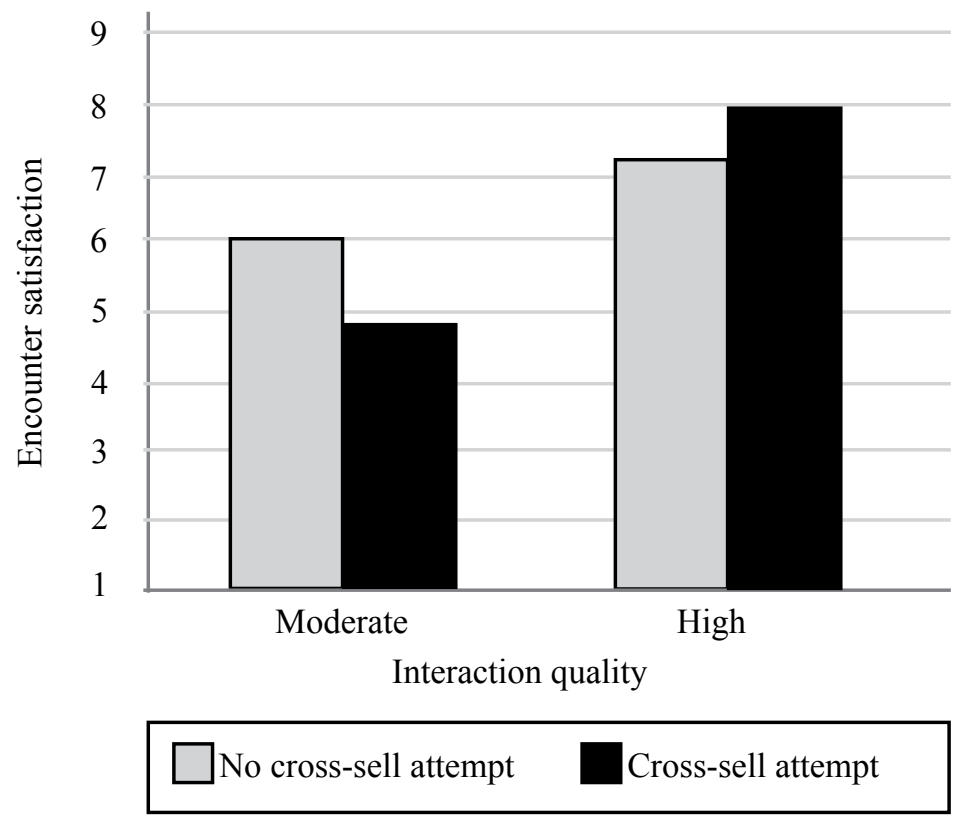

Satisfaction and purchase intention. Results revealed a significant main effect of interaction quality on satisfaction $(\alpha=.87 ; \mathrm{F}(1,114)=119.89, p<.001)$, which was qualified by a significant interaction quality $\times$ cross-sell interaction $(\mathrm{F}(1,114)=25.23, p$ $<.001)$. As shown in Figure 3.5, encounter satisfaction was higher in the high interaction quality $(\mathrm{M}=7.57, \mathrm{SD}=1.01)$ than in the moderate interaction quality condition $(\mathrm{M}=$ 
5.36, $\mathrm{SD}=1.34)$. A cross-sell attempt increased satisfaction when interaction quality was high $\left(\mathrm{M}_{\text {high }- \text { cross-sale }}=7.94, \mathrm{SD}=.85 ; \mathrm{M}_{\text {high }- \text { no cross-sale }}=7.24, \mathrm{SD}=1.04 ; \mathrm{F}(1,114)=6.52, p\right.$ $<.05)$ but decreased satisfaction when interaction quality was moderate $(\mathrm{M}$

$\left.=4.77, \mathrm{SD}=1.01 ; \mathrm{M}_{\text {moderate }- \text { no cross-sale }}=6.06, \mathrm{SD}=1.37 ; \mathrm{F}(1,114)=20.40, p<.001\right)$. In the absence of a cross-sell attempt, satisfaction also significantly differed between the interaction quality conditions $(\mathrm{F}(1,114)=17.18, p<.001)$. Besides, purchase intention was higher in the high interaction quality condition $(\mathrm{M}=6.10, \mathrm{SD}=2.04)$ than in the moderate interaction quality condition $(\mathrm{M}=3.26, \mathrm{SD}=1.67 ; \mathrm{F}(1,58)=35.07, p<.001)$.

\subsubsection{Discussion}

This study replicates the results for satisfaction of study 4 although outcome quality is reduced. In addition, results for purchase intention are consistent with those observed in study 2. Hence, study 5 provides support for our arguments that it is warmth that makes the positive service employee stereotype sufficiently instrumental to fulfill the self-protection goal and this also holds true under high cognitive load because warmth is easily processed and judged.

\subsection{General Discussion}

\subsubsection{Theoretical Discussion}

Given people's multiplicity of social category memberships as well as the prevalence of stereotype based judgments in everyday life, it is surprising that multiply categorizable people have received relatively scant attention in the literature (Bodenhausen and Peery 2009; Clark et al. 2009). While previous research focused on stereotyping upon initial exposure to a person and a single goal-relevant stereotype (e.g., Kunda et al. 2002; Sinclair and Kunda 1999; Spencer et al. 1998), our study advances understanding of multiply categorizable people by studying customers' motivated stereotype activation and application when CSRs gradually reveal cues for goal-relevant, conflicting stereotypes during a service recovery encounter.

Motivated stereotyping in interactions. Based on our discussion of the literature on stereotyping and goal pursuit, we proposed the degree of stereotype instrumentality and goal fulfillment to be important determinants of keeping and revising an initial impression and hence the pattern of motivated activation and application of stereotypes during interactions. Results of our studies clearly show that customers activate and apply the stereotype which is most instrumental for their self-protection goal. We identified warmth as the determinant of the instrumentality of service employee and salesperson stereotypes for customers' self-protection goal. The positive service employee stereotype and the negative salesperson stereotype are more strongly associated with high warmth (good-will) and low warmth (ill-will), respectively, than the ordinary service employee category, and hence more instrumental for the self-protection goal. Our studies show that such greater instrumentality induces impression revision (i.e., recategorization) and application of the negative salesperson stereotype when moderate interaction quality 
initially triggers the ordinary service employee category. Yet recategorization into the equally instrumental salesperson category does not occur when high interaction quality evokes the positive service employee stereotype that sufficiently fulfills the self-protection goal. The eliminated sensitivity to intention signals through motivated application of the positive service employee stereotype renders a cross-sell attempt ineffective in activating the negative salesperson stereotype. While previous research focused on stereotype activation and application upon initial exposure to a person (Kunda et al. 2002), our studies indicate that such focus can lead to premature conclusions as goal fulfillment and stereotype instrumentality induce different stereotypes to come and go during the time course of interactions.

We propose goal fulfillment and stereotype instrumentality as two determinants of stereotype activation and application during the time course of interactions in the context of the self-protection goal; therefore, our study invites further research to study the conditions under which the effectiveness of these two factors generalizes to contexts in which other factors interfere with or other goals guide impression formation. For example, an interpretation goal (i.e., the goal to understand and make sense of the world) may render differences in stereotype instrumentality irrelevant because any stereotype as long as it is instrumental would fulfill this goal (Stapel and Koomen 2001). Moreover, while our studies imply that warmth drives the instrumentality of stereotypes for a self-protection goal, prior research suggests 'competence' as such a determinant for a self-worth enhancement goal (e.g., Sinclair and Kunda 1999). Interestingly, warmth and competence are the two fundamental dimension underlying person judgment and stereotypes (Fiske et al. 2007). While warmth suggests the valence of a person's intent towards others, competence indicates his/her effective capacity to implement the intent (Cuddy et al. 2008). Because these judgments are deemed fundamental, it is plausible that these two dimensions drive stereotype instrumentality for many goals, as future research would have to explore.

Cognitive capacity. Prior research highlighted the substantial cognitive resource requirements of impression revision (e.g., Gilbert et al. 1988; Macrae et al. 1999). Literature also suggests that sufficient confidence in the validity of one's impressions to keep this impression requires enhanced elaboration and cognitive resources (e.g., Wegener et al. 2006). Yet our studies reveal that such resource requirements are bypassed when goal-relevant stereotype cues can be easily and rapidly processed and judged. Given the primacy of warmth judgment, warmth is such type of information. Accordingly, our first two studies show that high cognitive load does not change the pattern of stereotype activation and application observed under low cognitive load. This finding generalizes across contexts and cues related to industries, types of products, and service failures. While study 3 provides evidence for recategorization, study 4 confirms the independence of recategorization from cognitive resources. Results of study 4 also show that the ease of warmth judgment allows warmth evaluations to follow the pattern of stereotype activation and application under high cognitive load, implying effortless recategorization and goal fulfillment. Finally, study 5 shows that lowered outcome quality does not affect the activation and application of the positive service employee stereotype, which suggests that sufficient impression confidence is rather due to the goal-relevant warmth signal than 
other information. Overall, these studies suggest that the ease of warmth judgment allows motivation to overcome cognitive capacity requirements for recategorization and goal fulfillment.

While we focus on the nature of goal-relevant category cues, there might be other factors that eliminate cognitive resource requirements. One such factor could be related to individual differences in implicit theories of personality (e.g., Dweck, Chiu, and Hong 1995; Plaks et al. 2001). It is plausible that entity theorists, who believe that personality is fixed, more easily gain sufficient confidence in initial impressions, while incremental theorists, who believe personality is changeable, more easily recategorize and correct initial impressions. Accumulating an in-depth understanding of the factors that help people overcome cognitive capacity constraints would be worthwhile, in particular because higher levels of cognitive load tend to prevail in real life (e.g., Bargh 1989; Kunda and Spencer 2003).

Valence of stereotypes. Our studies focus on goal-relevant stereotypes that are of opposite valence and have conflicting implications for the self-protection goal. The results of the LDTs in studies 1 to 3 clearly illustrate the mutual exclusiveness of the service employee and salesperson stereotypes. The activation of one stereotype gives rise to the simultaneous inhibition of the other stereotype. Theoretical work on the 'multiple jeopardy' problem suggests that salience of a person's membership in multiple categories associated with only negative stereotypes may have additive or even multiplicative effects (Kulik et al. 2007). In contrast to our study which reveals recategorization, it is possible that when a person is associated with multiple goal-relevant stereotypes of the same valence, people would not recategorize that person but instead use the stereotypes cumulatively to fulfill their goal.

Besides, a primary focus of stereotyping research is on the factors that help people avoid stereotyping and encourage individualized impressions. Certainly, this is an important inquiry given the fatal consequences of prejudice and discrimination. Yet such focus inevitably draws attention to negative stereotypes and their incorrectness and implicitly implies that stereotyping needs to be avoided by all means. But stereotypes can also be positive and accurate (e.g., Jussim 2005). Our studies demonstrate that stereotyping can be useful for both the person who stereotypes and the person being stereotyped. When customers apply the positive service employee stereotype, they do not categorically refuse a product offer from which they would clearly benefit and CSRs do not mistakenly fall prey to the negative salesperson stereotype. As such, our study proposes positive stereotyping as an alternative way to prevent the activation of negative stereotypes. As people often do not have the ability and motivation to individuate, this might be a handy way to avoid deleterious effects of disadvantageous prejudice and discrimination.

Downstream consequences. Our study of the downstream consequences of service employee and salesperson stereotypes focused on two important outcomes for companies and customers: Purchase intention and encounter satisfaction. Similar to previous research (e.g., Darke and Ritchie 2007; Wegener et al. 2006), study 2 demonstrates the different ways in which activated stereotypes can exert their influence. When the ability to think about the cross-sell offer was high, activated stereotypes biased cognitive 
responses to the cross-sell offer which in turn influenced purchase intention. When the ability to think was curtailed, activated stereotypes served as a heuristic and their effect on purchase intention was direct in nature. Interestingly, the heuristic application of the service employee and salesperson stereotypes under high cognitive load led to greater differences in purchase intention than when stereotypes biased cross-sell offer related thoughts under low cognitive load. Previous research did not reveal such an effect when stereotypes were applied in person judgment (Wegener et al. 2006). Whether the way a stereotype exerts its influence leads to differences in judgments and behavior appears to depend on the target under scrutiny. In our studies, product related arguments seemed to have some leeway to influence customers' purchase intention when the ability to think was high.

Study 4 shows that cross-sell attempts seriously harm encounter satisfaction when interaction quality is moderate, implying serious dilution effects such that the salesperson stereotype negatively colors customers' experience and renders recovery efforts ineffective. Yet, cross-sell attempts increase encounter satisfaction when high interaction quality triggers the positive service employee stereotype, suggesting additional satisfaction gains from the cross-sell offer. These findings demonstrate that recovery provision and cross-selling become incompatible and reduce each other's effectiveness when cross-sell attempts trigger the negative salesperson stereotype; yet they become complementary and enhance each other's effectiveness when high interaction quality triggers the positive service employee stereotype.

Finally, study 5 reveals the same pattern of encounter satisfaction and purchase intention as in studies 2 and 4 despite lower outcome quality. Aaker, Vohs, and Mogilner (2010) suspected that perceived warmth is a more important driver of customers' purchase willingness than other perceptions, such as competence, in customer-company relationships in which trust is critical. Our study provides some support for this idea in the context of service relationships when service failures put trust at stake. The demonstrated importance of warmth might also explain why prior research found interactional justice and the 'human touch' to have a critical role in recovery encounters (e.g., Blodgett et al. 1997; Davidow 2003; Tax, Brown, and Chandrashekaran 1998).

\subsubsection{Limitations}

We recognize that our study is not without limitations, some of which highlight avenues for further research in addition to those already outlined. Concern may be raised as to the sufficiency of cognitive load induced by our manipulation. However, prior research that used the same manipulation found high cognitive load to have expected, theoretically grounded effects (e.g., Gilbert and Hixon 1991; Shiv and Fedorikhin 1999). Besides, a recall test of the eight-digit number at the end of the experiments revealed substantially reduced recall performance, indicating that the number was not subjected to long-term memory but taxed working memory as intended. Study 2 also shows that the number of thoughts was very low, as should be expected under conditions of curtailed thinking. Although these findings increase confidence in our manipulation, we invite replication studies employing different cognitive load manipulations. 
Because we used controlled lab experiments, role-play scenarios, and student subjects, caution should be exercised in generalizing our findings. Older consumers may have more experience in coping with persuasion attempts, richer knowledge of marketing tactics, and more strongly held stereotypes (e.g., Friestad and Wright 1994), which may impact the pattern of findings observed in our studies. Similarly, stereotypical representations of salespeople and service employees may be culture and age specific (e.g., McGarty, Yzerbyt, and Spears 2002). Besides, the scenario method lacks the richness of real interactions, limiting understanding of how other factors interact with our experimental factors. However, the scenario method has been widely adopted in previous research and allows for a clean manipulation of the experimental factors (e.g., Campbell and Kirmani 2000; Wagner, Hennig-Thurau, and Rudolph 2009). An intentional imposition of service failures on customers would certainly be highly undesirable and unethical from a managerial perspective. Besides, the role play scenarios presented a single incidence of a service failure and no information about the customer-company relationship. However, repeated service failures and accumulated dissatisfaction with the firm may reduce the effectiveness of high interaction quality in triggering a positive service employee stereotype, as negative pre-encounter expectations then possibly guide information processing during the recovery encounter. Because we focused on one-time customerCSR interactions in a pseudo-relationship, the question arises as to the likelihood of a cross-sell attempt evoking a negative salesperson stereotype when customers and CSR have a personal, high-quality, long-term relationship. Certainly, exploring the conditions under which our findings generalize to other situations, subject populations, and natural settings would be worthwhile.

\subsubsection{Managerial Implications}

Our study holds important implications and recommendations for cross-selling in inbound recovery calls. Firms should be aware that service/product failures are relationship transgressions that trigger uncertainty and distrust. In such situations, customers want to take their bearings and know whether their relationship partner is a 'friend' or a 'foe'. As our studies show, when CSRs provide adequate recovery, high-touch interpersonal treatment acts as a positive signal which induces customers to positively stereotype, allowing cross-sell attempts and negative sales stereotypes to stay 'under the radar'. As a result, cross-sell attempts are more likely to succeed and encounter satisfaction even exceeds 'recovery-only' levels. Yet a lack of such a high-touch response turns a cross-sell attempt into a detectable negative signal that induces customers to negatively stereotype. As a consequence, cross-sell attempts tend to fail and seriously harm CSRs' proper recovery provision efforts. Customer reactions in terms of purchase willingness and satisfaction can be quite extreme and short-cut, as customers seldom have ample cognitive resources in real life interactions with marketers. Figuratively, our studies demonstrate that crossselling in recovery encounters is truly a double-edged sword.

Call centers may want to design CSR training modules that teach strategies to enact and maintain sincere, warm, and customer-focused interpersonal behavior, in addition to modules that cover effective recovery provision, sales techniques, and the recognition 
of sales opportunities in recovery encounters. Role plays and records of customer-CSR interactions could serve to teach CSRs how to relate closely to customers in various recovery encounters and sensitize them to signals that indicate customers' abandonment of their self-protective mode. Because of the large call volumes CSRs handle daily, they may easily fall back into an assembly line mode of dealing with each customer. During personnel selection, call centers may therefore find it valuable to focus on candidates who have the personality to relate closely to customers. Because those candidates tend to identify with the expected role, they are more likely to provide continuously the expected quality in an authentic manner. Team managers would also be well advised to regularly encourage CSRs to treat customers in a way that recognizes them as valued relationship partners, while also providing moral and emotional support to help CSRs cope with the job demands. Performance evaluations should be aligned accordingly and avoid a major emphasis on efficiency metrics, such as call handling time. The strong focus on efficiency is prevalent but at odds with the requirement for CSRs to provide recovery that can be leveraged for immediate revenue generation. There is also the risk that CSRs become aware of the potential to fall prey to the negative salesperson stereotype. Such stereotype threat would have detrimental effects on sales performance (Steele and Aronson 1995). Stereotype threat can be reduced by making continuously salient CSRs' identity of service providers who are helpers and problem-solvers. Recalling situations in which cross-selling solved a customer's problem could be one effective way to do so.

Firms should be aware that a half-hearted implementation of cross-selling in recovery encounters could involve substantial costs and far reaching consequences that go beyond the loss of a customer's business. Our results imply that even if CSRs provide adequate recovery, the lack of a human touch turns a cross-sell attempt into another relationship transgression. Such a double deviation from customer expectations often leads to customer defection and negative word-of-mouth (Tripp and Grégroire 2011). The widespread use of the Internet and the prevalence of online platforms (e.g., complaints. com, YouTube, and Facebook) provide customers with easy access to a mass audience for sharing their negative experiences with firms. Recently, a YouTube video in which a customer voices his anger about an airline's recovery failure reached 5 million views in the first month (cf. Tripp and Grégroire 2011). Besides, literature documents the growing distrust in marketers and firms and the prevalence of negative marketing stereotypes (e.g., Darke and Ritchie 2007; Kramer 1999). Cross-selling in recovery encounters may not only fall prey to such generalized distrust but also aggravate the situation. A CSR subtype being less positive than current service employee stereotypes could develop, if cross-sell attempts frequently trigger negative sales stereotypes. The consequences for effective customer service provision and customer retention could be serious. Although our work suggests that positive stereotyping can prevent negative stereotypes, we would strongly advise against misusing this insight. Customers continuously learn and eventually become sensitive to any deceptive practice (Friestad and Wright 1994).

Because, nowadays, firms handle up to $70 \%$ of their customer interactions through call centers (Bodine 2011) and customer complaints and support requests make up almost half of inbound calls (CFI Group 2010), making the investments needed to successfully leverage customer service calls for relationship expansion is likely to pay off. However, 


\section{$76 \quad$ Chapter 3}

while $45.8 \%$ of the call centers with a service-sales program adhere to the 'every call is a sales opportunity' belief (ICMI 2007), our studies imply that call centers would be well advised to be more selective when it comes to cross-selling in recovery calls. For example, CSR desktop support could serve as an early warning system by providing CSRs with an indicator of the quality of the prior customer-company relationship. A history of failed services or cross-sell attempts could signal customers' negative pre-encounter expectations. Overall, our work implies that firms can benefit from cross-sell programs in recovery encounters when they create the conditions in which cross-sell attempts and hence negative stereotypes remain under customers' self-protection radar. 
Chapter 4

Conclusion 


\subsection{Introduction}

This dissertation set out to investigate whether, when, and how CSRs can effectively leverage inbound customer service calls for the enhancement of mutually beneficial customer-company relationships through cross-/up-selling. This inquiry is motivated by companies' need to obtain answers to those questions, the lack of understanding of employees' ambidexterity, and the importance of advancing understanding of how to create superior value for mutually beneficial customer-company relationships. This dissertation shows that CSRs can excel in serving well by selling well. This final chapter concludes the dissertation with a brief recap of the findings of the empirical studies, an answer to the overall research question, followed by a discussion of value creation through the alignment of sales with service, and future research directions.

\subsection{Discussion}

Companies want to leverage their costly inbound customer service call centers for relationship enhancement and revenue building. The alignment of the two customer retention tools - customer service and cross-/up-selling - at the existing inbound customer touch point promises superior value co-creation for mutually beneficial customer relationships. Hence it makes sense to ask CSRs to become ambidextrous and excel in serving well by selling well. However, the simultaneous pursuit of the seemingly conflicting service and sales goals requires CSRs to manage and overcome conflicting demands and trade-offs, which turns CSRs' service-sales alignment into a challenging endeavor. Therefore, we have asked:

\section{Which factors facilitate a CSR's ambidextrous behavior and impact its effectiveness?}

As the alignment of service and sales aims at superior value creation for mutually beneficial relationships, we study this research question from CSRs' (i.e. companies') and customers' perspectives, assess value creation for both relationship partners, and consider relationship characteristics and customer-CSR interaction contingencies. By addressing the specifics of employee-level ambidexterity in the context of CSRs' service-sales alignment, we identify factors that affect CSRs' effective ambidexterity from three areas of influence: within-person, macro-environment (i.e. call center), and micro-environment (i.e. service encounter).

First, we consider the service-sales alignment from the CSRs' perspective as their ambidextrous behavior is a key requirement for the delivery of a value proposition to the customer. The simultaneous engagement in seemingly conflicting tasks and/or switching between them at "minute intervals" poses a self-regulatory and motivational challenge for CSRs, which necessitates a specific motivational capacity. The joint presence of locomotion and assessment orientations embodies such within-person capacity that allows for effective self-regulation in the pursuit of seemingly conflicting goals. The results of our empirical investigation show that the strong desire for experiencing 
movement and progress facilitates ambidextrous behavior. Yet when it is complemented with the desire for critical evaluation and comparison, the resulting motivation to 'just do the right thing' is most conducive to ambidextrous behavior. Hence, CSRs who prefer to 'locomote' while at the same time want to 'assess' manage the ambidexterity challenge best. However, the valuable interplay of the two motivational orientations does not shape CSRs' ambidextrous behavior in isolation from their work environment. Prevalent call center characteristics are the organization of CSRs around team structures and operations that focus on standardization, routines, and efficiency, which encourage CSRs to respond with team identification and the exercise of bounded discretion. Our study shows that both of these responses strongly interfere with CSRs' assessment orientation. That is, the strong desire to be 'one' with the team and the routinized compliance with organizational prescriptions and routines render the motivation to 'do the right thing' ineffective in purposefully guiding CSRs' motivation to 'just do it' toward ambidextrous behavior.

Overall, we show that the right motivational capacity is a valuable withinperson factor that helps CSRs engage in ambidextrous behavior. However, characteristics of CSRs' macro-environment shape their responses and hence affect their motivational capacity. These influences are important to consider, as CSRs' ambidexterity has valuable consequences for customer satisfaction and sales performance.

Second, we consider the service-sales alignment from the customers' perspective as they are the relationship partners who interact with CSRs as value co-creators during service encounters. The dyadic nature of relationships and encounters suggests that CSRs' micro-environment can influence the effectiveness of their ambidextrous behavior. Service/ product failures as relationship transgressions change the state of the customer-company relationship. They trigger self-protection goals that motivate customers to stereotype to protect themselves from further threats in recovery encounters where they want to know whether their partner is their 'friend' or 'foe'. Customer-CSR interdependencies during encounters allow CSRs' relational behavior to influence which stereotype customers use to fulfill their self-protection goal. Our studies show that ambidextrous CSRs fall prey to a negative salesperson stereotype which signals ill-will, unless they provide high interaction quality during service recovery and thus convey good-will. Relating closely to customers evokes a positive service employee stereotype that allows cross-sell attempts and the negative salesperson stereotype to stay under customers' self-protection radar. In short, CSRs' ambidextrous behavior is effective when they demonstrate the company's goodwill and recover the relationship before they attempt to cross-sell in recovery encounters. When they provide adequate service recovery without closely relating to customers, the cross-sell attempt conveys ill-will which renders CSRs' ambidextrous behavior not only ineffective but harmful.

The set of empirical studies in this dissertation allow us to formulate the following answer to the overall research question: A CSR's unhindered motivation to 'just do the right thing' facilitates their ambidextrous behavior, and a factor that impacts its effectiveness is the state of the customer-company relationship which is influenced by the effect of CSRs' relational efforts on customers' perception of whether their relationship partner is their 'friend' or 'foe' during service encounters. 


\subsection{The Value of Serving Well by Selling Well}

While previous research has shown that ambidexterity leads to superior performance for companies (cf. Raisch and Birkinshaw 2008), CSRs' ambidexterity aims at superior value creation for mutually beneficial relationships. Thus, the assessment of value creation for both relationship partners - customers and companies - is imperative (Gwinner et al. 1998; Payne et al. 2008; Vargo and Lusch 2008). Certainly, our studies do not allow for a complete analysis of all costs and benefits of the service-sales alignment for companies and customers, but they provide insights into necessary inputs and potential outputs and hence the value that can be co-created.

As to the inputs, our studies imply that a successful service-sales alignment takes, first and foremost, the right people. For example, CSRs who have the motivational capacity to 'just do the right thing' and the ability to relate closely to customers are effective in aligning sales with service. Furthermore, call centers need to create the right work environment. Factors that are external and internal to service encounters affect CSRs' service-sales alignment and its effectiveness. For example, as our studies show, call center characteristics, such as team structures, can create conditions which interfere with CSRs' valuable motivational capacity. In service encounters, a successful servicesales alignment also requires good customer-CSR interactions. The results of our studies imply that immediate relationship expansion after a product/service failure necessitates CSRs' relational effort in addition to adequate recovery provision. This also implies that a successful service-sales alignment requires customer-company relationships which give customers the feeling of being a valued relationship partner. Finally, cross-/up-selling during customer service encounters consumes time, which is one of the many cost factors for companies and apparently the only one for customers. Although the necessary inputs appear to be substantial for companies, they should keep the following things in mind. First, good customer service (without cross-/up-sell efforts) also requires many of these inputs, such as having the right CSRs and a good work environment. Second, other inputs, such as healthy customer-company relationships, provide benefits above and beyond a successful service-sales alignment, such as positive word-of-mouth. Third, a successful service-sales alignment produces outputs that may outweigh the costs.

With regard to the outputs, our studies indicate that both relationship partners can benefit from the service-sales alignment. As chapter 2 shows, companies receive benefits in terms of customer satisfaction and sales performance gains that outweigh efficiency losses for CSRs. Customer satisfaction is a valuable output because it increases repurchase rates, customer retention, share of wallet, shareholder value, and contributes to companies' bottom line (cf. Aksoy et al. 2008). Enhanced sales performance in inbound customer service, which includes the selling of relational products, builds revenues, and increases customer satisfaction and retention. As chapter 3 shows, customers also benefit from the service-sales alignment, provided that the customer-company relationship is recovered by CSRs. We found that service encounters with cross-/up-sell efforts make customers more satisfied compared to 'service-only' encounters and allow them to satisfy additional needs. Increased need and customer satisfaction reflect benefits. Interestingly, chapter 3 also illustrates that companies can prevent customers from obtaining those 
benefits.

In general, the benefits of CSRs' ambidextrous behavior appear to arise from the complementary nature of customer service provision and cross-/up-selling at the customer touch point. As illustrated in chapter 2, cross-/up-selling efforts become more effective in enhancing sales performance with increasing levels of customer service provision, which basically reflects 'selling well by serving well'. Conversely, customer service provision becomes more effective in producing customer satisfaction with increasing cross-/upsell efforts, which reflects 'serving well by selling well'. While the former is relatively intuitive in a customer service context, the latter reveals the true value of service and sales as complements. These complementarities might not be derived to the same extent when customer service and cross-/up-selling are completely separate intrafirm functions. Outbound cross-/up-sell communication (e.g., via mail) requires customers to invest additional time to deal with these one-way messages, while companies must invest resources to produce and send them. Although nowadays customer relationship management (CRM) systems allow companies to target their customers with (mass-) customized outbound cross-/up-sell communication in a more efficient way (Boulding et al. 2005), there are strong indications that these messages are increasingly ineffective (Anderson and Ragsdale 2004; Godfrey et al. 2011). One reason might be that these value propositions can 'only' be based on available customer data, such as purchase history, and purchase probability estimations, amongst others (e.g., Boulding et al. 2005; Günes et al. 2010). Typically CSRs also have access to these value propositions and customer data through desktop solutions linked to CRM systems. Yet, in contrast to one-way outbound communication, the personal contact between CSRs and customers provides additional advantages of real-time two-way communication, which can make customers' specific needs more transparent, allowing for truly customized value propositions. As mentioned earlier, we cannot assess all costs and benefits of the service-sales alignment. However, our findings together with these considerations suggest that cross-/up-selling during customer service can be a way to nurture relationships that reduces costs for both partners through more efficient processes to interact and increases benefits and revenues through more effective customer need identification and satisfaction. Therefore, we conclude that the service-sales alignment can create superior value for customers and companies.

Along these lines, this dissertation attempts to contribute to knowledge on value co-creation for mutually beneficial customer-company relationships, which is a cornerstone for company survival. As Payne and colleagues (2008, p. 89) state, "value cocreation demands a change in the dominant logic for marketing from 'making, selling and servicing' to 'listening, customizing and co-creating'." For superior value co-creation for mutually beneficial customer-company relationships, the relational literature in marketing emphasizes the importance of breaking functional silos by enhancing cross-functional processes and information sharing between intrafirm functions, such as customer service, sales, operations, and marketing (e.g., Boulding et al. 2005; Payne and Frow 2005; Payne et al. 2008). The increasingly common business practice of cross-/up-selling in customer service clearly goes beyond that by uniting two intrafirm functions to enhance listening to customers, customization of value propositions, and value co-creation. This dissertation is a first attempt to understand CSRs' alignment of customer service and sales by providing 
insights into its antecedents, outcomes, and effectiveness.

\subsection{Directions for Future Research}

While we made specific suggestions for further research at the end of the previous two chapters, the integrated view on our findings, partially in relation to the relational literature in marketing, raises questions that point to important and interesting directions for future research.

This dissertation investigates personal ambidexterity and shows that employees' personal characteristics, such as their motivational orientations of locomotion and assessment facilitate their ambidextrous behavior. However, we also find that work environment characteristics can create motivational conditions that impair the functionality of these motivational orientations for ambidextrous behavior. Previous research on contextual ambidexterity suggests that a certain combination of organizational design elements (e.g., concurrent discipline, stretch, support, and trust) may enable and support employees to become ambidextrous (e.g., Gibson and Birkinshaw 2004). This inevitably raises the question as to how contextual ambidexterity and personal ambidexterity go together. Do the facilitators of contextual and personal ambidexterity enhance or detract from each others' effects? How should the organizational context be designed to foster personal ambidexterity?

Productivity-quality-revenue tensions are one of the challenges that CSRs face in their alignment of sales with service. Our studies provide some evidence for this tradeoff by revealing efficiency losses involved in the service-sales alignment. The marketing literature has paid some attention to the productivity-quality trade-off. So far, this research has mainly focused on whether a dual emphasis on improvements in quality through cost reduction and revenue expansion leads to better organizational performance than a single emphasis of either one (e.g., Anderson, Fornell, and Rust 1997; Mittal et al. 2005; Rust et al. 2002). Cost reduction is internally focused and centers on operational improvements that reduce costs and defects which in turn raise quality perceptions. Revenue expansion is externally focused toward customers and centers on product/service improvements which in turn drive market share and allow for cost reductions due to operational efficiencies based on increased scale. Although a dual emphasis has been shown to lead to superior long-term performance (Mittal et al. 2005), to date, the trade-off has not been resolved and we know little about how complementarity can be achieved. An exception is the study by Marinova et al. (2008) which proposes mechanisms (e.g., autonomy) through which the tensions are amplified and attenuated in business units. Ambidexterity research proposes structural solutions in addition to these contextual solutions. Future research may find it worthwhile to investigate how companies or organizational units can achieve a dual emphasis and which factors act as facilitators. Solutions to the productivity-quality trade-off would help to reduce the challenges ambidextrous CSRs currently face.

Because the requirements for ambidexterity extend to various organizational levels and areas, an advancement of our understanding of ambidexterity across multiple organizational levels and areas appears valuable. For example, this dissertation addresses 
CSRs' alignment of service and sales which are two tools for customer retention. Certainly, not all inbound calls lend themselves for relationship enhancement activities and there might be various customers who do not contact the inbound customer service center. To reach at least those customers, traditional (separated) outbound marketing for cross-/up-sell offers will still be needed. The result would be a combination of structural and personal ambidexterity. Recent research has shown that too much targeted relational communication for cross-/up-sell offers in one channel and across channels (e.g., mail, e-mail, phone) may risk customer annoyance and negative reactance (Godfrey et al. 2011). So far, however, these studies focus only on outbound communication. Resulting questions relate to the integration of these communication channels for inbound and outbound cross-/up-sell efforts and to what extent customers have different sensitivity thresholds regarding the volume of outbound versus inbound marketing. In addition to customer retention, companies must also engage in activities that foster customer acquisition. Research has shown that customer acquisition and retention involve conflicting demands, trade-offs, and compete for resources (e.g., Arnold et al. 2011; Voss and Voss 2008). At the same time, companies need to pursue both goals for long-term survival (e.g., HennigThurau et al. 2002). The relational literature in marketing also emphasizes the importance of better coordination and collaboration between diverse functions in companies, such as marketing and operations for enhanced value creation for customer-company relationships. Marketing and operations are separate functions in companies and the main 'drivers' of the productivity-quality trade-off. While operations focuses on process improvements to reduce costs and defects, marketing focuses on revenue expansion for the improvement of products/services (e.g., Rust et al. 2002). As mentioned before, both can also be complementary (Mittal et al. 2005). These observations raise many unanswered questions such as those pertaining to how ambidexterity is best achieved at each level and in each area of a company and why, how different forms of ambidexterity across levels and areas interact, and what kinds of coordination mechanisms are needed in order to achieve superior company performance.

In this final chapter, we faced several limitations in our assessment of the value that is co-created by the service-sales alignment for companies and customers. These limitations are due to not only the unavailability of data, but also the lack of appropriate performance measures. The relational literature in marketing points to the same issue (e.g., Boulding et al. 2005; Payne and Frow 2005). Most performance measures are functionally driven, such as sales performance for cross-/up-selling, and customer satisfaction, first call resolution, and call handling time for customer satisfaction. In addition, cost reductions through reduced call handling time, which allow for lower labor costs, tend to be easier to document compared to service quality improvements which generate, for example, customer satisfaction and positive word-of-mouth (Rust et al. 2002). In this regard, there are several questions that await answers. For example, what are appropriate performance measures of the service-sales alignment? To what extent are these appropriate for different organizational levels (i.e. CSR, call center, company)? Which time span should these measures comprise? What are the long-term consequences of a service-sales alignment?

Previous research on product/service recovery revealed a service recovery 
paradox in which customer satisfaction after recovery exceeds pre-failure levels (e.g., Hart, Heskett, and Sasser 1990; Smith and Bolton 1998). In chapter 3, we found that customer satisfaction with a recovery encounter which includes cross-sell efforts exceeds customer satisfaction with 'recovery-only' encounters. One may wonder whether this finding points to such a valuable service recovery paradox. Future research may want to address this question by measuring customer satisfaction with the company before the service/product failure as well as after recovery provision with cross-/up-sell efforts.

In this dissertation, we focus on the service-sales alignment in voice-to-voice encounters that are handled by inbound customer service call centers. However, today's call centers (or contact centers) are evolving into a major hub for handling customer contact by means of various other contact modes, such as e-mail, mail, and Internet chat via company websites and social media. These contact modes involve different communication characteristics (e.g., less non-verbal cues). Future research should explore whether, when, and how these contact modes can be effectively leveraged for relationship enhancement. Are there any differences in the service-sales alignment across these contact modes? Do customers' perceptions and reactions to the service-sales alignment differ, in particular because modes such as the Internet chat are relatively new for business contact and involve fewer associations with service and sales activities and stereotypes than more traditional ones such as the phone? Moreover, it is conceivable that the contact mode is another factor that impacts the effectiveness of CSRs' service-sales alignment. For example, customer service via e-mail involves two-way communication that is not real-time (compared to phone or chat). This contact mode therefore allows for less probing and exchange of verbal and non-verbal information that could help to make truly customized value propositions. Future research might want to investigate whether the effectiveness of CSRs' service-sales alignment differs across contact modes and the specific factors that drive such differences.

Finally, our studies highlight the important role of CSRs who eventually are the relationship partner for customers during service encounters. Their critical role as customer service providers has been highlighted extensively in the literature. The additional relationship enhancement responsibility through cross-/up-selling truly extends their impact on customer-company relationships. As Evans et al. (1999) note, successfully aligning service and sales requires CSRs to engage in diagnostic behavior and accurately infer customers' perception of the service experience. In addition, ambidextrous CSRs may also have a better understanding of when and why a new product/service is a better solution to the customer's problem or when it augments solution quality. They may therefore have both deep and diverse customer need knowledge and distinct abilities to sense customer needs and develop new solutions. That is, they may have an absorptive capacity that turns them into valuable innovators who could contribute to a company's new product/service development efforts. Investigating to what extent and how ambidextrous CSRs can contribute to companies' innovation efforts and success might be an interesting, relevant, and worthwhile avenue for future research. 


\subsection{Final Thought}

Current thinking in marketing has advanced the notion that companies can only make value propositions to customers because value is always co-created with them. An emphasis on value co-creation for mutually beneficial customer-company relationships, which are a cornerstone for company survival, requires companies to assess how and which value they can create with customers. Superior value co-creation can help companies to gain a sustainable competitive advantage. CSRs' service-sales alignment at the existing customer touch point promises to be a way to co-create superior value for mutually beneficial customer-company relationships. This dissertation attempts to contribute to the marketing literature by providing insights into antecedents, outcomes, and the effectiveness of the challenging endeavor of uniting two intrafirm functions for better listening to customers, customizing value propositions, and co-creating value. Our studies provide guidelines for companies, call centers, and CSRs who want and currently try to align cross-/up-selling with customer service provision. Overall, our findings imply that superior value can be co-created for customers and companies when CSRs excel in serving well by selling well. Notably, the opposite does work as well. 


\section{Appendix A}

\section{Chapter 2: Overview of Measures}

Customer Service Provision (New scale)

During conversation with customers, ...

- I usually try to calm complaining customers, so that we can jointly handle their complaints about their products.

- I usually provide solutions to customers' concerns related to the products they currently own.

- Having identified the customers' exact problem with their products, I solve it in a reliable way.

- I usually listen attentively to customers in order to take appropriate action to handle their concerns regarding their products.

- I usually pay attention to the customers' questions about their products to answer them correctly.

- Making sure that I fully understand the reason why the customers contact me allows me to better help them with their questions and concerns regarding their products.

\section{Cross-/Up-Selling (New scale)}

During conversation with customers, ...

- I usually explore potential matches between the customers' needs and the features of a product which they do not currently own.

- I usually gather as much customer information as possible to offer a suitable product to customers.

- I usually try to identify good ways of familiarizing customers with another product that can satisfy their needs.

- I usually ask questions to assess whether the customers would be willing to buy an additional product.

- I hardly neglect a good opportunity to advise customers of a product which they could benefit from.

- I usually offer an additional product which meets the customers' needs best.

Locomotion Orientation (Kruglanski et al. 2000)

\section{Parcel 1:}

- I feel excited just before I am about to reach a goal.

- By the time I accomplish a task, I already have the next one in mind.

- I am a "workaholic."

\section{Parcel 2:}

- When I decide to do something, I can't wait to get started.

- Most of the time my thoughts are occupied with the task I wish to accomplish.

- I enjoy actively doing things, more than just watching and observing.

Parcel 3:

- I I am a "doer".

- When I get started on something, I usually persevere until I finish it.

- I don't mind doing things even if they involve extra effort. 
Assessment Orientation (Kruglanski et al. 2000)

Parcel 1:

- I like evaluating other people's plans.

- I am a critical person.

- I often critique work done by myself or others.

Parcel 2:

- I often feel that I am being evaluated by others.

- When I meet a new person I usually evaluate how well he or she is doing on various dimensions (e.g., looks, achievements, social status, clothes).

- I spend a great deal of time taking inventory of my positive and negative characteristics.

Parcel 3:

- I am very self-critical and self-conscious about what I am saying.

- I often think that other people's choices and decisions are wrong.

- I often compare myself with other people.

Team Identification (Adapted from Mael and Ashforth (1992))

Parcel 1:

- My team's success is my success.

- When I talk about my team, I usually say "we" rather than "they".

- When someone praises my team, it feels like a personal compliment.

Parcel 2:

- I am very interested in what others think about my team.

- When someone criticizes my team, it feels like a personal insult.

Bounded Discretion (Kelley et al. 1996)

Parcel 1:

- I use routine procedures to complete my job tasks when possible.

- I consult my colleagues for ways to complete my job tasks when necessary.

- I consult organizational manuals for the right way to complete my job tasks when necessary.

Parcel 2:

- I try to develop a routine for each of the typical duties involved in my job.

- I decide how to perform my job duties based on training I have received.

Notes: $\quad$ All items were measured with 7-point Likert scales ranging from "strongly disagree" to "strongly agree". 


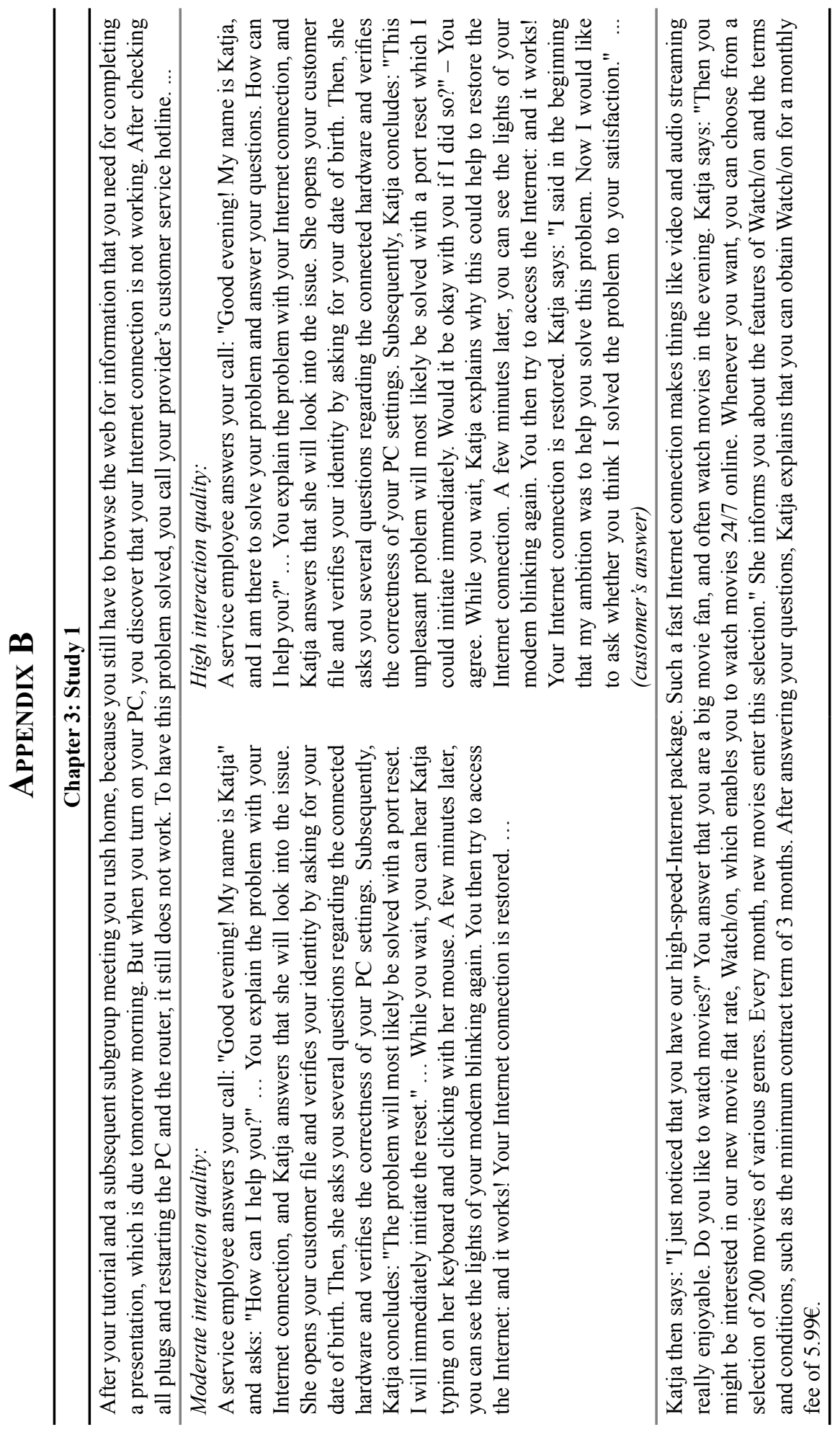




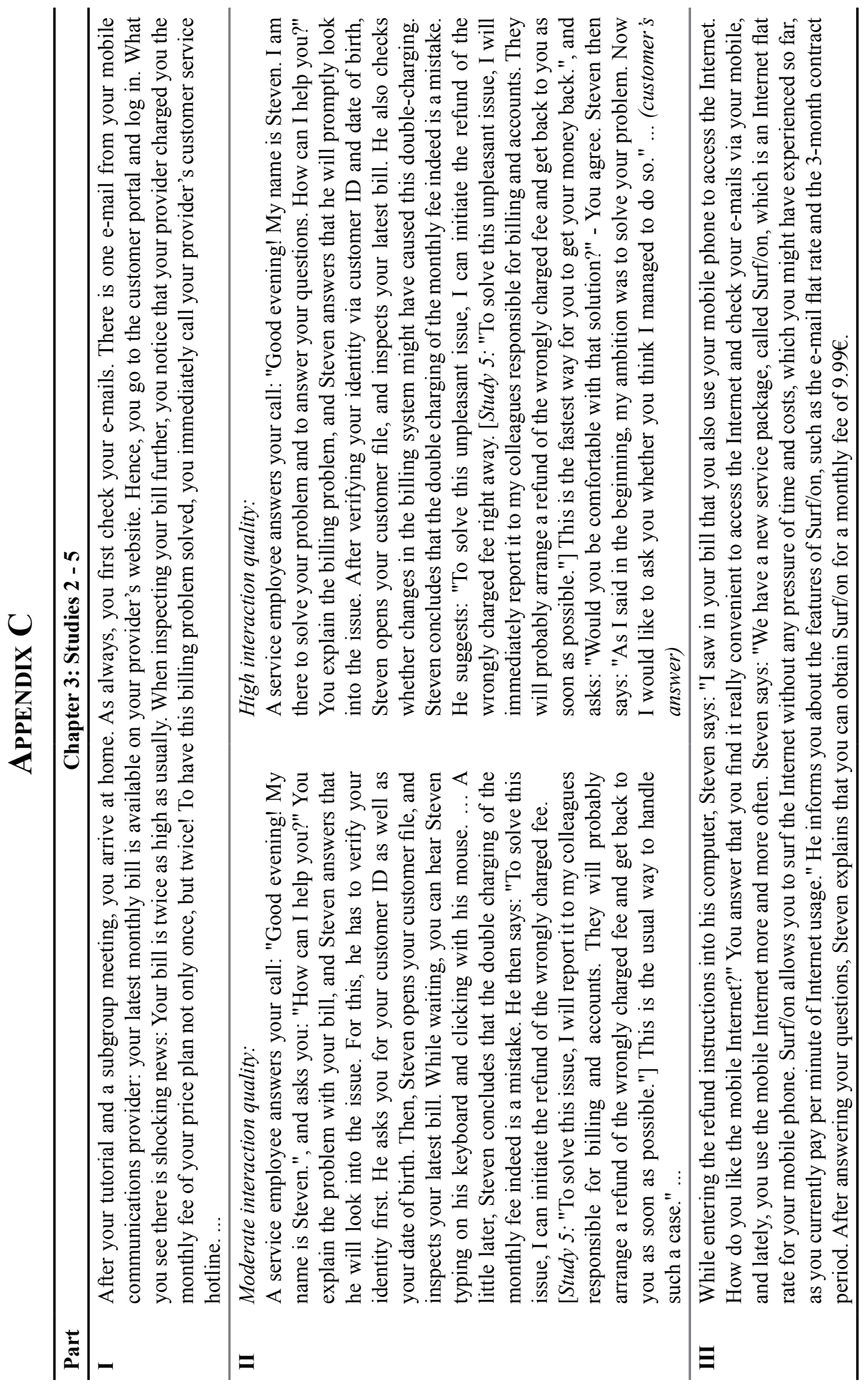




\section{REFERENCES}

\section{A}

Aaker, Jennifer, Susan Fournier, and S. Adam Brasel (2004), "When Good Brands Do Bad," Journal of Consumer Research, 31 (June), 1-16.

, Kathleen D. Vohs, and Cassie Mogilner (2010), "Nonprofits Are Seen as Warm and For-Profits as Competent: Firm Stereotypes Matter," Journal of Consumer Research, 37 (August), 224-37.

Adler, Paul S., Barbara Goldoftas, and David I. Levine (1999), "Flexibility versus Efficiency? A Case Study of Model Changeovers in the Toyota Production System," Organization Science, 10 (1), 43-68.

Aksin, O. Zeynep, Mor Armony, and Vijay Mehrotra (2007), "The Modern Call Center: A Multi-Disciplinary Perspective on Operations Management Research," Production and Operations Management, 16 (6), 665-88.

- and Patrick T. Harker (1999), "To Sell or Not to Sell: Determining the Trade-offs Between Service and Sales in Retail Banking Phone Centers," Journal of Service Research, 2 (1), 19-33.

Aksoy, Lerzan, Bruce Cooil, Christopher Groening, Timothy L. Keiningham, and Atakan Yalcin (2008), "The Long-Term Stock Market Valuation of Customer Satisfaction," Journal of Marketing, 72 (July), $105-22$.

Allport, G. W. (1954), The Nature of Prejudice. Reading, MA: Addison-Wesley.

Anderson, Elana and John Ragsdale (2004), "Why Marketing Should Own the Contact Center," Forrester Big Idea Report (April 9th, 2004), Forrester Research, Inc.

Anderson, Eugene W., Claes Fornell, and Roland T. Rust (1997), "Customer Satisfaction, Productivity, and Profitability: Differences Between Goods and Services," Marketing Science, 16 (2), 129-45.

Arnold, Todd J., Eric Fang, and Robert W. Palmatier (2011), "The Effects of Customer Acquisition and Retention Orientations on a Firm's Radical and Incremental Innovation Performance," Journal of the Academy of Marketing Science, 39 (2), 234-51.

Ashforth, Blake E., Spencer H. Harrison, and Kevin G. Corley (2008), "Identification in Organizations: An Examination of Four Fundamental Questions," Journal of Management, 34 (3), 325-74.

_ and Fred Mael (1989), "Social Identity Theory and the Organization," Academy of Management Review, 14 (1), 20-39.

Avnet, Tamar and E. Tory Higgins (2003), "Locomotion, Assessment, and Regulatory Fit: Value Transfer from "How" to "What"," Journal of Experimental Social Psychology, 39 (5), 525-30.

B

Babin, Barry J., James S. Boles, and William R. Darden (1995), "Salesperson Stereotypes, Consumer Emotions, and Their Impact on Information Processing," Journal of the Academy of Marketing Science, 23 (2), 94-105.

Bagozzi, Richard P. and Jeffrey R. Edwards (1998), "A General Approach for Representing Constructs in Organization Research," Organizational Research Methods, 1 (1), 45-87.

and Todd F. Heatherton (1994), "A General Approach to Representing Multifaceted Personality Constructs: Application to State Self-Esteem," Structural Equation Modeling, 1 (1), 35-67.

- and Youjae Yi (1988), "On the Evaluation of Structural Equation Models," Journal of the Academy of Marketing Science, 16 (1), 74-97.

Bain, Peter, Aileen Watson, Gareth Mulvey, Phil Taylor, and Gregor Gall (2002), "Taylorism, Targets, and the Pursuit of Quantity and Quality by Call Center Management," New Technology, Work and Employment, 17 (3), 170-85.

Balcetis, Emily and David Dunning (2006), "See What You Want to See: Motivational Influences on Visual Perception," Journal of Personality and Social Psychology, 91 (4), 612-625.

Barden, Jamie and Richard E. Petty (2008), "The Mere Perception of Elaboration Creates Attitude Certainty: Exploring the Thoughtfulness Heuristic," Journal of Personality and Social Psychology, 95 (3), 489-509.

Bargh, John A. (1989), "Conditional Automaticity: Varieties of Automatic Influence in Social Perception and 
Cognition," in Unintended Thought, J. S. Uleman and J. A. Bargh, eds. New York, The Guilford Press. $3-51$.

, M. Chen, and L. Burrows (1996), "Automaticity of Social Behavior: Direct Effects of Trait Construct and Stereotype Activation on Action," Journal of Personality and Social Psychology, 71, 230-44.

- Peter M. Gollwitzer, A. Lee-Chai, K. Barndollar, and R. Trötschel (2001), "The Automated Will:

Nonconscious Activation and Pursuit of Behavioral Goals," Journal of Personality and Social Psychology, 81 (6), 1014-27.

-, Michelle Green, and Gráinne Fitzsimons (2008), "The Selfish Goal: Unintended Consequences of Intended Goal Pursuits," Social Cognition, 26 (5), 534-54.

Bassili, John N. and Marilyn C. Smith (1986), "On the Spontaneity of Trait Attribution: Converging Evidence for the Role of Cognitive Strategy," Journal of Personality and Social Psychology, 50 (2), 239-45.

Baumeister, Roy F. and Kathleen D. Vohs (2007), "Self-Regulation, Ego Depletion, and Motivation," Social and Personality Psychology Compass, 1 (1), 115-28.

Beaujean, Marc, Jonathan Davidson, and Stacey Madge (2006), "The 'Moment of Truth' in Customer Service," The McKinsey Quarterly, 1, 62-73.

Berry, Leonard L. (1995), "Relationship Marketing of Services Growing Interest, Emerging Perspectives," Journal of the Academy of Marketing Science, 23 (Fall), 236-45.

Bitner, Mary Jo, Bernard H. Booms, and Lois A. Mohr (1994), "Critical Service Encounters: The Employee's Viewpoint," Journal of Marketing, 58 (October), 95-106.

$\ldots$, , and Mary Stanfield Tetreault (1990), "The Service Encounter: Diagnosing Favorable and Unfavorable Incidents," Journal of Marketing, 54 (January), 71-84.

- Stephen W. Brown, and Matthew L. Meuter (2000), "Technology Infusion in Service Encounters," Journal of the Academy of Marketing Science, 28 (1), 138-49.

Blodgett, Jeffrey G., Donna J. Hill, and Stephen S. Tax (1997), "The Effects of Distributive, Procedural, and Interactional Justice on Postcomplaint Behavior," Journal of Retailing, 73 (2), 185-210. and Stephen S. Tax (1993), "The Effects of Distributive and Interactional Justice on Complainants' Repatronage Intentions and Negative Word-of-Mouth Intentions," Journal of Consumer Satisfaction, Dissatisfaction and Complaining Behavior, 6, 100-10.

Bodenhausen, Galen V. and C. Neil Macrae (1998), "Stereotype Activation and Inhibition," in Stereotype Activation and Inhibition: Advances in Social Cognition, R. S. J. Wyer, ed. Mahwah, NJ, Lawrence Erlbaum Associates Inc., 1-52. and Destiny Peery (2009), "Social Categorization and Stereotyping In vivo: The VUCA Challenge," Social and Personality Psychology Compass, 3, 133-51.

Bodine, Kerry (2011), "Reinvent your Call Center Culture to Create Amazing Customer Experiences," Forrester For Customer Experience Professionals Report (February 23rd, 2011), Forrester Research, Inc.

Bolton, Ruth N. (1998), "A Dynamic Model of the Duration of the Customer's Relationship with a Continuous Service Provider: The Role of Satisfaction," Marketing Science, 17 (1), 45-65.

—_, Dhruv Grewal, and Michael Levy (2007), "Six Strategies for Competing through Service: An Agenda for Future Research," Journal of Retailing, 83 (1), 1-4.

Boon, Susan D. and John G. Holmes (1999), "Interpersonal Risk and the Evaluation of Transgressions in Close Relationships," Personal Relationships, 6 (2), 151-68.

Boulding, William, Richard Staelin, Michael Ehret, and Wesley J. Johnston (2005), "A Customer Relationship Management Roadmap: What Is Known, Potential Pitfalls, and Where to Go," Journal of Marketing, 69 (October), 155-66.

Brady, Michael K. and Joseph JR Cronin (2001), "Some New Thoughts on Conceptualizing Perceived Service Quality: A Hierarchical Approach," Journal of Marketing, 65 (July), 34-49.

C

Campbell, Margaret C. and Amna Kirmani (2000), "Consumers' Use of Persuasion Knowledge: The Effects of Accessibility and Cognitive Capacity on Perceptions of an Influence Agent," Journal of Consumer 
Research, 27 (June), 69-83.

Cao, Qing, Eric Gedajlovic, and Hongping Zhang (2009), "Unpacking Organizational Ambidexterity: Dimensions, Contingencies, and Synergistic Effects," Organization Science, 20 (4), 781-96.

Carver, Charles S. and Michael F. Scheier (2010), "Self-Regulation of Action and Affect," in Handbook of Self-Regulation, Second Edition: Research, Theory, and Applications, K. D. Vohs and R. F. Baumeister, eds. New York, The Guilford Press, 3-21.

CFI Group (2010), "Contact Center Satisfaction Index 2010," Claes Fornell International (accessed: June $1^{\text {st }}$, 2011), available at: www.cfigroup.com.

Chaiken, Shelly, Roger Giner-Sorolla, and Serena Chen (1996), "Beyond Accuracy: Defense and Impression Motives in Heuristic and Systematic Information Processing," in The Psychology of Action: Linking Cognition and Motivation to Behavior, P. M. Gollwitzer and J. A. Bargh, eds. New York, Guilford Press, 553-78.

Christopher, Martin, Adrian F. Payne, and David Ballantyne (1991), Relationship Marketing: Bringing Quality, Customer Service and Marketing Together. Oxford: Butterworth-Heinemann.

Clark, Jason K., Duane T. Wegener, Pablo Brinol, and Richard E. Petty (2009), "Discovering that the Shoe Fits: The Self-Validating Role of Stereotypes," Psychological Science, 20 (7), 846-52.

Coffman, Donna L. and Robert C. MacCallum (2005), "Using Parcels to Convert Path Analysis Models Into Latent Variable Models," Multivariate Behavioral Research, 40 (2), 235-59.

CSO Insights (2007), "Sales Performance Report 2007: Call Center Marketing \& Sales Optimization Study," Jim Dicky and Berry Trailer, eds., Boulder (CO), CSO Insights.

Cuddy, Amy J. C., Susan T. Fiske, and Peter Glick (2004), "When Professionals Become Mothers, Warmth Doesn't Cut the Ice," Journal of Social Issues, 60 (4), 701-18.

$[$ _ $—$, and (2008), "Warmth and Competence as Universal Dimensions of Social Perception: The Stereotype Content Model and the BIAS Map," Advances in Experimental Social Psychology, 40 (March), 61-149.

Czepiel, John A. (1990), "Service Encounters and Service Relationships: Implications for Research," Journal of Business Research, 20 (1), 13-21.

\section{D}

Darke, Peter R., Laurence Ashworth, and Kelley J. Main (2010), "Great Expectations and Broken Promises: Misleading Claims, Product Failure, Expectancy Disconfirmation and Consumer Distrust," Journal of the Academy of Marketing Science, 38, 347-62.

- and Robin J. B. Ritchie (2007), "The Defensive Consumer: Advertising Deception, Defensive Processing, and Distrust," Journal of Marketing Research, 44 (February), 114-27.

Davidow, Moshe (2003), "Organizational Responses to Customer Complaints: What Works and What Doesn't," Journal of Service Research, 5 (3), 225-50.

DeCarlo, Thomas E. (2005), "The Effects of Sales Message and Suspicion of Ulterior Motives on Salesperson Evaluation," Journal of Consumer Psychology, 15 (3), 238-49.

Deery, Stephen, Roderick Iverson, and Janet Walsh (2002), "Work Relationships in Telephone Call Centres: Understanding Emotional Exhaustion and Employee Withdrawal," Journal of Management Studies, 39 (4), 471-96.

Devine, Patricia G. (1989), "Stereotypes and Prejudice: Their Automatic and Controlled Components," Journal of Personality and Social Psychology, 56 (1), 5-18.

DeWitt, Tom, Doan T. Nguyen, and Roger Marshall (2008), "Exploring Customer Loyalty Following Service Recovery: The Mediating Effects of Trust and Emotions," Journal of Service Research, 10 (3), 269-81.

Dijksterhuis, Ap and Ad van Knippenberg (1995), "Memory for Stereotype-Consistent and StereotypeInconsistent Information as a Function of Processing Pace," European Journal of Social Psychology, 25, 689-93.

Domanski, Jim (2002), Add-On Selling: How to Squeeze Every Last Ounce of Sales Potential From Your Calls, Omaha: NE: Business by Phone Inc.

Dutton, Jane E., Janet M. Dukerich, and Celia V. Harquail (1994), "Organizational Images and Member 
Identification," Administrative Science Quarterly, 39 (2), 239-63.

Dweck, Carol S., Chi-Yue Chiu, and Ying-Yi Hong (1995), "Implicit Theories and Their Role in Judgments and Reactions: A World from two Perspectives," Psychological Inquiry, 6 (4), 267-85.

Dwyer, Robert F., Paul H. Schurr, and Sejo Oh (1987), "Developing Buyer-Seller Relationships," Journal of

$\mathbf{E}$ Marketing, 51 (April), 11-27.

Edwards, Jeffrey R. (1994), "The Study of Congruence in Organizational Behavior Research: Critique and a Proposed Alternative," Organizational Behavior and Human Decision Processes, 58 (1), 51-100.

Eichfeld, Andy, Timothy D. Morse, and Katherine W. Scott (2006), "Using Call Centers to Boost Revenue," The McKinsey Quarterly, May.

Evans, Kenneth R., Todd J. Arnold, and John A. Grant (1999), "Combining Service and Sales at the Point of Customer Contact - A Retail Banking Example," Journal of Service Research, 2 (1), 34-49.

F

Fazio, Russell H. (1990), "A Practical Guide to the Use of Response Latencies in Social Psychological Research," in Review of Personality and Social Psychology, C. Hendrick and M. S. Clark, eds. Newbury Park, CA, Sage, 74-97.

Fishbach, Ayelet and Melissa J. Ferguson (2007), "The Goal Construct in Social Psychology," in Social Psychology: Handbook of Basic Principles, A. W. Kruglanski and E. T. Higgins, eds. New York, Guilford Press.

Fiske, Susan T., Amy J. C. Cuddy, and Peter Glick (2002), "A Model of (Often Mixed) Stereotype Content: Competence and Warmth Respectively Follow From Perceived Status and Competition," Journal of Personality and Social Psychology, 82 (6), 878-902.

— - , and (2007), "Universal Dimensions of Social Cognition: Warmth and Competence," Trends in Cognitive Science, 11 (February), 77-83.

-, Monica Lin, and Steven L. Neuberg (1999), "The Continuum Model: Ten Years Later," in Dual Process Theories in Social Psychology, S. Chaiken and Y. Trope, eds. New York, Guilford, 231-54. - and Steven L. Neuberg (1990), "A Continuum of Impression Formation, from Category-Based to Individuating Processes: Influences of Information and Motivation on Attention and Interpretation," in Advances in Experimental Social Psychology, M. P. Zanna, eds. New York, NY, Academic Press Inc., $1-72$.

Fitzsimons, Gráinne and John A. Bargh (2004), "Automatic Self-Regulation," in Handbook of SelfRegulation: Research, Theory, and Applications, R. F. Baumeister and K. D. Vohs, eds. New York, The Guilford Press.

Folkes, Valerie S. and Vanessa M. Patrick (2003), "The Positivity Effect in Perceptions of Services: Seen One, Seen Them All?," Journal of Consumer Research, 30 (June), 125-37.

Fornell, Claes and David F. Larcker (1981), "Evaluating Structural Equation Models with Unobservable Variables and Measurement Error," Journal of Marketing Research, 18 (1), 39-50.

Förster, Jens, Nira Liberman, and E. Tory Higgins (2005), "Accessibility from Active and Fulfilled Goals," Journal of Experimental Social Psychology, 41, 220-39.

FORUM (2004), "Research Brief: How Customers View Cross-Selling - It's All about Service," The Forum Corporation (accessed: June 12 $2^{\text {th }}, 2011$ ), available at: http://www.forum.com/intelligence/research-tools. aspx.

Frankland, Dave (2008), "Defining an Enterprisewide Customer Contact Strategy," Forrester For Direct Marketing Professionals Report (October 22 $\left.2^{\text {nd }}, 2008\right)$, Forrester Research, Inc.

Frenkel, Stephen, May Tam, Marek Korczynski, and Karen Shire (1998), "Beyond Bureaucracy? Work Organization in Call Centres," The International Journal of Human Resource Management, 9 (6), 957-79.

Friestad, Marian and Peter Wright (1994), "The Persuasion Knowledge Model: How People Cope with Persuasion Attempts," Journal of Consumer Research, 21 (June), 1-31. 


\section{G}

Gibson, Christina and Julian Birkinshaw (2004), "The Antecedents, Consequences, and Mediating Role of Organizational Ambidexterity," Academy of Management Journal, 47 (April), 209-26.

— and (2001), "Contextual Determinants of Organizational Ambidexterity," Working Paper, Los Angeles, Center for Effective Organizations, Marshall School of Business, University of Southern California.

Gilbert, Daniel T., W. Pelham Brett, and S. Krull Douglas (1988), "On Cognitive Busyness: When Person Perceivers Meet Persons Perceived," Journal of Personality and Social Psychology, 54 (5), 733-40. - and J. Gregory Hixon (1991), "The Trouble of Thinking: Activation and Application of Stereotypic Beliefs," Journal of Personality and Social Psychology, 60 (4), 509-17.

Glick, Peter, Korin Wilk, and Michele Perreault (1995), "Images of Occupations: Components of Gender and Status in Occupational Stereotypes," Sex Roles, 32 (9/10), 565-82.

Godfrey, Andrea, Kathleen Seiders, and Glenn B. Voss (2011), "Enough is Enough! The Fine Line in Executing Multichannel Relational Communication," Journal of Marketing, 75 (July), 94-109.

Gollwitzer, Peter M. and Gordon B. Moskowitz (1996), "Goal Effects on Action and Cognition," in Social Psychology: Handbook of Basic Principles, E. T. Higgins and A. W. Kruglanski, eds. New York, Guilford Press, 361-99.

Grandey, Alicia A., Glenda M. Fisk, Anna A. Mattila, Karen J. Jansen, and Lori A. Sideman (2005), "Is 'Service With a Smile' Enough? Authenticity of Positive Displays During Service Encounters," Organizational Behavior and Human Decision Processes, 96 (January), 38-55.

Günes, Evrim D., O. Zeynep Aksin, E. Lerzan Örmeci, and S. Hazal Özden (2010), "Modeling Customer Reactions to Sales Attempts: If Cross-Selling Backfires," Journal of Service Research, 13 (2), 168-83.

Gupta, Anil K., Ken G. Smith, and Christina E. Shalley (2006), "The Interplay Between Exploration and Exploitation," Academy of Management Journal, 49 (4), 693-706.

, Paul E. Tesluk, and M. Susan Taylor (2007), "Innovation At and Across Multiple Levels of Analysis," Organization Science, 18 (6), 885-97.

Gustafsson, Anders, Michael D. Johnson, and Inger Roos (2005), "The Effects of Customer Satisfaction, Relationship Commitment Dimensions, and Triggers on Customer Retention," Journal of Marketing, 69 (October), 210-18.

Gutek, Barbara, Anita D. Bhappu, Matthew A. Liao-Troth, and Bennett Cherry (1999), "Distinguishing between Service Relationships and Encounters," Journal of Applied Psychology, 84 (2), 218-33.

Gwinner, Kevin P., Mary Jo Bitner, Stephen W. Brown, and Ajith Kumar (2005), "Service Customization through Employee Adaptiveness," Journal of Service Research, 8 (2), 131-48.

— Dwayne D. Gremler, and Mary Jo Bitner (1998), "Relational Benefits in Services Industries: The Customer's Perspective," Journal of the Academy of Marketing Science, 26 (Spring), 101-14.

H

Hansler, Jeffrey (2009), "Difference Between Customer Service and Sales," (accessed: June 1 1 , 2011), available at: http://powerpersuasion-jkh.blogspot.com/2009/02/difference-between-customer-serviceand.html.

Hart, Christopher W. L., James L. Heskett, and W. Earl Jr. Sasser (1990), "The Profitable Art of Service Recovery," Harvard Business Review, 68 (July), 148-56.

Harter, James K., Frank L. Schmidt, and Theodore L. Hayes (2002), "Business-Unit-Level Relationship Between Employee Satisfaction, Employee Engagement, and Business Outcomes: A Meta-Analysis," Journal of Applied Psychology, 87 (2), 268-79.

Hartman, Katherine B. (2006), "Television and Movie Representations of Salespeople: Beyond Willy Loman," Journal of Personal Selling and Sales Management, 26 (3), 283-92.

Hash, Susan (2010), "Adding Sales to Your Service Culture," Contact Center Pipeline, May 2010, Pipeline Publishing Group, Inc.

Haslam, Alexander S., Clair Powell, and John C. Turner (2000), "Social Identity, Self-Categorization and Work Motivation: Rethinking the Contribution of the Group to Positive and Sustainable Organizational 
Outcomes," Applied Psychology: An International Review, 49 (3), 319-39.

$\mathrm{He}, \mathrm{Zi}$-Lin and Poh-Kam Wong (2004), "Exploration vs. Exploitation: An Empirical Test of the Ambidexterity Hypothesis," Organization Science, 15 (4), 481-94.

Hennig-Thurau, Thorsten, Markus Groth, Michael Paul, and Dwayne D. Gremler (2006), "Are All Smiles Created Equal? How Emotional Contagion and Emotional Labor Affect Service Relationships," Journal of Marketing, 70 (July), 58-73.

, Kevin P. Gwinner, and Dwayne D. Gremler (2002), "Understanding Relationship Marketing Outcomes: An Integration of Relational Benefits and Relationship Quality," Journal of Service Research, 4 (3), 230-47.

Heskett, James L., Thomas O. Jones, Gary W. Loveman, Earl W. Jr. Sasser, and Leonard A. Schlesinger (1994), "Putting the Service-Profit Chain to Work," Harvard Business Review, 82 (March-April), 164-74.

Hess, Ronald L. Jr., Shankar Ganesan, and Noreen M. Klein (2007), "Interactional Service Failures in a Pseudorelationship: The Role of Organizational Attributions," Journal of Retailing, 83 (1), 79-95.

Higgins, E. Tory, Arie W. Kruglanski, and Antonio Pierro (2003), "Regulatory mode: Locomotion and assessment as distinct orientations," in Advances in Experimental Social Psychology, M. P. Zanna, eds. New York, Academic Press.

Hilton, James L. and William von Hippel (1996), "Stereotypes," Annual Review of Psychology, 47 (February), $237-71$.

I

ICMI (2007), "Call Center Management Review: 2007 Call Center Cross-Selling Survey Report," International Customer Management Institute, CMP Media.

J

Jarvenpaa, Sirkka L., Kathleen Knoll, and Dorothy E. Leidner (1998), "Is Anybody Out There? Antecedents of Trust in Global Virtual Teams," Journal of Management Information Systems, 14 (4), 29-64.

Judd, Charles M., Laurie James-Hawkins, Vincent Yzerbyt, and Yoshihisa Kashima (2005), "Fundamental Dimensions of Social Judgment: Understanding the Relations between Judgments of Competence and Warmth," Journal of Personality and Social Psychology, 89 (6), 899-913.

Jussim, Lee (2005), "Accuracy: Criticisms, Controversies, Criteria, Components, and Cognitive Processes," in Advances in Experimental Social Psychology, M. P. Zanna, eds. New York, Academic Press, 1-93.

K

Kamakura, Wagner A., M. Wedel, F. de Rossa, and J. A. Mazzon (2003), "Cross-Selling through Database Marketing: A Mixed Data Factor Analyzer for Data Augmentation and Prediction," International Journal of Research in Marketing, 20 (1), 45-65.

-, Sridhar N. Ramaswami, and Rajendra K. Srivastava (1991), "Applying Latent Trait Analysis in the Evaluation of Prospects for Cross-Selling of Financial Services," International Journal of Research in Marketing, 8 (4), 329-49.

Kelley, Scott (1993), "Discretion and the Service Employee," Journal of Retailing, 69 (1), 104-26.

—, T. Longfellow, and J. Malehorn (1996), "Organizational Determinants of Service Employees' Exercise of Routine, Creative, and Deviant Discretion," Journal of Retailing, 72 (2), 135-57.

Klein, Andreas and Helfried Moosbrugger (2000), "Maximum Likelihood Estimation of Latent Interaction Effects with the LMS Method," Psychometrika, 65 (4), 457-74.

Kramer, Roderick M. (1999), "Trust and Distrust in Organizations: Emerging Perspectives, Enduring Questions," Annual Review of Psychology, 50, 569-98.

Kristof-Brown, Amy L., Ryan D. Zimmerman, and Erin C. Johnson (2005), "Consequences of Individuals' Fit at Work: A Meta-Analysis of Person-Job, Person-Organization, Person-Group, and Person-Supervisor Fit," Personnel Psychology, 58 (2), 281-342.

Kruglanski, Arie W., Edward Orehek, E. Tory Higgins, Antonio Pierro, and Idit Shalev (2010), "Modes of Self-Regulation: Assessment and Locomotion as Independent Determinants in Goal Pursuit," in Handbook of Personality and Self-Regulation, R. H. Hoyle, eds. Malden, Blackwell-Wiley, 375-402. 
-, Antonio Pierro, Tory E. Higgins, and Dora Capozza (2007), "'One the Move' or 'Staying Put': Locomotion, Need for Closure, and Reactions to Organizational Change," Journal of Applied Social Psychology, 37 (6), 1305-40.

, Erik P. Thompson, Tory E. Higgins, M. Nadir Atash, Antonio Pierro, James Y. Shah, and Scott Spiegel (2000), "To 'Do the Right Thing' or to 'Just Do It': Locomotion and Assessment as Distinct SelfRegulatory Imperatives," Journal of Personality and Social Psychology, 79 (5), 793-815.

Kulik, Carol T., Loriann Roberson, and Elissa L. Perry (2007), "The Multiple-Category Problem: Category Activation and Inhibition In The Hiring Process," Academy of Management Review, 32 (2), 529-48.

Kunda, Ziva, Paul G. Davies, Barbara D. Adams, and Steven J. Spencer (2002), "The Dynamic Time Course of Stereotype Activation: Activation, Dissipation, and Resurrection," Journal of Personality and Social Psychology, 82 (3), 283-99.

and Steven J. Spencer (2003), "When Do Stereotypes Come to Mind and When Do They Color Judgment? A Goal-Based Theoretical Framework for Stereotype Activation and Application," Psychological Bulletin, 129 (4), 522-44.

Kurt, Didem, J. Jeffrey Inman, and Jennifer J. Argo (2011), "The Influence of Friends on Consumer Spending: The Role of Agency-Communion Orientation and Self-Monitoring," Journal of Marketing Research, 48 (4), 741-54.

L

Lang, Peter J., Margaret M. Bradley, and Bruce N. Cuthbert (1997), "Motivated Attention: Affect, Activation, and Action," in Attention and Orienting, P. J. Lang, R. F. Simons and M. T. Balaban, eds. Mahwah New Jersey, Lawrence Erlbaum Associates, 95-135.

Lee, Nick, Anna Sandfield, and Baljit Dhaliwal (2007), "An Empirical Study of Salesperson Stereotypes amongst UK Students and their Implications for Recruitment," Journal of Marketing Management, 23 (7-8), 723-44.

Levinthal, D. A. and James G. March (1993), "The Myopia of Learning," Strategic Management Journal, 14 (Winter), 95-112.

Liao, Hui (2007), "Do It Right This Time: The Role of Employee Service Recovery Performance in CustomerPerceived Justice and Customer Loyalty after Service Failures," Journal of Applied Psychology, 92 (2), 475-89.

Lusch, Robert F., Stephen L. Vargo, and Matthew O'Brian (2007), "Competing Through Service: Insights from the Service-Dominant Logic," Journal of Retailing, 83 (1), 5-18.

\section{M}

Ma, Zhenfeng and Laurette Dubé (2011), "Process and Outcome Interdependency in Frontline Service Encounters," Journal of Marketing, 75 (May), 83-98.

Macrae, C. Neil and Galen V. Bodenhausen (2000), "Social Cognition: Thinking Categorically about Others," Annual Review of Psychology, 41, 93-120.

— - , and Alan B. Milne (1995), "The Dissection of Selection in Person Perception: Inhibitory Processes in Social Stereotyping," Journal of Personality and Social Psychology, 69 (3), 397-407.

— - Astrid M. Schloerscheidt, and Alan B. Milne (1999), "Tales of the Unexpected: Executive Function and Person Perception," Journal of Personality and Social Psychology, 76 (2), 200-13.

Mael, Fred and Blake E. Ashforth (1992), "Alumni and Their Alma Mater: A Partial Test of the Reformulated Model of Organizational Identification," Journal of Organizational Behavior, 13 (2), 103-23.

Main, Kelley J., Darren W. Dahl, and Peter R. Darke (2007), "Deliberative and Automatic Bases of Suspicion: Empirical Evidence of the Sinister Attribution Error," Journal of Consumer Psychology, 17 (1), 59-69.

March, James G. (1991), "Exploration and Exploitation in Organizational Learning," Organization Science, 2 (1), 71-87.

and Herbert A. Simon (1958), Organizations. New York: John Wiley \& Sons.

Marinova, Detelina, Jun Ye, and Jagdip Singh (2008), "Do Frontline Mechanisms Matter? Impact of Quality and Productivity Orientations on Unit Revenue, Efficiency, and Customer Satisfaction," Journal of Marketing, 72 (March), 28-45. 
Markides, Costas (2007), "In Search of Ambidextrous Professors," Academy of Management Journal, 50 (4), $762-68$

Matos, Celso A. de, Jorge L. Henrique, and Carlos A. V. Rossi (2007), "Service Recovery Paradox: A MetaAnalysis," Journal of Service Research, 10 (1), 60-77.

Matta, Shashi and Valerie S. Folkes (2005), "Inferences about the Brand from Counterstereotypical Service Providers," Journal of Consumer Research, 32 (September), 196-206.

Mayer, Roger C., James H. Davis, and F. David Schoorman (1995), "An Integrative Model of Organizational Trust," Academy of Management Review, 20 (3), 709-34.

McCallum, Richard J. and Wayne Harrison (1985), "Interdependence in the Service Encounter," in The Service Encounter: Managing Employee/Customer Interaction in Services Businesses, J. A. Czepiel, M. R. Solomon, and C. F. Surprenant, eds. Lexington, MA, Lexington Books, 35-48.

McGarty, Craig, Vincent Yzerbyt, and Russell Spears (2002), "Social, Cultural and Cognitive Factors in Stereotype Formation," in Stereotypes as Explanations, C. McGarty, V. Yzerbyt, and R. Spears, eds. Cambridge, Cambridge University Press.

Minnucci, Jay (2009), "Sales as a Service," Contact Center Pipeline, November, Pipeline Publishing Group, Inc.: Annapolis, MD.

Mittal, Vikas, Eugene W. Anderson, Akin Sayrak, and Pandu Tadikamalla (2005), "Dual Emphasis and the Long-Term Financial Impact of Customer Satisfaction," Marketing Science, 24 (4), 544-55.

Mohr, Lois A. and Mary Jo Bitner (1995), "The Role of Employee Effort in Satisfaction with Service Transactions," Journal of Business Research, 32 (3), 239-52.

Mom, Tom J. M., Frans A. J. van den Bosch, and Henk W. Volberda (2009), "Understanding Variation in Managers' Ambidexterity: Investigating Direct and Interaction Effects of Formal Structural and Personal Coordination Mechanisms," Organization Science, 20 (4), 812-28.

Murray, Sandra L., John G. Holmes, and Dale W. Griffin (2000), "Self-Esteem and the Quest for Felt Security: How Perceived Regard Regulates Attachment Processes," Journal of Personality and Social Psychology, 78 (3), 478-98.

Muthén, Linda K. and Bengt O. Muthén (1998-2009), Mplus User's Guide. Fifth Edition. Los Angeles, C.A.: Muthén \& Muthén.

$\mathbf{N}$

Netemeyer, Richard G., William O. Bearden, and Subhash Sharma (2003), Scaling Procedures: Issues and Applications, Thousand Oaks: Sage Publications.

$\mathbf{P}$

Palmatier, Robert W., Rajiv P. Dant, Dhruv Grewal, and Kenneth R. Evans (2006), "Factors Influencing the Effectiveness of Relationship Marketing: A Meta-Analysis," Journal of Marketing, 70 (October), $136-53$.

Parasuraman, A., Valarie A. Zeithaml, and Leonard L. Berry (1988), "SERVQUAL: A Multiple-Item Scale for Measuring Consumer Perceptions of Service Quality," Journal of Retailing, 64 (1), 12-40.

Parvatiyar, Atul and Jagdish N. Sheth (2001), "Customer Relationship Management: Emerging Practice, Process, and Discipline," Journal of Economic and Social Research, 3 (2), 1-34.

Payne, Adrian F. and Pennie Frow (2005), "A Strategic Framework for Customer Relationship Management," Journal of Marketing, 69 (October), 167-76.

— Kaj Storbacka, and Pennie Frow (2008), "Managing the Co-Creation of Value," Journal of the Academy of Marketing Science, 36 (1), 83-96.

Periatt, Jeffrey A., Stephen A. LeMay, and Subhra Chakrabarty (2004), "The Selling Orientation-Customer Orientation (SOCO) Scale: Cross-Validation of the Revised Version," Journal of Personal Selling and Sales Management, 24 (1), 49-54.

Petty, Richard E. and John T. Cacioppo (1986), Communication and Persuasion: Central and Peripheral Routes to Attitude Change. New York: Springer-Verlag.

Pierro, Antonio, Arie W. Kruglanski, and E. Tory Higgins (2006), "Regulatory Mode and the Joys of Doing: Effects of 'Locomotion' and 'Assessment' on Intrinsic and Extrinsic Task-Motivation," European 
Journal of Personality, 20, 355-75.

-, Susanne Leder, Lucia Mannetti, E. Tory Higgins, Arie W. Kruglanski, and Antonio Aiello (2008),

"Regulatory Mode Effects on Counterfactual Thinking and Regret," Journal of Experimental Social Psychology, 44, 321-29.

Plaks, Jason E., Carol S. Dweck, Steven J. Stroessner, and Jeffrey W. Sherman (2001), "Person Theories and Attention Allocation: Preferences for Stereotypic Versus Counterstereotypic Information," Journal of Personality and Social Psychology, 80 (6), 876-93.

Plouffe, Christopher R., John Hulland, and Trent Wachner (2009), "Customer-Directed Selling Behaviors and Performance: A Comparison of Existing Perspectives," Journal of the Academy of Marketing Science, 37 (4), 422-39.

Podsakoff, Philip M., Scott B. MacKenzie, and Nathan P. Podsakoff (2003), "Common Method Biases in Behavioral Research: A Critical Review of the Literature and Recommended Remedies," Journal of Applied Psychology, 88 (5), 879-903.

Preacher, Kristopher J. and Andrew F. Hayes (2008), "Asymptotic and Resampling Strategies for Assessing and Comparing Indirect Effects in Multiple Mediator Models," Behavior Research Methods, 40 (3), 879-91.

Price, Linda L., Eric J. Arnould, and Patrick Tierney (1995), "Going to Extremes: Managing Service $\underline{R}$ Encounters and Assessing Provider Performance," Journal of Marketing, 59 (April), 83-97.

Raisch, Sebastian and Julian Birkinshaw (2008), "Organizational Ambidexterity: Antecedents, Outcomes, and Moderators," Journal of Management, 34 (3), 375-409.

, Gilbert Probst, and Michael L. Tushman (2009), "Organizational Ambidexterity: Balancing Exploitation and Exploration for Sustained Performance," Organization Science, 20 (4), 685-95. - and Florian Hotz (2010), "Shaping the Context For Learning: Corporate Alignment Initiatives, Environmental Munificence, and Firm Performance," in Strategic Reconfigurations: Building Dynamic Capabilities in Rapid Innovation-Based Industries, S. Wall, C. Zimmermann, R. Klingebiel and D. Lange, eds. Cheltenham, Edward Elgar Publishing, 62-85.

Ravald, Annika and Christian Grönroos (1996), "The Value Concept and Relationship Marketing," European Journal of Marketing, 30 (2), 19-30.

Reichheld, Fredrick F. (1996), The Loyalty Effect. Boston, MA: Harvard Business School Press.

Reinartz, Werner J. and V. Kumar (2003), "The Impact of Customer Relationship Characteristics on Profitable Lifetime Duration," Journal of Marketing, 67 (January), 77-99.

_ Measurement and Impact on Performance," Journal of Marketing Research, 41 (3), 293-305.

Roux, Dominique (2008), "Consumers Faced with Telephone Selling: Metacognition, Resistance and Strategies," Advances in Consumer Research, 35, 467-74.

Rust, Roland T. and Tuck S. Chung (2006), "Marketing Models of Service and Relationships," Marketing Science, 25 (6), 560-80.

\section{$\mathbf{S}$} Cost Reduction, or Both?," Journal of Marketing, 66 (October), 7-24.

Satorra, Albert and Peter Bentler (1999), "A Scaled Difference Chi-square Test Statistic for Moment Structure Analysis," No. 260, UCLA Statistics Electronic Publications.

Saxe, Robert and Barton A. Weitz (1982), "The SOCO Scale: A Measure of the Customer Orientation of Salespeople," Journal of Marketing Research, 19 (August), 343-51.

Schneider, Benjamin (2007), "Evolution of the Study and Practice of Personality at Work," Human Resource Management, 46 (4), 583-10.

and David E. Bowen (1995), Winning the Service Game. Boston, MA: Harvard Business School Press.

Schwartz, Norbert (2004), "Metacognitive Experiences in Consumer Judgment and Decision Making," Journal of Consumer Psychology, 14 (4), 332-48. 
Shah, James Y. and Arie W. Kruglanski (2003), "When Opportunity Knocks: Bottom-Up Priming of Goals by Means and Its Effects on Self-Regulation," Journal of Personality and Social Psychology, 84 (6), 1109-22.

Sherman, Jeffrey W., Angela Y. Lee, Gayle R. Bessenoff, and Leigh A. Frost (1998), "Stereotype Efficiency Reconsidered: Encoding Flexibility under Cognitive Load," Journal of Personality and Social Psychology, 75 (3), 589-606.

Sheth, Jagdish N. and Arun Sharma (2008), "The Impact of the Product to Service Shift in Industrial Markets and the Evolution of the Sales Organization," Industrial Marketing Management, 37 (3), 260-69.

—_ Rajendra S. Sisodia, and Arun Sharma (2000), "The Antecedents and Consequences of CustomerCentric Marketing," Journal of the Academy of Marketing Science, 28 (1), 55-66. - and Can Uslay (2007), "Implications of the Revised Definition of Marketing: From Exchange to Value Creation," Journal of Public Policy \& Marketing, 26 (2), 302-307.

Shiv, Baba and Alexander Fedorikhin (1999), "Heart and Mind in Conflict: The Interplay of Affect and Cognition in Consumer Decision Making," Journal of Consumer Research, 26 (December), 278-91.

Shrout, Patrick E. and Niall Bolger (2002), "Mediation in Experimental and Nonexperimental Studies: New Procedures and Recommendations," Psychological Methods, 7 (4), $422-45$.

Sinclair, Lisa and Ziva Kunda (1999), "Reactions to a Black Professional: Motivated Inhibition and Activation of Conflicting Stereotypes," Journal of Personality and Social Psychology, 77 (5), 885-904.

Singh, Jagdip (2000), "Performance Productivity and Quality of Frontline Employees in Service Organizations," Journal of Marketing, 64 (April), 15-34. - and Deepak Sirdeshmukh (2000), "Agency and Trust Mechanisms in Consumer Satisfaction and Loyalty Judgments," Journal of the Academy of Marketing Science, 28 (1), 150-67.

Smith, Amy K. and Ruth N. Bolton (1998), "An Experimental Investigation of Customer Reactions to Service Failure and Recovery Encounters: Paradox or Peril?," Journal of Service Research, 1 (1), 65-81. , and Janet Wagner (1999), "A Model of Customer Satisfaction with Service Encounters Involving Failure and Recovery," Journal of Marketing Research, 36 (August), 356-72.

Solomon, Michael R., Carol Surprenant, John A. Czepiel, and Evelyn G. Gutman (1985), "A Role Theory Perspective on Dyadic Interactions: The Service Encounter," Journal of Marketing, 49 (Winter), 99-111.

Sparks, Beverley A. and Janet R. McColl-Kennedy (1998), "The Application of Procedural Justice Principles to Service Recovery Attempts: Outcomes for Customer Satisfaction," in Advances in Consumer Research, J. W. Alba and J. W. Hutchinson, eds. Provo, UT, Association for Consumer Research, $156-61$.

Spencer, Steven J., Steven Fein, Connie T. Wolfe, Christina Fong, and Meghan A. Dunn (1998), "Automatic Activation of Stereotypes: The Role of Self-Image Threat," Personality \& Social Psychology Bulletin, 24 (11), 1139-52.

Spherion (2002), "The Call Center Becomes a Revenue Generator," White Paper, Spherion Pacific Enterprises LLC, (accessed: June 1 ${ }^{\text {st }}, 2011$ ), available at: http://jobfunctions.bnet.com/abstract.aspx?docid=58723.

Stangor, Charles and James E. Lange (1994), "Mental Representations of Social Groups: Advances in Understanding Stereotypes and Stereotyping," in Advances in Experimental Social Psychology, 26, San Diego, CA, Academic Press.

Stapel, Diederik A. and Willem Koomen (2001), "When We Wonder What It All Means: Interpretation Goals Facilitate Accessibility and Stereotyping Effects," Personality \& Social Psychology Bulletin, 27 (8), 915-29.

Steele, C. M. and J. Aronson (1995), "Stereotype Threat and the Intellectual Test Performance of AfricanAmericans," Journal of Personality and Social Psychology, 69 (5), 797-811.

Strack, Fritz and Roland Deutsch (2004), "Reflective and Impulsive Determinants of Social Behavior," Personality and Social Psychology Review, 8 (3), 220-47.

Sujan, Mita, James R. Bettman, and Harish Sujan (1986), "Effects of Consumer Expectations on Information Processing in Selling Encounters," Journal of Marketing Research, 23 (November), 346-353. 
Surprenant, Carol F. and Michael R. Solomon (1987), "Predictability and Personalization in the Service Encounter," Journal of Marketing, 51 (April), 86-96.

\section{T}

Tax, Stephen S., Stephen W. Brown, and Murali Chandrashekaran (1998), "Customer Evaluations of Service Complaint Experiences: Implications for Relationship Marketing," Journal of Marketing, 62 (April), 60-76.

Tormala, Zakary L., Richard E. Petty, and Pablo Brinol (2002), "Ease of Retrieval Effects in Persuasion: A Self-Validation Analysis," Personality \& Social Psychology Bulletin, 28 (12), 1700-12.

Tripp, Thomas M. and Yany Grégoire (2011), "When Unhappy Customers Strike Back on the Internet," MITSloan Management Review, Spring, 1-8.

Tushman, Michael L. and Charles A. O’Reilly (1996), "Ambidextrous Organizations: Managing Evolutionary and Revolutionary Change," California Management Review, 38 (4), 8-30.

V

Vachhani, Sheena J. (2006), "The Death of a Salesman? An Exploration into the Discursive Production of Sales Identities," Culture and Organization, 12 (3), 249-64.

Van Knippenberg, Daan (2000), "Work Motivation and Performance: A Social Identity Perspective," Applied Psychology: An International Review, 49 (3), 357-71.

Vargo, Stephen L. and Robert F. Lusch (2004), "Evolving to a New Dominant Logic for Marketing," Journal of Marketing, 68 (January), 1-17.

- and (2008), "Service-Dominant Logic: Continuing the Evolution," Journal of the Academy of Marketing Science, 36, 1-10.

Voss, Glenn B. and Zannie G. Voss (2008), "Competitive Density and the Customer Acquisition-Retention Trade-Off," Journal of Marketing, 72 (November), 3-18.

W

Wagner, Tillmann, Thorsten Hennig-Thurau, and Thomas Rudolph (2009), "Does Customer Demotion Jeopardize Loyalty," Journal of Marketing, 73 (May), 69-85.

Wan, Lisa C., Michael K. Hui, and Robert S. Jr. Wyer (2011), "The Role of Relationship Norms in Responses to Service Failures," Journal of Consumer Research, 38 (2), 260-77.

Wang, Ze, Aaron Arndt, Surendra Singh, and Monica Biernat (2009), "The Impact of Accent Stereotypes on Service Outcomes and Its Boundary Conditions," Advances in Consumer Research, 36, 940-41.

Wegener, Duane T., Jason K. Clark, and Richard E. Petty (2006), "Not All Stereotyping Is Created Equal: Differential Consequences of Thoughtful Versus Nonthoughtful Stereotyping," Journal of Personality and Social Psychology, 90 (1), 42-59.

Wegner, Daniel M. and John A. Bargh (1998), "Control and Automaticity in Social Life," in The Handbook of Social Psychology, D. T. Gilbert, S. T. Fiske and L. Gardner, eds. New York, Mc Graw-Hill, 446-96.

Weitz, Barton A. (1978), "The Relationship between Salesperson Performance and Understanding of Customer Decision Making," Journal of Marketing Research, 15 (November), 501-16.

(1981), "Effectiveness in Sales Interactions: A Contingency Framework," Journal of Marketing, 45 (Winter), 85-103.

Z , Harish Sujan, and Mita Sujan (1986), "Knowledge, Motivation, and Adaptive Behavior: A Framework for Improving Selling Effectiveness," Journal of Marketing, 50 (October), 85-103.

Zeithaml, Valarie A. (2000), "Service Quality, Profitability, and the Economic Worth of Customers: What We Know and What We Need to Learn," Journal of the Academy of Marketing Science, 28 (1), 67-85.

— Mary Jo Bitner, and Dwayne D. Gremler (2006), Services Marketing: Integrating Customer Focus across the Firm. New York, NY: McGraw-Hill.

Zemborain, Marin R. and Gita V. Johar (2007), "Attitudinal Ambivalence and Openness to Persuasion: A Framework for Interpersonal Influence," Journal of Consumer Research, 33 (March), 506-14. 


\section{Curriculum Vitae}

Claudia Jasmand was born June, Friday $13^{\text {th }}, 1980$ in Wismar, Germany. She received preuniversity education at the Laurentian Regional High School in Lachute, Canada, where she was included in the Laurentian Regional High School Honour Book and obtained her Secondary School Diploma in 1998. Two years later, she graduated from the Helene Weigel Gymnasium in Wismar, Germany, with the Abitur and was awarded with the best student award 2000. From 2000 to 2005, she studied International Business with a major in Information Management at the University of Paderborn, Germany, and obtained the degree Diplom-Kauffrau. From 2005 to 2006, she studied International Business with a major in Marketing at Maastricht University, The Netherlands, and obtained the degree Master of Science (cum laude). These studies were sponsored by the German Academic Exchange Service (DAAD). Besides, she was runner-up in the National Master's Thesis Competition (Nationale Marketing Scriptie Prijs).

Claudia joined the Maastricht University School of Business and Economics as a junior lecturer in 2006 and as a doctoral candidate in 2007. She was a consortium fellow of the AMA Sheth Foundation Doctoral Consortium 2008 and $2^{\text {nd }}$ runner-up in the 2011 Fisher IMS and AMA SERVSIG Dissertation Proposal Award Competition. Together with the teaching staff of Brand Management, she was awarded with the UM Education Prize 2009 for outstanding contribution to education at Maastricht University. With Professor Richard P. Bagozzi as her sponsor, she spent six months as a visiting scholar in the Stephen M. Ross School of Business of the University of Michigan, United States (2010/2011). Since September 2011 she has worked as an assistant professor of marketing in the Imperial College Business School at Imperial College London, United Kingdom. 

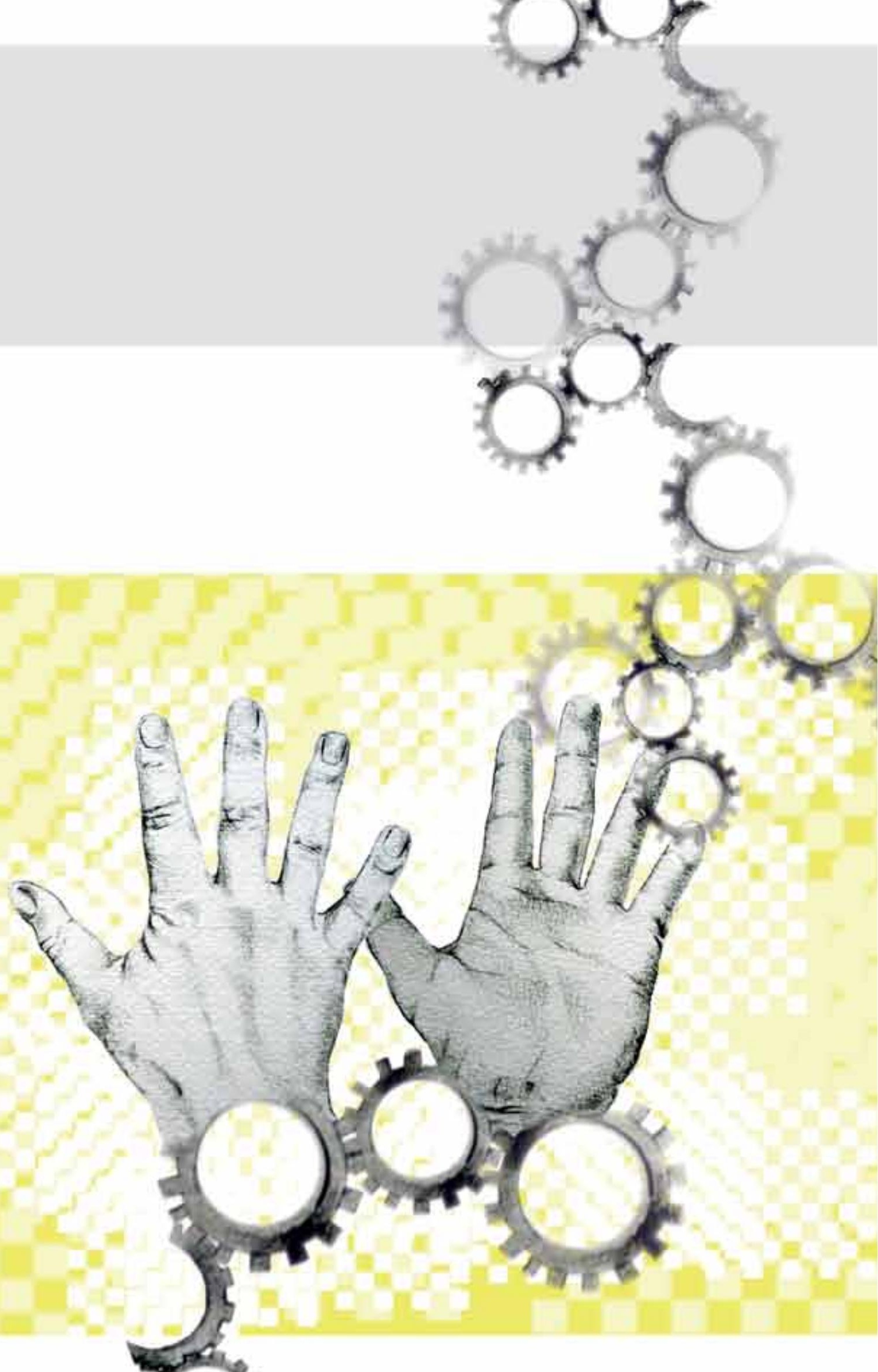